\title{
Sistema de Informação de Mortalidade nos Municípios do Estado de São Paulo: análise situacional
}

Cátia Martinez Minto

Dissertação apresentada ao Programa de Pós-graduação em Saúde Pública da FSP/USP, para obtenção do título de Mestre em Ciências.

Área de concentração de Epidemiologia Orientador: Prof ${ }^{\mathrm{a}}$. Dr ${ }^{\mathrm{a}}$. Zilda Pereira da Silva

Versão Original (revisada)

São Paulo

2015 
É expressamente proibida a comercialização deste documento, tanto na sua forma impressa como eletrônica. Sua reprodução total ou parcial é permitida exclusivamente para fins acadêmicos e científicos, desde que na reprodução figure a identificação do autor, título, instituição e ano da tese/dissertação. 


\section{DEDICATÓRIAS}

Dedico este trabalho a minha família: Sávio meu marido e companheiro na vida e nos sonhos, Túlio e Bruno meus filhos, que juntos sempre me apoiaram nas horas difíceis e compartilharam comigo as alegrias.

A Zilda minha orientadora e que durante este período esteve ao meu lado incondicionalmente, em todos os momentos me auxiliando nesta jornada. 


\section{AGRADECIMENTOS}

Agradeço a muitas pessoas que estiveram junto comigo durante este trabalho:

Aos meus pais, Joel e Diva, que me ensinaram a acreditar na escolha de meus caminhos e trabalharam muito para realizá-los.

Vilma Luz amiga, colega de trabalho e companheira de tantos anos, por estar sempre me escutando e mostrando outros caminhos.

Ao querido Prof Ruy Laurenti ( in memoria) pelo incentivo e por me mostrar de forma apaixonante, a importância do trabalho no sistema de mortalidade.

A Profa. Marcia Furquin pela parceria na elaboração deste trabalho.

Ao Prof. Gizelton pelas valiosas orientações.

A Profa. Lucia Izumi por aceitar em realizar minha banca.

Ao Prof. Marcos Boulos pela permissibilidade da parceria entre a SES-SP e a FSPUSP.

A Alice Tiago de Souza, pelo acompanhamento e apoio.

A Clelia Aranda por dividir sua experiência e pelas orientações.

Marcos Drumond por me atender mesmo sem tempo e contribuir com sábia discussão e sugestões na qualidade de juiz da validação do questionário.

Ana Vidor pelas sugestões na elaboração do questionário, na qualidade de juiz da validação do questionário.

Katia Rocini pela revisão inicial do trabalho.

Luiza Maronez pelo auxílio no monitoramento dos retornos dos questionários.

Ricardo Mangabeira pela participação no pré-teste do questionário.

Eliana de Fátima Paulo pela compreensão da realização deste trabalho.

Neide Takaoka pelas revisões e contribuições no texto.

Moises Menezes e Carlos Tavares pelo fornecimento das tabelas utilizadas neste trabalho. 
Todos os diretores dos Grupos de Vigilância Epidemiológica que auxiliaram no retorno dos questionários.

Todos os interlocutores do SIM dos GVEs que estiveram sempre aos meu lado e fizeram a interlocução com os municípios a fim de que estes participassem.

Todos os interlocutores do SIM dos municípios do Estado de São Paulo pela participação na pesquisa. 


\section{RESUMO}

Introdução: O Sistema de Informação de Mortalidade (SIM) é uma ferramenta importante para o diagnóstico da situação de saúde das populações, gerando conhecimento para fundamentar a gestão e o planejamento de intervenções na área de saúde. Com a implantação do Sistema Único de Saúde (SUS), os municípios passaram a assumir novas atribuições, como a organização e coordenação dos sistemas de informação em saúde, bem como a utilização da epidemiologia para o estabelecimento de prioridades. Objetivo: conhecer a situação da descentralização do SIM nos municípios paulistas sobre 6 dimensões: perfil profissional, estrutura, capacitação técnica, processo de trabalho, gestão do sistema e disseminação dos dados. Métodos: Foi aplicado questionário eletrônico para 645 responsáveis técnicos municipais. Os municípios foram agrupados, por porte populacional, em: Grupo 1, $\leq 30.000$; Grupo 2, de 30.001 a 200.000 e Grupo 3, >200.000 habitantes. Os dados foram analisados por meio de estatística descritiva, com medidas de distribuição e de tendência central. Teste de qui-quadrado e ANOVA foram utilizados para comparação de proporções e médias, respectivamente, entre os grupos. Resultados: Obteve-se resposta de 584 municípios (90,5\%), sendo 91,0\% do Grupo 1, 88,7\% do Grupo 2 e 92,5\% do Grupo 3. Predominam para todos os Grupos: responsáveis técnicos do sexo feminino, idade média de 39,3 anos, com superior completo, enfermeiras, vínculo efetivo e com mais de 3 anos de trabalho no SIM. No Grupo 1, o SIM está alocado na Vigilância Epidemiológica, as equipes tem um profissional, contam com 1 computador com sistema operacional mais antigo, receberam treinamento do sistema, 30\% realizam busca ativa de óbitos, não utilizam relatório do sistema e sua maior dificuldade é realizar codificação de causa de morte, os dados são mais utilizados pela Atenção Básica, e avaliam que a descentralização trouxe muitos benefícios. No Grupo 2, está alocado também na Vigilância Epidemiológica, suas equipes tem de 2 a 3 profissionais, contam com um computador com versões do sistema operacional mais novas, receberam treinamento do sistema, realizam revisão dos campos em branco da DO e utilizam relatórios do sistema, tem dificuldade na codificação de causa de morte, os dados são utilizados pelo Comitê de Investigação de Morte Materna e Infantil para planejamento e pactuação, e apontam pouco benefício na captação de óbitos fora do município. No Grupo 3, o SIM está alocado no Setor de Informação, tem equipes com 2 a 5 profissionais, 2 computadores, sistemas operacionais novos, profissionais capacitados, usam os relatórios do sistema, as áreas que mais utilizam os dados são o Planejamento de Ações e o Secretário de Saúde, apresentam poucas dificuldades e apontam muitos benefícios na descentralização do sistema. Conclusão: O SIM está amplamente implantado nos municípios paulistas, bem consolidado no Grupo 3, no entanto persistem problemas para a operação do sistema e codificação de causa de morte nos Grupos 1 e 2. Recomenda-se maior atenção do nível regional e estadual para as questões de gestão e capacitação profissional.

Palavra chave: sistemas de informação de mortalidade; descentralização; municipalização. 


\section{ABSTRACT}

Introduction: Mortality Information System (MIS) is an important tool and can be applied for the population health analisys, to support for the management and planning of interventions in healthcare. With the implementation of the Unified Health System (SUS), new assignments were initiated on the municipalities, such as organizing and coordinating health information systems, as the use of epidemiology to establish priorities. Objective: to describe the MIS decentralization in the counties based on 6 dimensions: professional profile, physical structure, technical training, work process, system management, dissemination of data, difficulties and benefits of decentralization. Methods: electronic questionnaire was applied to 645 technical experts in each municipality. The municipalities were grouped by population size: Group 1, $\leq 30,000$; Group 2, 30,001-200,000 and Group 3, >200,000 inhabitants. Data analysis used descriptive statistics, with distribution and measures of central tendency. Chi-square test and ANOVA were used to compare proportions and averages, respectively, between groups. Results: 584 municipalities responded (90.5\%), 91.0\% of Group 1, 88.7\% of Group 2 and $92.5 \%$ of Group 3. The predominant profile of responsible technicians for all groups were: female, mean age 39.3 years, college education, nurse, and permanent employed with more than three years work on the MIS. In Group 1 the MIS was allocated in Epidemiologic Surveillance service, the team has 1 professional, the structure has 1 computer with older operating system, received training about the system, 30\% carry out active search for underreported deaths, do not use reports from the system and has difficulty in codifying the causes of death, data is used by the Primary Care and indicate that decentralization brings many benefits. In Group 2 the MIS is also allocated to the Epidemiological Surveillance, their teams have 2-3 professionals, have a computer with new operating system version, received training about the system, review of blank fields on the death certificate, use reports from the system and has difficulty in codifying the cause of death. The data are used by the Maternal and Infant Death Investigation Committee for planning and agreement, and indicate little benefit in attracting information of deaths outside the municipality. In Group 3, the MIS is allocated in Information Sector, have teams with 2-5 professionals, 2 computers, new computer operating system installed, qualified professionals, areas that used the data are Action Planning and Secretary Health, present few difficulties and point out the many benefits the system decentralization. Conclusion: The MIS is widely used in the counties and consolidated in Group 3, but problems remain for the adequate system operation and coding of cause death in Group 1 and 2. We recommend more attention from the regional and state level to these issues management and professional training.

Keyword: mortality information systems; decentralization; municipalization. 


\section{SUMÁRIO}

1.INTRODUÇÃOO 16

$\begin{array}{ll}\text { 1.1 Municipalização dos Sistemas de informação } & 18\end{array}$

1.2 Sistemas de Informação de Mortalidade (SIM) 23

1.2.1 Documento Padrão 25

1.2.2 Estrutura do Sistema de Informação 26

1.3 Descentralização do SIM no Estado de São Paulo 29

1.4 Fluxo da Informação SIM no Estado de São Paulo 35

1.5 Justificativa 40

2.OBJETIVOS 42

2.1 Objetivo Geral 42

2.2 Objetivos Específicos $\quad 42$

3. MATERIAIS E MÉTODOS 43

3.1 Delineamento do estudo 43

3.2 Instrumento de coleta de dados 43

3.3 Diagrama Estrutural das dimensões e variáveis do estudo 44

3.4 Aplicação do questionário $\quad 47$

3.5 Análise dos dados $\quad 47$

3.6 Procedimentos éticos 48

4. RESULTADOS 49

4.1 Dimensão Profissional do Responsável Técnico 50

4.2 Dimensão Estrutura 56

4.3 Dimensão Capacidade Técnica 64

4.4 Dimensão Processo de Trabalho 68

$\begin{array}{ll}\text { 4.5 Dimensão Gestão } & 71\end{array}$

4.6 Dimensão Disseminação de dados 76

$\begin{array}{lr}\text { 5. DISCUSSÃO } & 80\end{array}$

6. CONCLUSÃO 101

7. REFERÊNCIAS BIBLIOGRAFICAS 106

$\begin{array}{ll}\text { ANEXOS } & 113\end{array}$

$\begin{array}{ll}\text { Anexo I Modelo da DO } & 113\end{array}$

$\begin{array}{ll}\text { Anexo II Fluxo das vias da DO } & 114\end{array}$ 
Anexo III Termo de Sigilo e Confidencialidade

Anexo IV Questionário SIM e SINASC

Anexo V Questionário SIM

Anexo VI Carta de apresentação da Pesquisa 


\section{LISTA DE TABELAS}

Tabela 01 Número de municípios por Grupos de Vigilância Epidemiológica

GVE e Departamentos Regionais de Saúde - DRS, 2015

Tabela 02 Número e proporção de municípios existentes e participantes da pesquisa por porte populacional, Estado São Paulo, 2015

Tabela 03 Número e proporção de municípios participantes da pesquisa, por GVE. Estado São Paulo, 2015

Tabela 04 Número e proporção de responsáveis técnicos municipais pelo SIM, segundo sexo, idade e escolaridade, por porte populacional, Estado de São Paulo, 2015

Tabela 05 Número e proporção de responsáveis técnicos municipais do SIM, segundo formação, por porte populacional, Estado São Paulo, 2015

Tabela 06 Número e proporção de responsáveis técnicos municipais pelo SIM, segundo vínculo, função, tempo de trabalho na área de saúde e no SIM, por porte populacional, Estado de São Paulo, 2015

Tabela 07 Número de sistemas com responsabilidade conjunta com SIM e SINASC, Estados São Paulo, 2015

Tabela 08 Número e proporção de municípios, segundo local onde está alocado o SIM, por porte populacional, Estados São Paulo, 2015

Tabela 09 Número e proporção de municípios, segundo número total de pessoas que trabalham no SIM, por porte populacional, Estado São Paulo, 2015

Tabela 10 Número e proporção de respondentes, segundo número de pessoas que trabalham com o SIM por nível de instrução, Estado São Paulo, dezembro de 2014

Tabela 11 Número e proporção de municípios, segundo atividades desenvolvidas, por porte populacional, Estado de São Paulo, 2015

Tabela 12 Número e proporção de municípios, segundo número de computadores como SIM instalado, por porte populacional, Estado São Paulo, 2015

Tabela 13 Número e proporção de municípios, segundo tipo de sistema operacional dos computadores onde está instalado o SIM, por porte populacional, Estado São Paulo, 2015

Tabela 14 Número e proporção de municípios, segundo acesso a internet, por porte populacional, Estados São Paulo, 2015 
Tabela 15 Número e proporção de municípios, segundo a disponibilidade de suporte técnico de informática, por porte populacional, Estado São Paulo, 2015

Tabela 16 Número e proporção de municípios, segundo o local de guarda dos impressos da declaração de óbito em branco, por porte populacional, Estado São Paulo, 201

Tabela 17 Número e proporção de municípios, segundo treinamento institucional para trabalhar com o SIM, por porte populacional, Estado São Paulo, 2015

Tabela 18 Número e proporção de municípios, segundo instituição que ministrou treinamento para trabalhar com o SIM, por porte populacional, Estado São Paulo, 2015

Tabela 19 Número e proporção de municípios, segundo o tipo de treinamento no sistema operacional recebido nos dois últimos anos no SIM, Estado São Paulo, 2015

Tabela 20 Número e proporção de municípios, segundo o tipo de treinamento sobre o SIM recebido nos dois últimos anos no SIM, Estado São Paulo, 2015

Tabela 21 Número e proporção de municípios que realizaram treinamentos sobre preenchimento de DO no ultimo ano, segundo profissionais, por porte populacional, Estado São Paulo, 2015

Tabela 22 Número e proporção de municípios, segundo controle de entrega de impressos de DO a estabelecimentos de saúde e profissionais autônomos, por porte populacional, Estado de São Paulo, 2015

Tabela 23 Número e proporção de municípios, segundo realização de busca ativa de óbitos, por porte populacional, Estado São Paulo, 2015

Tabela 24 Número e proporção de municípios, segundo busca de esclarecimento de dúvidas, Estado de São Paulo, 2015

Tabela 25 Número e proporção de municípios, segundo a realização de procedimento ao identificar que o volume mensal de óbitos esta abaixo do esperado, por porte populacional, Estado de São Paulo, 2015

Tabela 26 Número e proporção de municípios, segundo a realização de revisão da DO para identificação de campos em brancos ou incorretos antes da digitação, por porte populacional, Estado São Paulo, 2015

Tabela 27 Número e proporção de municípios, segundo a utilização de relatórios do sistema para gerar indicadores, por porte populacional, Estado São Paulo, 2015 
Tabela 28 Número e proporção de municípios, segundo a utilização do tabwin do sistema, por porte populacional, Estado de São Paulo, 2015

Tabela 29 Número e proporção de municípios, segundo a solicitação de dados/informações do sistema SIM pelo secretario de Saúde, por porte populacional, Estado São Paulo, 2015

Tabela 30 Número e proporção de municípios, segundo as três áreas que mais solicitam dados/informações do SIM, por porte populacional, Estado de São Paulo, 2015

Tabela 31 Número e proporção de municípios, segundo os principais usos das informações do SIM, por porte populacional, Estado de São Paulo, 2015 


\section{LISTA DE TABELAS DO ANEXO VII}

Tabela 1A Número e proporção de responsáveis técnicos municipais do SIM, segundo escolaridade, tempo de trabalho na área de saúde e no SIM, por porte populacional do município, Estado de São Paulo, 2009

Tabela 2A Número e proporção de responsáveis técnicos municipais do SIM, segundo formação no ensino superior, por porte populacional do município, Estado de São Paulo, 2009

Tabela 3A Número e proporção de responsáveis técnicos municipais do SIM, segundo atividades realizadas, por porte populacional do município, Estado de São Paulo, 2009

Tabela 4A Número e proporção de municípios, segundo a utilização do Tabwin do sistema, por porte populacional do município, Estado de São Paulo, 2009

Tabela 5A Número e proporção de municípios, segundo motivos para não utilização de relatórios do sistema para gerar indicadores, Estado São Paulo, 2015

Tabela 6A Municípios segundo grau de dificuldade na realização de algumas atividades do SIM, Estado de São Paulo, 2015

Tabela 7A Proporção de municípios que avaliaram como alto e muito alto benefício da descentralização do SIM, por tipo de benéfico, segundo porte populacional, Estado de São Paulo, 2015 


\section{LISTA DE FIGURAS}

Figura 01 Mapa do Estado de São Paulo com divisões por Departamentos Regionais - DRS e Grupo de Vigilância Epidemiológica-GVE

Figura 02 Fluxo das Informações do SIM e SINASC, no Estado de São Paulo

Figura 03 Proporção de municípios que realizaram treinamento para preenchimento da Declaração de Óbito, por tipo de profissional, segundo porte populacional, Estado e São Paulo, 2015

Figura 04 Municípios segundo grau de dificuldade na realização de algumas atividades do SIM, segundo porte populacional, Estado de São Paulo, 2015

Figura 05 Distribuição dos municípios, segundo avaliação dos benefícios da descentralização do SIM, por porte populacional, Estado de São Paulo, 2015 


\section{LISTA DE SIGLAS}

CBCD Centro Brasileiro de Classificação de Doenças

CCD Coordenadoria de Controle de Doenças

CENEPI Centro Nacional de Epidemiologia

CGAIS Coordenação-Geral de Análise de Informações em Saúde

CGR Colegiado de Gestão Regional

CIB Comissão Intergestora Bipartite

CID Classificação Internacional de Doenças

CIVS Centro de Informações Estratégicas de Vigilância em Saúde

CEP Comitê de Ética e Pesquisa

CLT Consolidação das Leis do Trabalho

CSPU Cadastro de Sistema e Permissões aos Usuários

DATASUS Departamento de Informática do Sistema Único de Saúde

DIR Direção Regional de Saúde

DNV Declaração de Nascido Vivo

DO Declaração de Óbito

DOE Diário Oficial do Estado

DOU Diário Oficial da União

DRS Departamento Regional de Saúde

FORMSUS Formulário Eletrônico do SUS

FSEADE Fundação Sistema Estadual de Análise de Dados

GM Gabinete do Ministro

GVE Grupo de Vigilância Epidemiológica

IML Instituto Médico Legal

MS Ministério da Saúde

NAOR Núcleos de Apoio Operacional

NOAS Normas Operacionais de Atenção a Saúde

NOB Normas Operacionais Básicas

OMS Organização Mundial de Saúde

OPAS Organização Pan-Americana de Saúde 
PT

SES

SIA

$\mathrm{SIH}$

SIM

SINAN

SINASC

SI PNI

SIS

SMS

SPSS

SUS

SVO

SVS

USP
Portaria

Secretaria de Estado da Saúde

Sistema de Informação Ambulatorial

Sistema de Informação Hospitalar

Sistema de Informação de Mortalidade

Sistema de Informação de Notificação Compulsória

Sistema de Informação de Nascido Vivo

Sistema de |Informação do Programa Nacional de Imunização

Sistemas de Informação em Saúde

Secretaria Municipal de Saúde

Statistical Package for the Social Sciences

Sistema Único de Saúde

Serviço de Verificação de Óbito

Secretaria de Vigilância a Saúde

Universidade São Paulo 


\section{INTRODUÇÃO}

A tomada de decisão em saúde pública é dependente da disponibilização oportuna de dados confiáveis. O papel dos sistemas de informação em saúde (SIS) é produzir, analisar e divulgar tais dados. Assim, os SISs constituem-se em ferramentas importantes para o diagnóstico de situações de saúde, gerando conhecimento que deve fundamentar a gestão dos serviços e o planejamento de intervenções no quadro de necessidades de saúde da população.

Segundo a OMS, Sistema de Informação em Saúde (SIS) é um sistema que integra a coleta de dados, processamento, comunicação e uso da informação necessária para melhorar a eficácia e eficiência do serviço de saúde, através de uma melhor gestão em todos os níveis dos serviços de saúde (WHO, 2004). A OMS coloca os SISs como um dos seis blocos essenciais na construção de um sistema de saúde: prestação de serviços, profissionais de saúde, informação, produtos médicos, vacinas e tecnologias, financiamento, e liderança e governança. Afirma ainda que um sistema de informações em saúde que funcione bem é aquele que não só garante a produção de informação confiável e oportuna sobre o estado de saúde da população, seus determinantes e o desempenho do sistema de saúde, mas também que produz análises para orientar as atividades em todos os outros blocos do sistema. (WHO, 2004).

Para Laurenti e colaboradores (2006), historicamente, foram os estudos epidemiológicos que permitiram conhecer, primeiro, aspectos das doenças transmissíveis e depois as não transmissíveis, mostrando a importância da epidemiologia na administração e no planejamento de ações de saúde e serviços de saúde. Assim, os autores destacam que as organizações ligadas à saúde necessitam dos instrumentos básicos da Epidemiologia para tomar decisões seguras quanto à política de saúde, baseadas em evidências epidemiológicas, utilizando-se, principalmente, da análise dos dados de mortalidade e de morbidade. 
Nesse campo, dois estudos realizados a partir do registro de eventos vitais foram precursores. $\mathrm{O}$ primeiro foi a análise dos registros paroquiais de morte em Londres feita por Graunt, no século XVII, que mostrou a predominância dos óbitos masculinos sobre os femininos, dos da zona urbana sobre os da rural e a compatibilidade entre causas de morte e faixas etárias, e posteriormente os estudos realizados por Willian Farr, sobre os nascimentos e as mortes também em Londres.

As estatísticas vitais tratam de dados individualizados, obrigatórios e de registro único e como tal são importante fonte de conhecimento para a área de saúde. O seu uso permite: avaliar a situação da saúde; avaliar programas de saúde; realizar a vigilância epidemiológica; analisar tendências; realizar estudos de epidemiologia descritiva; realizar estudos retrospectivos; realizar estudos prospectivos; avaliar a mortalidade evitável; identificar a multiplicidade de causas de morte; subsidiar o setor econômico; avaliar o impacto dos fatores de risco, ente outros usos (LAURENTI e col, 2006).

Historicamente, os registros civis apareceram muito antes dos serviços de estatística. No Brasil, o primeiro ato governamental sobre registros civis de eventos vitais data de 1814 e visava interditar a realização de enterros sem a declaração médica da morte. Outros atos foram feitos no sentido de tornar obrigatórios os registros de eventos vitais dos não católicos. Em 1870, foi criada uma Diretoria Geral de Estatísticas que tinha a competência de trabalhar com os dados de nascimentos, casamentos e óbitos; entretanto, somente em 1888 foi estabelecida a primeira lei de obrigatoriedade dos registros civis por conta do Estado (MELLO, 1992). Várias modificações legislativas ocorreram no Brasil, desde então, destacando-se entre elas a Lei n ${ }^{\circ} 6.015$ de 1973, Lei dos Registros Civis, que vigora até hoje, modificada pela Lei ${ }^{\circ}$ 6.216/75.

Outro passo importante foi dado em 1975 com a criação do Sistema de Informações de Mortalidade (SIM), que se tornou o sistema de informação de saúde mais antigo do país. Nas décadas seguintes, foram implantados inúmeros sistemas de informações em saúde, entre os quais destacamos dois importantes sistemas de base epidemiológica: o Sistema de Informação de Doenças de Notificação Compulsória (SDNC), criado também em 1975 e que foi precursor 
do atual SINAN (Sistema de Informação de Agravos de Notificação) e o Sistema de Informações de Nascidos Vivos (SINASC), na década de 1990.

Nos últimos anos, os SISs tiveram um crescimento acelerado, especialmente com a implantação do SUS e com o desenvolvimento da área de tecnologia da informação. Em 1991, foi criado o Departamento de Informática do SUS (DATASUS), responsável pela informatização das atividades dos SUS, e que tem entre suas atribuições: "desenvolver, pesquisar e incorporar produtos e serviços de tecnologia da informação que possibilitem a implementação de sistemas e a disseminação de informações necessárias às ações de saúde, em consonância com as diretrizes da Política Nacional de Saúde" (DATASUS, 2014).

\subsection{Municipalização dos Sistemas de Informação}

No âmbito municipal, Branco (1996) relata que, na década de 1990, alguns municípios tinham sistemas próprios que subsidiavam o planejamento de ações de saúde, mas a grande maioria dos municípios brasileiros trabalhava precariamente, efetuando somente a coleta, ainda que com grande grau de heterogeneidade entre eles. De uma forma geral, existiam esforços de alguns municípios em gerar, processar, analisar informações em saúde. Alguns apresentavam seus resultados periodicamente e em eventos científicos (BRANCO, 1996).

A Lei Orgânica do Sistema Único de Saúde (SUS) $n^{\circ} 8.080 / 90$ (BRASIL, 1990) apresenta entre seus princípios e diretrizes a descentralização político-administrativa, com direção única em cada esfera de governo, dando ênfase à descentralização dos serviços para os municípios, bem como, a regionalização e hierarquização da rede de serviços de saúde. Define ainda como atribuições comuns entre a União, Estados e Municípios: o acompanhamento, a avaliação e a divulgação do nível de saúde da população, a organização e coordenação do sistema de informação em saúde, bem como a utilização da epidemiologia para o estabelecimento de prioridades, alocação de recursos e orientação programática. Neste contexto, marcado pela valorização 
da gestão participativa, municípios e estados passaram a ter papel fundamental na geração e no uso de dados abordados nos diferentes subsistemas de informação em saúde existentes no país (BRASIL, 2009).

As novas responsabilidades de gestão atribuídas aos municípios, com necessidade de articulação nacional e de instituições estaduais e municipais, evidenciou que a informação em saúde é um pré-requisito para o monitoramento e a avaliação das experiências municipais no Sistema Único de Saúde (SUS) (BRANCO, 2004). Assim, os sistemas de informações tornam-se instrumentos de apoio decisório para o conhecimento da realidade socioeconômica, demográfica e epidemiológica e que visam ao planejamento, à gestão, à organização e à avaliação nos vários níveis de gestão que constituem o SUS (MORAES, 2003; MOTA \& CARVALHO, 2003; BRANCO, 2006).

Assim, com o avanço da descentralização ocorrida no país, os municípios foram colocados em situação de destaque, uma vez que deixaram a condição de meros coletores de dados, emergindo como produtores e disseminadores de informações, com enorme potencial para contribuírem nas tomadas de decisões, bem como, para o fortalecimento das ações de saúde.

Esse processo de organização das informações em saúde no nível municipal implicou na estruturação do ambiente informacional das secretarias municipais de saúde, para que fossem construídos mecanismos e condições que criassem ambiente propício para o estabelecimento de uma sinergia de competências, recursos, produtos e resultados (VASCONCELOS et al, 2002).

Porém, na visão de Viacava e Ramos (2009), com o advento do processo de municipalização, houve uma radicalização na descentralização dos sistemas de informação em saúde, sem que houvesse um processo cuidadoso de transferência de responsabilidades do nível central para os demais.

Os Sistemas de Informações em Saúde (SIS) nacionais foram construídos antes da implantação do Sistema Único de Saúde (SUS), com sua estruturação voltada a atender a esfera federal. Com a implantação das diretrizes do SUS, especificamente a descentralização de ações e de atividades para esfera estadual e municipal, a operacionalização de boa parte dos sistemas foi transferida para esfera municipal, porém mantendo-se a lógica existente do 
nível central, ou seja, sem adequação para estas esferas. Para Branco (1996), esse movimento na década de 1990 implicou mais em desconcentração de etapas como digitação, processamento e acesso final dos dados, do que propriamente uma descentralização dos sistemas.

A implementação de um sistema de informação é um processo complexo que exige habilidades técnicas e organizacionais. Solomon et al. (1991) indicam a necessidade de se estabelecer um plano para a sua implantação, com capacitação, desenvolvimento de um sistema de controle de qualidade dos dados e a política de acesso aos dados. A esses requisitos podese acrescentar a necessidade de definir a instituição responsável pelo sistema, a fonte de obtenção de dados e o fluxo de informações.

Para a avaliação de um sistema de informação também se deve estabelecer medidas da capacidade de captação/cobertura de eventos e da qualidade da informação disponível, mensurações essas que dependem das atividades de controle de qualidade. Outro elemento indispensável diz respeito à documentação dos procedimentos a serem realizados, sendo que o desenvolvimento de tal documentação deve ser anterior ao processo de implantação do sistema (SOLOMON et al., 1991). Todas essas questões foram pensadas quando da implantação do SIM e do SINASC centralizado e também posteriormente quando da sua descentralização. Estes sistemas foram os primeiros a passar pela descentralização, porém são poucos os estudos que avaliam este processo.

Nos estudos de avaliação, pode-se abordar diferentes dimensões, para Guimarães (2013) a avaliação da estrutura busca saber em que medida os recursos são empregados de modo adequado para atingir os resultados esperados. Já a avaliação do processo é uma maneira de saber em que medida os serviços são adequados para atingir os resultados esperados.

Foram realizados poucos estudos sobre a avaliação das rotinas de procedimentos do SINASC, após os primeiros estudos logo após a sua implantação (MELLO, 2009). Pesquisa realizada no estado de São Paulo mostrou existirem dificuldades na digitação de dados em algumas secretarias municipais de saúde, pois os mesmos funcionários eram encarregados de 
digitar os documentos do SIM, do SINASC e do SINAN. Outro estudo realizado em Ilhéus (BA) verificou existir atraso na recepção de DNs pela Secretaria Municipal de Saúde e na digitação de dados, provocando perda de documentos (RIBEIRO, 2003).

Estudo recente sobre o processo de trabalho do SINASC verificou que em muitos municípios mineiros não existia a rotina de busca ativa de eventos nas instituições notificadoras; retorno de impressos a fim de completarem campos em branco; correção de campos obrigatórios; inadequação na periodicidade do envio de lotes de eventos; revisão de campos incorretos e incompletos; controle de impressos distribuídos em relação a sua utilização; monitoramento; avaliação; auditoria, dentre outros (GUIMARÃES et al, 2011).

Em relação à infraestrutura para operação do SISs, Guimarães e colaboradores (2013) identificaram nos municípios mineiros o uso de computador compartilhado com outros sistemas de informação e a presença de impressora de uso coletivo; a escassez de material de consumo utilizado no processo de trabalho; e a inadequação da sala de realização das atividades, indicando a existência de problemas de infraestrutura e equipamentos.

Frias et al (2008) utilizou um modelo operacional em estudo realizado em aglomerados de municípios classificados com grande deficiência das informações vitais, onde pontuou que os problemas no SIM de acordo com seis componentes sistematizados neste modelo: notificação, coleta e processamento de dados, análise dos dados, busca ativa em fontes alternativas, divulgação das informações, normatização e fluxos entre as esfera de gestão do sistema. Para cada componente, foram identificados as atividades que compunham e os recursos necessários para o desenvolvimento das atividades.

Outro aspecto importante refere-se aos recursos humanos. A evolução da informática e dos sistemas de informação aconteceu em ritmos distintos da formação de profissionais específicos e da capacitação do corpo de técnicos existentes na área da saúde. Existiu uma forte resistência de profissionais na inclusão digital, corroborando com o enfraquecimento de qualificação de pessoal. A insuficiência de recursos humanos foi apontada por Branco (1996) como ponto importante na descentralização dos SIS, devido à atrofia dos 
municípios, enquanto estas funções eram realizadas somente na esfera federal e estadual.

No início dos anos 2000, pesquisa em municípios gaúchos de pequeno porte (VIDOR et al, 2011) identificou que $74,0 \%$ do corpo técnico que trabalhava com os SISs também realizava outras tarefas além da alimentação dos SISs. Este mesmo estudo relata que no tocante à capacitação, 72,0\% dos técnicos municipais tinham recebido treinamento nos últimos 12 meses, e que este foi voltado para questões relacionadas à atualização do programa, captação de eventos, processamento e transferência de dados e também sobre como controlar a distribuição de impressos de DNV. Os autores identificaram também alguns pontos problemáticos quanto a recursos humanos, como a falta da categoria de processador de dados no serviço público de saúde, falta de qualificação dos profissionais que atuam na operacionalização dos SISs, além do já citado acúmulo de funções para o técnico do SISs.

$\mathrm{Na}$ linha de produção da informação com qualidade, o componente humano é identificado como tutor frente aos problemas identificados na operacionalização do SIM, como a ausência de capacitação, alta rotatividade para desenvolvimento e gerenciamento da informação nos municípios (FRIAS et al.).

As informações dos SISs geram indicadores que sinalizam a situação de saúde de determinado território, que permitem subsidiar os gestores para tomadas de decisões através de planejamento de ações de saúde. O estudo realizado nos municípios gaúchos de pequeno porte aponta que 59,0\% dos municípios realizavam análise local dos dados e geravam indicadores utilizados para o planejamento; 19,0\% analisavam os dados, mas não utilizavam para planejamento de ações de saúde, enquanto $17,0 \%$ os dados não eram utilizados para análises (VIDOR et al, 2011).

Atualmente, no território nacional a maioria dos indicadores produzidos está pactuado entre Municípios e Estados, cuja avaliação se dá de forma periódica através de monitoramento dos sistemas, apresentado nos relatórios de gestão e vinculado ao repasse de verba. Este ponto tem sido identificado por municípios como a obrigatoriedade da alimentação de sistemas vinculada ao 
controle orçamentário e repasses financeiros do nível central (VIDOR et al, 2011). Tal fato reforça a ideia de que a utilização do SIS está limitada à rotina para o recebimento de verbas.

\subsection{Sistema de Informação de Mortalidade - SIM}

Em julho de 1975, o Ministério da Saúde (MS), reconhecendo a importância de dados de mortalidade para ações específicas, designou um grupo de trabalho, para a elaboração das linhas mestras de um subsistema de mortalidade. Segundo Mello Jorge e colaboradores (2009), esse grupo sugeriu uma série de procedimentos que foram adotados na implantação do SIM:

- A adoção de um modelo único de atestado de óbito para o Brasil, seguindo o padrão internacional proposto pela OMS em 1948 quanto às causa morte;

- A impressão e distribuição do documento ficaram a cargo do Ministério da Saúde, que distribuía para as Secretarias Estaduais de Saúde, e estas às Secretarias Municipais de Saúde;

- As declarações de óbito deveriam seguir um fluxo padronizado;

- O processamento dos dados deveria ser feito no nível central, a partir da ideia reinante, à época, de que as ações deveriam estar sempre centralizadas, da dificuldade operacional representada pela codificação das causas de morte e da constatação de que as unidades da federação (UFs) não dispunham de equipamentos de informática para que a descentralização pudesse ser viável.

Suprir as falhas existentes na captação do Sistema do Registro Civil e permitir conhecer o perfil epidemiológico da mortalidade em todo o país, foram premissas que pautaram a concepção do SIM (MELLO, 2007).

A partir de então, o Sistema de Informações sobre Mortalidade (SIM) começou a ser implantado em todo o país, de forma centralizada, mas promovendo os ajustes devidos nos estados que já dispunham de algum sistema de dados. Esta nova concepção trouxe muitos resultados positivos para 
produção de informações, devido a criação de um fluxo padronizado para os dados. O estabelecimento de uma gestão centralizada no Ministério da Saúde se deu por falta de equipamentos de informática nos municípios. Coube então ao MS responsabilidade de viabilizar a impressão e distribuição de formulários de DO, a codificação das causas de morte e o processamento dos dados coletados (MELLO et al, 2009).

Desde a sua implantação o SIM esteve sob a gerência de diferentes setores do Ministério da Saúde, em razão de mudanças em sua estrutura. A partir de 2003, o órgão gestor passou a ser a Secretaria de Vigilância em Saúde (SVS), criada pelo Decreto no 476, de 9 de junho de 2003 (BRASIL, 2009).

Para o bom funcionamento do SIM é necessário um grande aporte quanto a material de apoio para um bom preenchimento do impresso, a quem seleciona e codifica a causa básica de morte, opera o sistema, faz a manutenção do software, realiza o monitoramento dos dados, analisa os indicadores gerados dentre outros. A definição de atribuição entre as diversas instâncias, segundo a Portaria MS/SVS $n^{\circ} 116 / 2009$, fornece um norte para que esta cadeia de informações, na descentralização, atenda a meta desejada.

O SIM permite muitos benefícios destacando a construção principal de indicadores de saúde, e análises estatísticas, epidemiológicas e sóciodemográficas. Dentro de suas funcionalidades apresenta a declaração de óbito informatizada, geração de arquivos de dados em várias extensões para análises em outros aplicativos, retroalimentação de informações ocorridas em outros municípios diferente da residência, controle de distribuição de impressos de DO, transmissão de dados automatizada de forma ágil e segura e backup online dos níveis de instalação (DATASUS, 2015).

O SIM vem apresentando crescimento importante na sua cobertura, esta é definida pela razão entre óbitos coletados e óbitos estimados pelo IBGE, atingindo, em 2011, no Brasil 96,1\% e próximo de $100 \%$ para o estado de São Paulo ${ }^{1}$.

\footnotetext{
${ }^{1}$ Disponível em http://tabnet.datasus.gov.br/cgi/sim/Consolida_Sim_2011.pdf acesso em 8/06/2015.
} 


\subsubsection{Documento Padrão}

O documento que alimenta o SIM é a declaração de óbito (DO) (anexo I), documento padrão de uso no território nacional e obrigatório, impresso em três vias autocopiativas e pré-numerada sequencialmente, sendo esta única no país. A primeira via é de cor branca, a segunda via de cor amarela e a terceira via de cor rosa, para diferentes destinos depois de preenchido. O formulário é composto de nove blocos com 59 variáveis organizadas: Bloco I identificação, Bloco II - residência, Bloco III - ocorrência, Bloco IV - óbito fetal ou menor de um ano, Bloco V - condições e causas do óbito, Bloco VI médico responsável, Bloco VII - causas externas, Bloco VIII - cartório e Bloco IX - local sem médico (BRASIL, 2011).

A DO atende três finalidades: a legal, que atende ao artigo 77 da Lei ${ }^{\circ}$ 6015 e lei $\mathrm{n}^{\circ}$ 6216, dos Registros Públicos e determina aos Cartórios de Registro Civil emitir a Certidão de Óbito para efeito de sepultamento e outras medidas legais; a demográfica, para estudos da dinâmica populacional, quanto a estatísticas de estrutura e distribuição da população; e epidemiológica, que subsidia as estatísticas vitais e estuda os indicadores de saúde para o conhecimento do perfil saúde-doença e formulação de políticas públicas (BRASIL, 2011).

Em princípio, a responsabilidade quanto ao preenchimento da Declaração de Óbito é atribuída ao profissional médico, conforme o disposto no artigo 84 do Código de Ética Médica Capítulo X, que expressa: “é vedado ao médico deixar de atestar óbito de paciente ao qual vinha prestando assistência , exceto quando houver indícios de morte violenta” (Resolução CFM n 1931, 2009).

A DO deve ser preenchida para todos os óbitos por causa natural ou por causa acidental e/ou violenta, para os tipos de óbitos fetais e não fetais ocorridos em estabelecimentos de saúde, domicílios ou outros locais (BRASIL, 2006).

O preenchimento da DO de óbitos de causas naturais é feito pelo médico assistente ou substituto, para quando a causa de morte for conhecida, seja um óbito ocorrido em estabelecimento de saúde ou domicilio. Quando a morte for 
natural e a causa for desconhecida tanto para casos onde era acompanhado pelo médico assistente como casos onde não tinha acompanhamento de um médico, esta DO será preenchida por um médico do Serviço de Verificação de Óbito (SVO), após procedimento de necropsia.

Nos casos de óbitos de causas externas, seja acidental, violenta, ou evento de intenção ignorada, a DO deverá ser emitida pelo médico perito do Instituto Médico Legal (IML), após necropsia.

Em localidades onde não se tem a referência para SVO, a responsabilidade é atribuída ao médico do serviço público de saúde mais próximo ao local onde ocorreu o evento ou o médico designado pela Secretaria Municipal de Saúde ou qualquer médico da localidade. Quando não se tem IML de referência, a DO deverá ser emitida por médico da localidade ou outro profissional investido pela autoridade judicial ou policial na função de perito legista eventual (ad hoc). Excepcionalmente para locais onde não tenham médico, entendendo isto como nenhum médico no território de abrangência, a DO será preenchida pelo Oficial do Registro de Cartório com a presença de um familiar/acompanhante e duas testemunhas que assinarão no bloco nove da DO referente à local sem médico, conforme estabelece a Portaria $\mathrm{n}^{\circ} 116$ de 11/02/2009 em seu artigo 19.

\subsubsection{Estrutura do Sistema de Informação de Mortalidade}

O Sistema de informação sobre mortalidade dispõe de um ambiente de compartilhamento de informações on-line. Sua estrutura contem módulos para serem executados em diversas instâncias:

$\checkmark$ Sistema Local - nos municípios, cuja funcionalidade principal é inclusão de eventos.

$\checkmark$ Sistema regional - nos GVEs - validação de lotes e monitoramento.

$\checkmark$ Sistema Estadual - recebimento dos lotes municipais, monitoramento e manutenção do sistema.

$\checkmark$ Sistema Federal - recebimento dos lotes, monitoramento, manutenção e 
gerenciamento total do sistema.

Em todas as instâncias o sistema possui diversas funcionalidades e aplicações:

$\checkmark$ Retroalimentação de registros de interesse para uma Unidade Federativa (UF) ou município digitados em outra UF ou município;

$\checkmark$ Área para supervisores regionais ou estaduais realizarem a codificação e seleção de causas de morte, via on-line para registros oriundos de municípios sem codificadores.

$\checkmark$ Módulo de investigação de óbitos;

$\checkmark$ Acesso a listagens de óbitos de mulheres em idade fértil (10 a 49 anos), maternos, infantil e fetal;

$\checkmark$ Área para digitação dos resultados das investigações, utilizando fichas sínteses publicada nas Portarias $n^{\circ} 1.119$, de 05 de junho de 2008, que regulamenta a Vigilância de Óbitos Maternos, e n ${ }^{\circ} 72$ de 11 de janeiro de 2010, que estabelece que a Vigilância do Óbito Infantil e Fetal é obrigatória nos serviços de saúde (públicos e privados) que integram o Sistema Único de Saúde (SUS);

$\checkmark$ Relatórios de acompanhamento dos casos segundo status da investigação;

$\checkmark$ Download e atualização de tabelas básicas como estabelecimentos de saúde (CNES), cartórios população, cadastro de médicos no CRM;

$\checkmark$ Download de Backup centralizado para recuperar bases locais;

$\checkmark$ Download de registros codificados para locais sem codificadores;

Auditoria de volumes entre níveis de informação do sistema (municipal, regional, estadual e federal);

$\checkmark$ Relatório de produção (transferência, recebimento, etc.);

$\checkmark$ Alimentação e relatórios sobre distribuição de formulários de DO;

$\checkmark$ Relatório de duplicidades.

O acesso ao sistema é restrito às pessoas previamente cadastradas a fim de garantir a confidencialidade dos dados pessoais dos envolvidos nos 
registros. A responsabilidade por cadastrar os gestores estaduais é do Ministério da Saúde, assim como é de responsabilidade do gestor estadual do sistema cadastrar todos os gestores regionais e municipais e estes cadastram os responsáveis técnicos pelo SIM nas instituições (hospitais, unidades de saúde, SVO e IML). Para cada cadastro é permitido um tipo de acesso específico a cada usuário do sistema.

Segundo o Manual do Sistema do Ministério da Saúde, ${ }^{2}$ para instalação do sistema é necessário que o equipamento tenha configurações mínimas:

Computador com processador Pentium IV $1500 \mathrm{mhz}$ ou compatível

$\checkmark$ Sistema Operacional Windows 2000 ou superior

Browser (navegador de internet)

Memória mínima de 512 MB de RAM

$\checkmark$ Espaço em disco de no mínimo 5 GB para o sistema (dependendo do volume de dados a ser armazenado

$\checkmark$ Unidade de disco; "drive de 3.5 "

$\checkmark$ Unidade de CD

$\checkmark$ Placa de vídeo e Monitor: VGA - compatível, no mínimo 256 cores

$\checkmark$ Mouse

Impressora

O Ministério da Saúde recomenda que o computador que operar o SIM não tenha mais nenhum outro sistema instalado, salvo o SINASC, devido a incompatibilidade dos programas, para não travar os softwares e, consequentemente, perder todas as informações.

Outra peculiaridade apontada no manual do instalador, é que para instalar o sistema o gestor do SIM local deva ter senha de Administrador da máquina/computador para fazer as instalação ou alteração de qualquer configuração.

\footnotetext{
${ }^{2}$ Disponível em: http://svs.aids.gov.br/cgiae/sim, acesso em 21.05.2015.
} 


\subsection{Descentralização do SIM no Estado de São Paulo}

Desde a criação do Sistema Único de Saúde (SUS) em 1988, o Brasil vem realizando avanços em relação à descentralização da gestão de ações e serviços para os estados e os municípios. Em relação à descentralização do SISs, um passo importante foi dado com a Norma Operacional Básica do SUS 01/96 (BRASIL, 1996), que foi instituída com o propósito de definir mudanças na lógica de alocação de recursos financeiros, utilizando-se da informação para a programação, controle e avaliação. Porém, é só a partir dos anos 2000, que processo de descentralização dos SISs se completa.

O Estado de São Paulo é a unidade mais rica da federação, composto por 645 municípios, a segunda maior em relação ao volume de municípios e o estado mais populoso do país com 41,3 milhões de habitantes, o equivalente a $22,0 \%$ da população total do país. A diferença do porte populacional entre os municípios é grande, destacando-se algumas metrópoles, sendo a principal o município de São Paulo com aproximadamente 12 milhões de habitantes, correspondendo a um terço do total da população paulista. O município de Guarulhos e Campinas são outros exemplos de grandes cidades, com mais de 1 milhão de habitantes, bem como o oposto é exemplificado pelo município de Borá, com apenas 800 habitantes. Há uma grande concentração de municípios de pequeno porte:

\footnotetext{
$\checkmark 456$ municípios até 30.000 habitantes $(70,7 \%)$

$\checkmark 150$ municípios de 30.001 a 200.000 habitantes $(23,3 \%)$ 39 municípios acima de 200.001 habitantes $(6,0 \%)$
}

O Estado possui 63.651 estabelecimentos de saúde públicos e privados, e destes 2.237 são unidades passíveis de registro de eventos vitais. A distribuição destes no território se dá de forma desigual entre os municípios, onde 40,2\% destes não possuem hospitais. 
Neste contexto, a Secretaria do Estado da Saúde considerou esta característica, somada às necessidades da população, e em consonância com os princípios do Sistema Único de Saúde (SUS) de descentralização, integralidade e acessibilidade, dentre outras, para organizar a divisão administrativa dos DRS e dos GVE.

No decorrer do tempo muitas normas foram feitas com o objetivo de construir uma descentralização onde o município tivesse o comando único do sistema de saúde. Em 2003, o Ministério de Saúde publicou as portarias $\mathrm{n}^{\circ}$ 384/GM e n 385/GM, que alteravam as Normas Operacionais de Atenção a Saúde - NOAS/2002, referente à habilitação e desabilitação dos municípios, estados e distrito federal, seguida da Portaria $n^{\circ}$ 2023/GM de 23 de setembro de 2004, que estabelece aos municípios uma única forma de Gestão, a Plena do Sistema Municipal, o que fez com que o Estado de São Paulo revesse suas estruturas administrativas e seu novo papel frente ao Sistema de Saúde (Mendes 2010).

O Decreto Estadual $\mathrm{n}^{\circ}$ 51307/2006 orientou a reestruturação organizacional da $\mathrm{CCD}$ e estabeleceu a transferência administrativa às áreas de Vigilância Epidemiológica e Sanitária das Direções Regionais de Saúde ( DIR) para a CCD, dando origem a 28 diretorias técnicas de vigilância epidemiológica e sanitária, bem como aos núcleos de apoio operacionais (NAOR) ( PRADO, 2012). Atualmente, a divisão administrativa da Secretaria de Saúde do Estado de São Paulo (SES/SP) conta com cinco macrorregiões, 17 Departamentos Regionais de Saúde (DRS) e 28 Grupos de Vigilâncias Epidemiológicas Regionais (GVE) como apresentado na figura 1.

Em termos de gestão, todos os 645 municípios possuem a Gestão Plena do Sistema, ou seja, tem o comando único do sistema de saúde no seu território.

Já os Grupos de Vigilância Epidemiológica (GVE) tem como função coordenar, supervisionar e controlar ações de vigilância epidemiológica; analisar epidemiologicamente o comportamento das doenças; propor, executar 
e realizar inquéritos epidemiológicos; propiciar integração entre os órgãos de vigilância epidemiológica; realizar treinamentos e capacitações; monitorar sistemas de vigilância a saúde; apoiar municípios nas ações; distribuir impressos de DO e DNV dentre outros. Sua organização territorial se deu respeitando as demais organizações administrativas do governo do Estado. Os GVEs apresentam um número variado de municípios em seu território conforme ilustrado na Tabela 1 .

Os DRSs apresentam grande diversidade entre si, tanto no tamanho, porte populacionais como em suas características estruturais de serviço de saúde. Observa-se que há muitos municípios que não tem serviços de saúde com leitos hospitalares, direcionando o atendimento da sua população para municípios maiores. Estas características justificam um esforço permanente em organizar os fluxos de assistência e consequentemente os fluxos administrativos. 
Tabela 01: Número de municípios por Grupos de Vigilância Epidemiológica GVE e Departamentos Regionais de Saúde - DRS, 2015.

\begin{tabular}{|c|c|c|}
\hline $\begin{array}{l}\text { Departamento Regional de } \\
\text { Saúde (DRS) }\end{array}$ & $\begin{array}{c}\text { Grupo de Vigilância } \\
\text { Epidemiológica (GVE) }\end{array}$ & $\begin{array}{l}\text { Número de } \\
\text { Municípios }\end{array}$ \\
\hline \multirow{5}{*}{ DRS I - Grande São Paulo } & GVE I - Capital & 1 \\
\hline & GVE VII - Santo André & 7 \\
\hline & GVE VIII - Mogi das Cruzes & 11 \\
\hline & GVE IX - Franco da Rocha & 5 \\
\hline & GVE X - Osasco & 15 \\
\hline DRS II - Araçatuba & GVE XI - Araçatuba & 40 \\
\hline DRSIII - Araraquara & GVE XII - Araraquara & 24 \\
\hline DRS IV - Baixada Santista & GVE XXV - Santos & 9 \\
\hline DRS V - Barretos & GVE XIV - Barretos & 18 \\
\hline \multirow{2}{*}{ DRS VI - Bauru } & GVE XV - Bauru & 38 \\
\hline & GVE XVI - Botucatu & 30 \\
\hline DRS VII - Campinas & GVE XVII - Campinas & 42 \\
\hline DRS VIII - Franca & GVE XVIII - Franca & 22 \\
\hline \multirow{2}{*}{ DRS IX - Marília } & GVE XIX - Marília & 37 \\
\hline & GVE XIII - Assis & 25 \\
\hline DRS X - Piracicaba & GVE XX-Piracicaba & 26 \\
\hline \multirow{2}{*}{ DRS XI - Presidente Prudente } & GVE XXII - Presidente Venceslau & 21 \\
\hline & GVE XXI - Presidente Prudente & 24 \\
\hline DRS XII - Registro & GVE XXIII - Registro & 15 \\
\hline DRS XIII - Ribeirão Preto & GVE XXIV - Ribeirão Preto & 26 \\
\hline DSR XIV - S. João Boa Vista & GVE XXVI - São João da Boa Vista & 20 \\
\hline \multirow{2}{*}{ DRS XV - S.José do Rio Preto } & GVE XXIX - São José do Rio Preto & 67 \\
\hline & GVE XXX - Jales & 35 \\
\hline \multirow{2}{*}{ DRS XVI - Sorocaba } & GVE XXXI - Sorocaba & 33 \\
\hline & GVE XXXII - Itapeva & 15 \\
\hline \multirow{3}{*}{$\begin{array}{l}\text { DRS XVII - São José dos } \\
\text { Campos }\end{array}$} & GVE XXVIII - Caraguatatuba & 4 \\
\hline & GVE XXVII - São José dos Campos & 8 \\
\hline & GVE XXXIII - Taubaté & 27 \\
\hline \multicolumn{2}{|c|}{ Total do Estado de São Paulo } & 645 \\
\hline
\end{tabular}

Fonte: Secretaria do Estado de São Paulo (SES), 2013. 
Figura 01: Mapa do Estado de São Paulo com divisões por Departamentos Regionais - DRS e Grupo de Vigilância EpidemiológicaGVE.

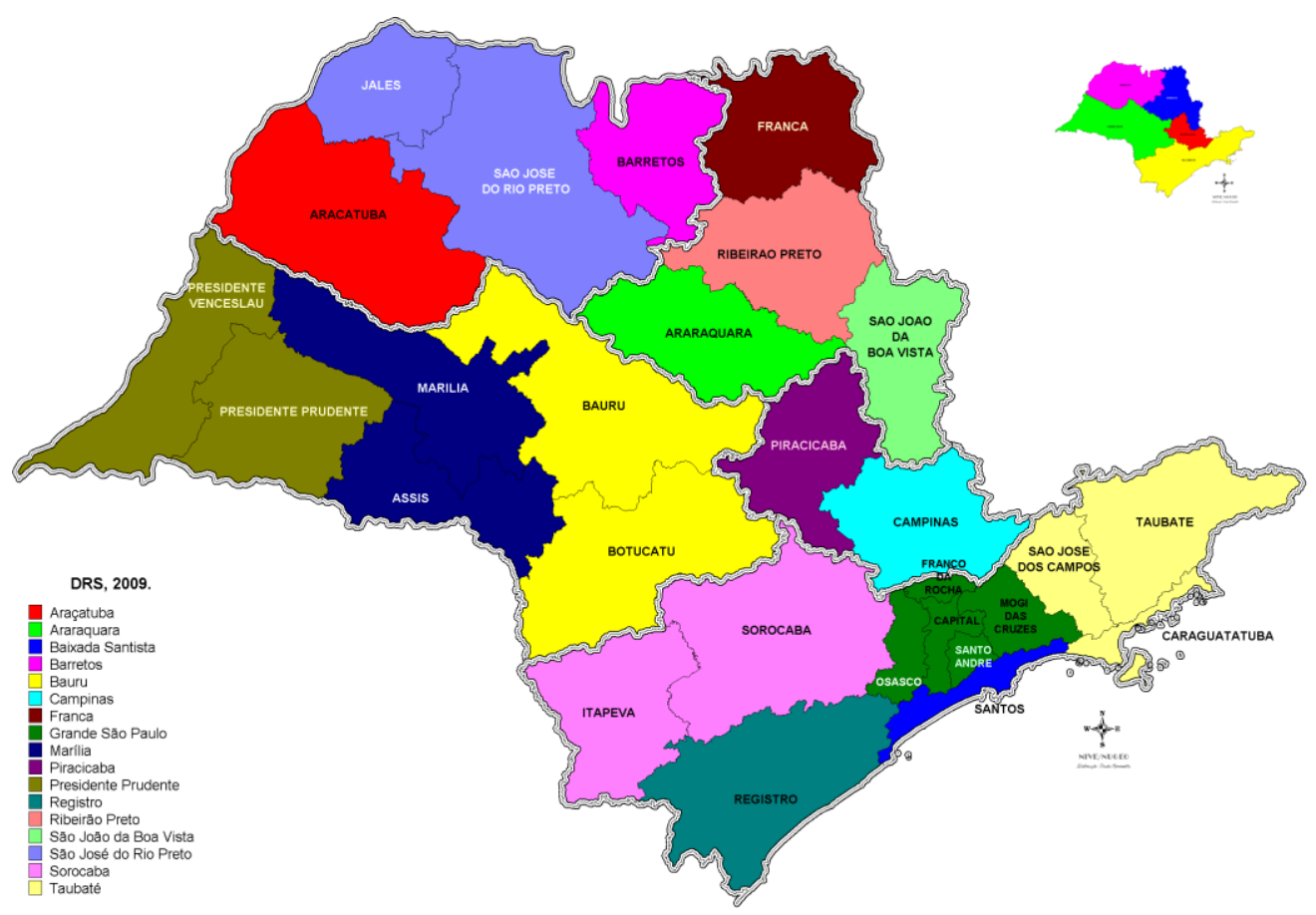

Fonte: Secretaria de Saúde do Estado de São Paulo (SES, 2009).

O processo de implantação do SUS no país, ao final da década de 1980, desencadeou a descentralização de ações de saúde dando enfoque a esfera municipal na política de gestão do sistema. Isto resultou em um crescimento de investimento na área de informática dos serviços de saúde, propiciando a descentralização da produção, análise e monitoramento dos dados no nível local (ALMEIDA, 1998; MELLO et al., 2009).

Muitas iniciativas para descentralização das informações ocorreram com sucesso por parte de alguns municípios no estado de São Paulo, principalmente os de grande porte populacional, permitindo agilidade da produção de informações, diagnósticos, planejamento e tomada de decisões (SCHOEPS, 2012).

O marco da descentralização do sistema SIM se deu com o avanço tecnológico e a implantação de um aplicativo para seleção e codificação da 
causa básica de morte, o "Seletor de Causa Básica- SCB”. Sua padronização permitiu que os municípios e estados realizassem a codificação dentro das diretrizes do Centro Brasileiro de Classificação de Doenças (CBCD). Sua efetivação ocorreu em 2003 com a publicação da Portaria MS/SVS nº 20 de 3 de outubro (MELLO et al., 2009).

Em 2005, a Comissão Intergestora Bipartite (CIB), seguindo o processo de descentralização das informações, publicou a deliberação $n^{\circ} 37 / 2005$, que determinava que a partir do ano de 2006 as bases de dados de óbitos e nascidos vivos seriam abastecidas a partir das Secretarias Municipais de Saúde (SMS), sob a gestão dos sistemas feita pela Coordenadoria de Controle de Doenças (CCD), órgão responsável pela vigilância em saúde no âmbito da Secretaria de Estado da Saúde de São Paulo.

Com o avanço do processo de municipalização, houve uma importante aproximação dos gestores locais e técnicos com a realidade sanitária local, através de informações e dados coletados pelos SIS, permitindo uma visão mais ampla e precisa da situação de saúde.

Neste processo, foi repassado ao município, inicialmente, a gestão dos Sistemas de Informação de Mortalidade (SIM) e de Nascidos Vivos (SINASC), com suas competências, atribuições e fluxos. Porém, há que se ressaltar que as questões estruturais não foram completamente estabelecidas, no que diz respeito à necessidade de equipamentos, recursos humanos, treinamentos e tecnologia de informação que subsidiasse as SMS.

Todo este processo de descentralização do SIM trouxe muitos avanços para o gestor local, mas ainda observa-se que há muito que se aprimorar em todas as etapas de produção. Assim, pesquisas que avaliem a implantação da descentralização dos SISs podem contribuir para identificação de problemas relacionados à sua organização e funcionamento no nível municipal e fornecer subsídios para decisões que visem o seu aprimoramento e consolidação. 


\subsection{Fluxo da Informação do SIM}

As DOs são impressas pelo Ministério da Saúde e distribuídas às secretarias estaduais de saúde para subsequente fornecimento às secretarias municipais de saúde, que as repassam aos estabelecimentos de saúde, institutos de medicina legal, serviços de verificação de óbito. Atualmente, compete às secretarias municipais de saúde o controle da distribuição das DOs aos hospitais e médicos.

No passado, o sistema previa que, uma vez registrado o óbito no Cartório do Registro Civil, conforme a legislação vigente (Lei dos Registros Públicos), a primeira via devia ser recolhida semanal ou mensalmente nos cartórios pelos órgãos estaduais responsáveis pelas estatísticas de mortalidade. Já se preconizava, também, à época, que essa fonte básica poderia ser complementada, em algumas áreas (em especial onde o registro civil apresentasse deficiência), com a coleta de dados feita diretamente em hospitais, cemitérios e unidades de saúde (BRASIL, 1984-1988).

No Estado de São Paulo, desde 1882, a produção das estatísticas vitais era feita com base na coleta de dados em cartórios de registro civil, pela então chamada Seção Especial de Estatística Demógrafo-Sanitária da Secretaria do Interior. Em 1942, essa atribuição foi incorporada pela Diretoria de Estatísticas Demográficas, do recém-criado Departamento Estadual de Estatística - DEE e, posteriormente, em 1979, assumida pela Fundação Sistema Estadual de Análise de Dados (FSEADE), vinculada à Secretaria de Planejamento do Estado (WALDVOGEL \& FERREIRA, 2003). Os dados coletados pela Fundação Seade eram enviados para a Secretaria de Estado da Saúde e diretamente para o Ministério da Saúde, e para o Sistema de Estatísticas do Registro Civil, coordenado pelo IBGE. Assim, diferente do que ocorria na maioria dos outros estados, onde esse fluxo passava pelas Secretarias Estaduais de Saúde, em São Paulo, a Fundação Seade realizou essa atividade até 2006.

Em 2009, o Ministério da Saúde (Portaria SVS/MS nº116/2009) regulamenta a coleta de dados, fluxo e periodicidade de envio das informações 
sobre óbitos e nascidos vivos para o Sistema de Informações em Saúde sob a gestão da Secretaria de Vigilância em Saúde do Ministério da Saúde. Nessa portaria são estabelecidas as competências dos gestores estaduais e municipais do SIM e do SINASC, nos respectivos âmbitos. Posteriormente, são estabelecidos o bloqueio do repasse de recursos do Componente de Vigilância e Promoção da Saúde para Estados e de Municípios com irregularidade na alimentação do SIM (portarias SVS/MS nº 3252 e SVS/MS nº 201/2010).

Como relatado acima, a DO é preenchida em três vias a fim de atender suas finalidades. O fluxo da informação inicia no município de ocorrência em estabelecimentos de saúde, domicílio ou em vias públicas. O médico preenche a DO e a partir daí a informação segue para as Secretarias Municipais de Saúde através da primeira via (cor branca). A via amarela é dada ao familiar para que seja realizado o registro em cartório e sepultamento, e a terceira via (cor rosa) é encaminhada para arquivamento junto ao prontuário do paciente (anexo II).

Recebido o impresso da DO, compete às Secretarias Municipais de Saúde inserir por meio de digitação os dados no sistema local, mesmo que o óbito não seja de residente em seu município, segundo a Portaria MS $n^{\circ}$ $116 / 2009$.

Para sequência do fluxo das informações, a SMS deve processar consolidar e transferir os lotes que contem os registros dos eventos, conforme os fluxos estabelecidos pelas Secretarias Estaduais e pelo nível federal. Para a finalidade de controle, o MS, estabeleceu que o monitoramento fosse mensal, e isto faz com que as outras instâncias se organizem a fim do cumprimento da mesma.

A partir de novembro de 2014, a Portaria MS/SVS n 1271 estabelece que todos os óbitos maternos declarados e infantis, sejam notificados, através do sistema SIM, ao MS semanalmente.

Em São Paulo, o fluxo do SIM/SINASC se dá em uma estrutura diferente do fluxo nacional padrão. Atende a lógica da divisão administrativa relatada, incluindo os GVEs no fluxo de dados (Figura 2). A alimentação do 
sistema é realizada pelo sistema local SIM/SINASC, sempre por ocorrência do evento e posteriormente o arquivo é exportado, ao mesmo tempo, para GVE, SES e MS. Para isto ocorrer, foi desenvolvido uma área onde ocorrem as transferências dos arquivos, denominado de "Balcão Virtual". Trata-se de um ambiente compartilhado e seguro que atende tanto os municípios, GVEs e o Centro de Informação Estratégica em Vigilância a Saúde (CIVS/CCD), para envio e recebimento de arquivos (PRADO, 2012).

Figura 02 - Fluxo das Informações do SIM e SINASC, no Estado de São Paulo.

\section{Fluxo das Informações}

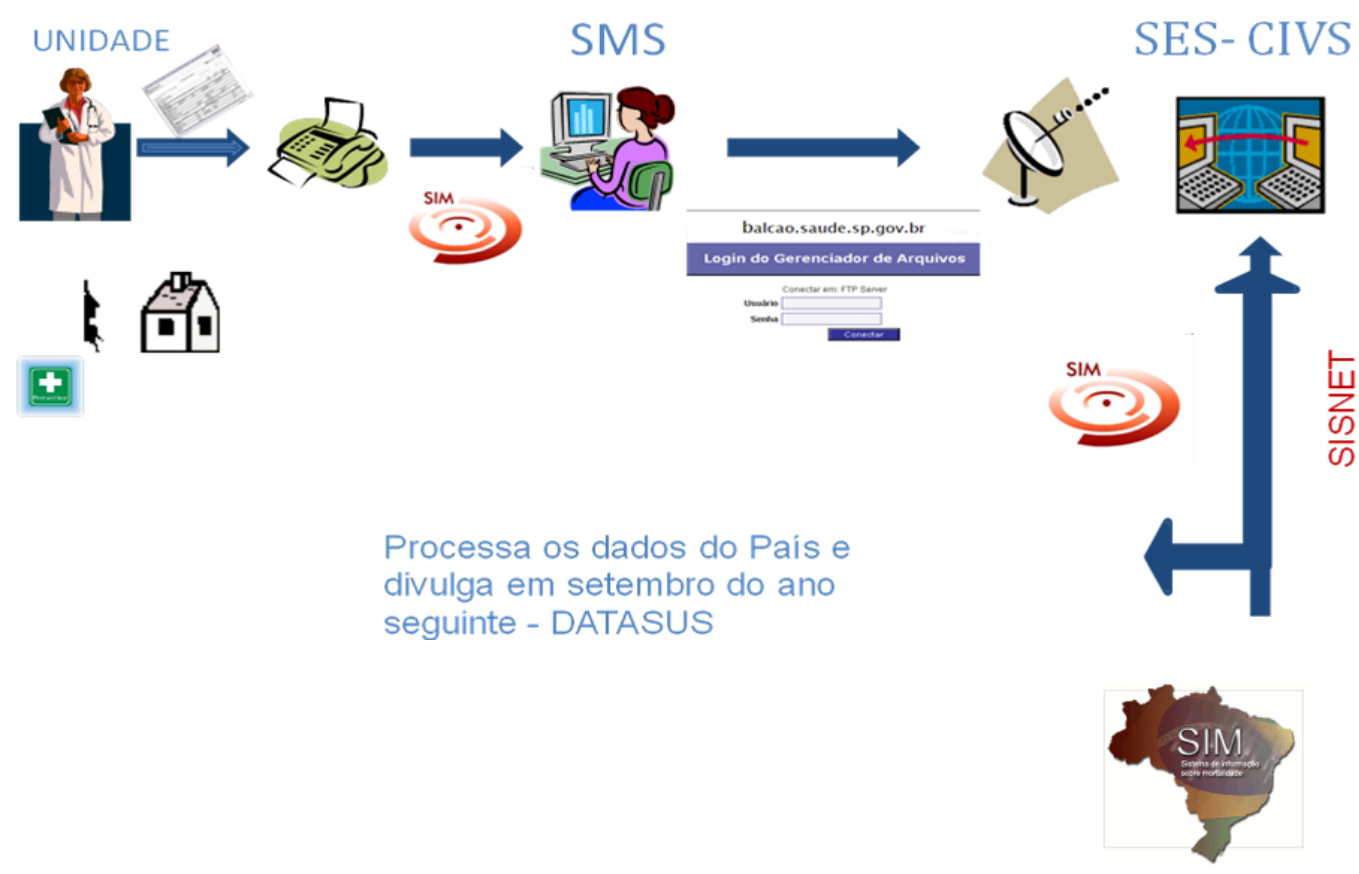

Os GVEs e o CIVS/CCD capturam os arquivos nesse ambiente, fazem monitoramento da regularidade do envio e do volume de eventos captados por município. Posteriormente ao envio ao MS, são realizados procedimentos de avaliação de qualidade dos dados, que inclui análise de completitude de todos os campos, consistência interna de campos, duplicidade de registros, entre outros. Os registros identificados são devolvidos, via GVE, aos municípios 
para as devidas correções. Os possíveis ajustes são realizados no sistema local e posteriormente reenviados para o nível federal, seguindo o fluxo anteriormente descrito.

Atendendo às diretrizes nacionais que regulamentam a coleta e fluxo de dados (Portaria SVS/MS n 116/2009) e com a implantação da Gestão de Formulários das DOs e DNVs, a SES normatizou o fluxo de cadastro e acesso de responsáveis técnicos aos sistemas SIM e SINASC no âmbito estadual. Os municípios e os GVEs passam a ter um profissional de nível superior que responde pelo sistema, após firmar compromisso com um Termo de Sigilo e Confidencialidade dos dados (Anexo III) (Resolução SS nº66/2010).

Ainda em 2010, a SES normatizou as responsabilidades da gestão, guarda, distribuição e controle dos formulários (Resolução SS n 67/2010) e a CCD regulamentou os procedimentos operacionais para cadastro de profissionais e/ou instituições para retirada e devolução dos impressos de DO e DNV junto aos GVEs (Portaria CCD nº 17/2010).

Ficou estabelecido, em instâncias da Comissão Intergestores Bipartite (Portaria CCD no 18/2010), que a periodicidade de envio de lotes com registros de eventos ocorridos nos municípios seria: quinzenal para os municípios que sediam estabelecimentos de saúde com potencial ocorrência de nascimentos e óbitos (hospitais, pronto-socorro, unidade mista, entre outros), e mensal para os municípios com estabelecimentos que só eventualmente tem a ocorrência de eventos vitais. Dentre os municípios do Estado de São Paulo, atualmente 259 realizam envio de arquivo de eventos mensalmente e 386 quinzenalmente.

Como os dados do SIM geram informações importantes para a gestão de saúde em todos os níveis, a fim de garantir a regularidade de envio desses dados para os níveis estadual e federal, o Ministério da Saúde e o Centro de Informações Estratégicas em Vigilância a Saúde do Estado (CIVS/CCD) realizam monitoramento mensal através de dois quesitos: 
$\checkmark$ O envio regular dos lotes contendo os eventos mensalmente, sem falha por dois meses consecutivos ou três intercalados.

$\checkmark$ O volume de eventos esperados (por uma série histórica) registrados no mês da ocorrência do evento ou até 60 dias.

No caso de não cumprimento, as portarias SVS/MS no 3252/2009 e SVS/MS n 201/2010 estabelecem e regulamentam o bloqueio do repasse de recursos do Componente de Vigilância e Promoção da Saúde para Estados e Municípios com dois meses consecutivos ou três meses intercalados sem alimentação do SIM.

Com a descentralização desses sistemas, os municípios passaram a lidar com a complexidade que estes apresentam em seu processo de trabalho. Etapas como coleta da informação, seleção de causa básica de morte (SIM) e de anomalias congênitas (SINASC) pelo uso da CID 10, processamento dos dados, geração de relatórios de informação, confecção de indicadores de saúde, análise situacional e gestão de formulários necessitam de estrutura física própria, recursos humanos capacitados, suporte técnico de informática, apoio dos gestores na interface com outras instâncias e principalmente capacidade de produção e análise das informações.

Durante esse processo, a SES utilizou estratégias para apoiar os municípios, que incluíram orientações técnicas, realização de videoconferências, treinamentos, entre outros (PRADO, 2012). Porém, a alta rotatividade dos profissionais envolvidos com o SIM no nível local compromete a eficácia dessas ações. 


\subsection{Justificativa}

O processo de descentralização dos SISs se intensificou nos últimos anos e para alguns autores (VIACAVA e ALMEIDA, 2009) isso ocorreu sem que houvesse um processo cuidadoso de transferência de responsabilidades do nível central para os demais. Existem poucos estudos sobre a operacionalização e o gerenciamento dos sistemas de informações no âmbito municipal. Esses estudos tem mostrado a existência de grande heterogeneidade entre os municípios brasileiros, no que diz respeito tanto aos processos de trabalho, como a infraestrutura e a recursos humanos. Se por um lado a maioria deles efetua apenas procedimentos de coleta de dados para os sistemas de âmbito federal ou estadual, no outro extremo há secretarias que, além dessa função, produzem, processam, organizam e analisam a informação em saúde de seu município (BRANCO, 1996).

Os avanços no processo de descentralização, a necessidade de ampliar a cobertura e melhorar a qualidade das informações justificam a preocupação dos gestores com a qualificação dos profissionais que operam os sistemas. A introdução contínua de novas tecnologias e mudanças nos processos de trabalho conformam o dinamismo da área, demandando constantes atualizações e treinamentos. Porém, manter um corpo técnico atualizado não é um desafio fácil de enfrentar, considerando a grande rotatividade desses profissionais, especialmente nos menores municípios.

Embora os gestores necessitem cada vez mais de informações de qualidade, o cenário gerencial, por vezes, é marcado por informações inadequadas, dispersas, atrasadas ou não confiáveis. E para se obter informações confiáveis deve-se considerar que estas são consequência da qualidade com que se realizam todas as etapas, desde a coleta ou registro até a disponibilização dos dados produzidos pelos Sistemas de Informação.

A qualificação da gestão nos municípios tem importância estratégica para efetivar a descentralização da gestão em saúde no Estado. Nesse sentido, conhecer as características da operacionalização do SIM, bem como 
dificuldades enfrentadas pelos municípios, pode contribuir para a compreensão de suas necessidades e subsidiar a utilização desses sistemas como ferramentas de apoio à gestão municipal.

Segundo Pereira (2011), são poucos os estudos que avaliam a estrutura e o funcionamento do Sistema de forma integral, hoje as avaliações são mais voltadas para a cobertura e qualidade da informação.

Assim, esse estudo visa conhecer as características estruturais (recursos humanos, infraestrutura, informática), processo de trabalho e uso das informações do SIM na gestão nos municípios do Estado do São Paulo. Com isso pretende-se gerar novos conhecimentos que possibilitem ações para o aprimoramento deste sistema de informação nos municípios paulistas. 


\section{OBJETIVOS}

\subsection{Objetivo Geral}

Estudar as características da produção dos dados e gerenciamento das informações do Sistema de Informação de Mortalidade (SIM) pelos municípios do Estado de São Paulo.

\subsection{Objetivos Específicos}

- Descrever as características do perfil profissional do responsável técnico pelo Sistema de Informação de Mortalidade (SIM);

- Descrever as características estruturais das secretarias municipais de saúde para operar o Sistema de Informação de Mortalidade (SIM);

- Identificar a utilização dos dados pelas secretarias municipais na sua rotina de trabalho, especificamente em ações de planejamento e avaliação;

- Descrever as dificuldades no processo de trabalho;

- Descrever os benefícios da descentralização do SIM para os municípios. 


\section{MATERIAIS E MÉTODO}

\subsection{Delineamento do Estudo}

Estudo exploratório e descritivo de abordagem quantitativa por meio de aplicação de questionário aos municípios do estado de São Paulo.

Este estudo está acoplado à pesquisa "Descentralização dos Sistemas de Informação de Saúde nos Municípios do Estado de São Paulo" realizado em parceria entre a Faculdade de Saúde Publica - USP e o Centro de Informações Estratégicas em Vigilância à Saúde da Secretaria do Estado da Saúde de São Paulo, que tem por objetivo conhecer a situação atual da descentralização dos sistemas de informações em saúde de base epidemiológica, mais especificamente o SIM, SINASC e o SINAN.

Nesta dissertação serão estudados os dados referentes ao sistema de informação de mortalidade-SIM.

\subsection{Instrumento de coleta de dados}

Foi desenvolvido um questionário eletrônico no aplicativo FORMSUS dirigido aos Responsáveis Técnicos Municipais do SIM nos 645 municípios do Estado de São Paulo. 


\subsection{Diagrama Estrutural das Dimensões e Variáveis do Estudo}

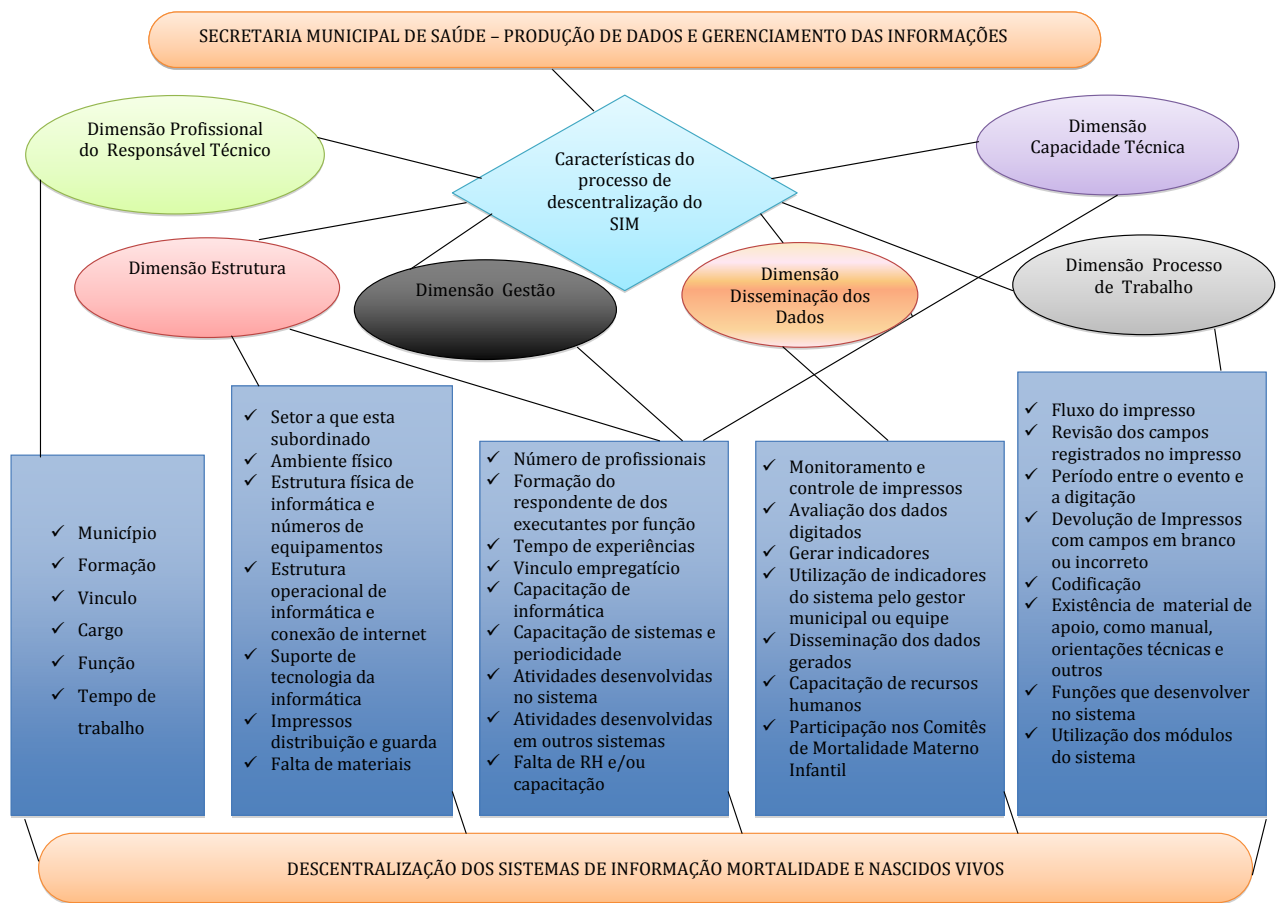

Foram investigadas as seguintes variáveis:

$\checkmark$ Perfil do responsável técnico: dados pessoais e profissionais, formação, tempo de trabalho, tempo na função, responsabilidades;

$\checkmark$ Infraestrutura: em que setor está alocado o SIM; tamanho e composição da equipe; equipamentos de informática: quantidade de microcomputadores, sistemas operacionais utilizados, capacidade e utilização exclusiva; servidores exclusivos, acesso à internet, suporte técnico, impressora; segurança da guarda dos impressos de DO, e outros;

Capacitação profissional: treinamentos realizados; 
$\checkmark$ Processo de trabalho: competências, periodicidade, fluxos, relação entre as instâncias e unidades de saúde, processamento dos dados, controle do documento padrão DO, busca ativa de eventos, revisão de informações coletadas; utilização do módulo web de investigação;

$\checkmark$ Gestão do sistema: monitoramento de volume de eventos; emissão de relatórios; utilização da ferramenta do tabwin; emissão de relatórios

$\checkmark$ Disseminação de dados; áreas técnicas e administrativas que mais utilizam os dados/informação, principais uso da informação;

Dificuldades encontradas na operação do sistema;

Grau de benefícios da descentralização do sistema.

Como na quase totalidade dos municípios o sistema SIM é gerenciado junto com o SINASC, foi elaborado um questionário abordando os dois sistemas, isto porque a arquitetura e lógica de ambos são idênticas. Apenas para três municípios foram elaborados questionários específicos para o SIM e para o SINASC, uma vez que nestes municípios há responsáveis distintos para cada sistema.

O questionário foi discutido com o grupo da pesquisa principal e profissionais da Secretaria do Estado da Saúde. Foi realizado também um teste do questionário eletrônico, para avaliar o aplicativo em relação à conectividade, fluxo e demais funcionalidade.

Seguindo metodologia adotada por Barreira (2007), optou-se como estratégia adaptar solicitando a opinião de três especialistas denominados de “juízes” na validação do conteúdo e forma do questionário. Segundo Barreira (2007), a aplicação de um questionário necessita de uma validação do instrumento, de forma independente, preferencialmente por especialista na área, para que possam realizar críticas, a fim de permitir adequação ao objeto a ser mensurado.

A escolha foi baseada na experiência dos profissionais em relação à área de informação em saúde, gestão de sistema e participação em pesquisas, 
tivemos resposta de dois dos "juízes, sendo um destes profissional que atua na área de informações em saúde em um município de grande porte do Estado de São Paulo e outro atua também com informações de saúde em outro estado brasileiro. Ambos tem experiência com o Sistema de Informação de Mortalidade - SIM.

Foi encaminhado aos juízes uma carta acompanhada do questionário e um quadro para avaliação e validação das questões, onde poderia sugerir: manter a questão; manter a questão com alterações ou excluir a questão e na coluna de observações ele poderia fazer seus comentários (MESSAS,2013). Nesta análise foi solicitado que o mesmo levasse em consideração os seguintes quesitos, adaptados do estudo de Barreira (2007):

$\checkmark$ Clareza: se o enunciado e as alternativas da questão são plenamente inteligíveis, sem gerar interpretações distintas;

$\checkmark$ Aplicabilidade: se a questão se aplica adequadamente ao objetivo proposto;

$\checkmark$ Poder discriminativo: se a questão consegue separar por categorias os resultados esperados;

$\checkmark$ Presença de vieses: se a questão ou alternativas oferecem possibilidade de desvios de respostas;

$\checkmark$ Redundância: se a questão repete temas abordados em outra questão.

A partir das sugestões dos juízes, foram realizadas as alterações pertinentes. O instrumento final foi construído com um total de 153 questões, sendo 136 questões fechadas e 17 questões abertas, todas de caráter obrigatório, com exceção da última questão que se referia a comentários adicionais (anexo IV). Em seguida foram elaborados os questionários que abordavam separadamente o SIM (anexo V) e o SINASC, ambos continham 115 questões, sendo 16 abertas e 99 fechadas. 


\subsection{Aplicação do questionário}

Devido ao grande volume de municípios do estado de São Paulo, a pesquisa quantitativa foi realizada por meio de um questionário eletrônico. Optou-se por utilizar o Formulário FORMSUS, um serviço do DATASUS para a criação de formulários na WEB, que permite coletar e armazenar dados de forma organizada, além de gerar relatórios. O FORMSUS é um serviço de uso público e gratuito com normas de utilização definidas, compatíveis com a legislação e com a Política de Informação e Informática do SUS e muito utilizado por secretarias estaduais e municipais de saúde. Para criar os formulários é necessário estar cadastrado como Gestor de Formulário do FORMSUS e realizar curso de formação. É de responsabilidade de cada gestor de formulário cuidar de sua aplicação e garantir a aplicação das normas.

A aplicação do questionário foi realizada com a colaboração do Centro de Informações Estratégicas em Vigilância à Saúde da SES-SP e dos GVEs, que foram os responsáveis pelo contato com os municípios.

Inicialmente foi enviada uma carta convite (anexo VI) aos responsáveis técnicos municipais, que continha a justificativa do estudo e o link para acesso ao questionário eletrônico. Semanalmente foi monitorado o volume e identificados os municípios não respondentes. Esta listagem era repassada aos GVEs para que estes entrassem em contato com os responsáveis técnicos dos municípios para reforçar o convite para participar da pesquisa. A aplicação do questionário foi realizada no período de 23 de março a 15 de maio de 2015.

\subsection{Análise dos dados}

Os dados foram analisados por meio de estatística descritiva, com a elaboração de medidas de distribuição e, em alguns casos, de medidas de tendência central. Os resultados foram analisados segundo porte populacional 
dos municípios, com base na estimativa da população de 2014 (IBGE), estratificado em três categorias: Grupo 1 (G1) até 30.000 habitantes, Grupo 2 (G2) 30.001 a 200.000 habitantes e Grupo 3 (G3) acima de 200.001 habitantes. A escolha destas categorias considerou o recorte de menos de 30.000 habitantes, uma vez que o Ministério da Saúde utiliza este recorte para realização de monitoramento da regularidade na alimentação do SIM, para fins de manutenção do repasse de recursos do componente de vigilância promoção da Saúde (Portaria MS/SVS n²01/2010).

Os testes de qui-quadrado e a ANOVA foram utilizados para comparação entre proporções e médias, respectivamente, entre os grupos de municípios, utilizando-se nível de significância $\mathrm{p}<0,05$.

Os dados foram processados no programa Statistical Package for the Social Sciences versão 17.0 (SPSS).

\subsection{Procedimentos éticos}

O projeto foi submetido e aprovado pelo Comitê de Ética e Pesquisa (CEP) da Faculdade de Saúde Pública da Universidade de São Paulo (Parecer 766.167). 


\section{RESULTADOS}

A pesquisa foi encaminhada para os 645 municípios do Estado de São Paulo, durante um período de 52 dias corridos. Obteve-se retorno de 584 municípios $(90,5 \%)$.

Quando se analisa a participação na pesquisa segundo porte populacional dos municípios, observa-se que os maiores, com mais de 200.000 habitantes, apresentaram maior participação (92,5\%), seguidos dos municípios menores, com população abaixo de 30.000 habitantes $(91,0 \%)$, ficando os municípios com população entre 30.001 a 200.000 habitantes com cobertura de $88,7 \%$ (Tabela 02).

Tabela 02 - Número e proporção de municípios existentes e participantes da pesquisa por porte populacional, Estado São Paulo, 2015.

\begin{tabular}{lccc}
\hline \multirow{2}{*}{ Porte Populacional } & \multicolumn{3}{c}{ Municípios } \\
\cline { 2 - 4 } & Total & Respondentes & \% \\
\hline Até 30.000 hab. & 446 & 406 & 91,0 \\
De 30.001 a 200.000 hab. & 159 & 141 & 88,7 \\
Maior que 200.000 hab. & 40 & 37 & 92,5 \\
\hline Total & $\mathbf{6 4 5}$ & $\mathbf{5 8 4}$ & $\mathbf{9 0 , 5}$ \\
\hline
\end{tabular}

A Tabela 03 mostra que a cobertura por GVE não foi uniforme. Para um pouco mais da metade dos 28 GVEs (15) houve resposta de todos os municípios de sua abrangência. Nove GVEs ficaram com um percentual de reposta entre $80,0 \%$ a 99,9\%, dentre estes se destaca São José do Rio Preto com 97,0\%, o GVE que supervisiona o maior número de municípios (67). Somente 4 GVEs apresentaram retorno entre 60,0\% e 79,9\%: Campinas $(61,9 \%)$, Araçatuba (67,5\%), Franca $(68,2 \%)$ e São João da Boa Vista $(70,0 \%)$. 
Tabela 03 - Número e proporção de municípios participantes da pesquisa, por GVE. Estado São Paulo, 2015.

\begin{tabular}{|c|c|c|c|}
\hline GVE & $\mathbf{N}^{\circ}$. municípios & $\begin{array}{l}\mathrm{N}^{\circ} \text {. municípios } \\
\text { respondentes }\end{array}$ & $\%$ \\
\hline GVE I - Capital & 1 & 1 & 100,0 \\
\hline GVE IX - Franco da Rocha & 5 & 5 & 100,0 \\
\hline GVE VII - Santo André & 7 & 7 & 100,0 \\
\hline GVE VIII - Mogi das Cruzes & 11 & 10 & 90,9 \\
\hline GVE X - Osasco & 15 & 12 & 80,0 \\
\hline GVE XI - Araçatuba & 40 & 27 & 70,0 \\
\hline GVE XII - Araraquara & 24 & 21 & 67,5 \\
\hline GVE XIII - Assis & 25 & 25 & 100,0 \\
\hline GVE XIV - Barretos & 18 & 16 & 88,9 \\
\hline GVE XIX - Marilia & 37 & 36 & 97,3 \\
\hline GVE XV - Bauru & 38 & 37 & 97,4 \\
\hline GVE XVI - Botucatu & 30 & 30 & 100,0 \\
\hline GVE XVII - Campinas & 42 & 26 & 61,9 \\
\hline GVE XVIII - Franca & 22 & 15 & 68,2 \\
\hline GVE XX-Piracicaba & 26 & 21 & 80,8 \\
\hline GVE XXI - Presidente Prudente & 24 & 24 & 100,0 \\
\hline GVE XXII - Presidente Venceslau & 21 & 21 & 100,0 \\
\hline GVE XXIII - Registro & 15 & 15 & 100,0 \\
\hline GVE XXIV - Ribeirão Preto & 26 & 25 & 96,2 \\
\hline GVE XXIX - São José do Rio Preto & 67 & 65 & 97,0 \\
\hline GVE XXV - Santos & 9 & 9 & 100,0 \\
\hline GVE XXVI - São João da Boa Vista & 20 & 14 & 70,0 \\
\hline GVE XXVII - São José dos Campos & 8 & 8 & 100,0 \\
\hline GVE XXVIII - Caraguatatuba & 4 & 4 & 100,0 \\
\hline GVE XXX - Jales & 35 & 35 & 100,0 \\
\hline GVE XXXI - Sorocaba & 33 & 33 & 100,0 \\
\hline GVE XXXII - Itapeva & 15 & 15 & 100,0 \\
\hline GVE XXXIII - Taubaté & 27 & 27 & 100,0 \\
\hline Total do Estado & 645 & 584 & 90,5 \\
\hline
\end{tabular}

\subsection{Dimensão Profissional do Responsável Técnico}

Em relação ao perfil dos responsáveis técnicos pelo SIM, predomina o sexo feminino $(81,5 \%)$ em todos os grupos de municípios, sendo que no grupo com mais de 200.000 habitantes, observa-se que este percentual cai para 
$75,7 \%$, porém as diferenças não foram estatisticamente significantes (Tabela $04)$.

A idade dos responsáveis técnicos variou de 20 a 67 anos, sendo a média de 39,3 anos (IC: 29,5 - 49,1), com aumento dos municípios de pequeno porte $(37,7$; IC: 28,6 - 46,8) para os maiores (47,1 anos; IC: 35,3 58,8). Nos menores municípios, $63,5 \%$ dos responsáveis tem menos de 40 anos, proporção que diminui para $48,2 \%$ e $27,0 \%$, respectivamente nos médios e grandes. Neste último grupo, quase metade dos responsáveis tem 50 anos ou mais. Verificou-se que as diferenças de idade entre os grupos de municípios foram significantes.

Quanto à escolaridade, a pesquisa mostrou que a maioria dos responsáveis apresenta curso superior completo $(78,9 \%)$, e mais de um terço contam com pós-graduação concluída ou em andamento. Destaca-se o maior percentual de superior completo $(86,5 \%)$ e de pós-graduação $(56,8 \%)$ em municípios maiores. Essas diferenças foram estatisticamente significantes. Entre os $21,1 \%$ que não possuem ensino superior, verificou-se pequena presença de profissionais com ensino fundamental $(1,7 \%)$, restritos aos municípios de pequeno e médio porte (anexo VII tabela 1A).

Quanto aos que possuem superior completo, predominam os responsáveis com formação na área de conhecimento ${ }^{3}$ em Ciências da Saúde (76,5\%), com proporções próximas nos três grupos de municípios, sem diferenças estatisticamente significantes $(p=0,375)$. Em seguida aparece a área de Ciências Sociais Aplicadas (14,0\%), com presença mais representativa nos municípios grandes $(23,8 \%)$ do que nos pequenos $(12,6 \%)$.

\footnotetext{
${ }^{3}$ De acordo com classificação adotada pelo CNPq.
} 
Tabela 04 - Número e proporção de responsáveis técnicos municipais pelo SIM, segundo sexo, idade e escolaridade, por porte populacional, Estado de São Paulo, 2015

\begin{tabular}{|c|c|c|c|c|c|c|c|c|}
\hline \multirow{3}{*}{ Variáveis } & \multicolumn{6}{|c|}{ Porte dos Municípios (habitantes) } & \multirow{2}{*}{\multicolumn{2}{|c|}{ Total }} \\
\hline & \multicolumn{2}{|c|}{ Até $\mathbf{3 0 . 0 0 0}$} & \multicolumn{2}{|c|}{$\begin{array}{c}\text { De 30.001 a } \\
200.000\end{array}$} & \multicolumn{2}{|c|}{$\begin{array}{l}\text { Maior que } \\
200.000\end{array}$} & & \\
\hline & $\mathrm{N}$ & $\%$ & $\mathrm{~N}$ & $\%$ & $\mathrm{~N}$ & $\%$ & $\mathrm{~N}$ & $\%$ \\
\hline \multicolumn{9}{|l|}{ Sexo* } \\
\hline Masculino & 80 & 19,7 & 19 & 13,5 & 9 & 24,3 & 108 & 18,5 \\
\hline Feminino & 326 & 80,3 & 122 & 86,5 & 28 & 75,7 & 476 & 81,5 \\
\hline \multicolumn{9}{|l|}{ Idade $^{* *}$} \\
\hline Menos de 40 anos & 258 & 63,5 & 68 & 48,2 & 10 & 27,0 & 336 & 57,5 \\
\hline De 40 a 49 anos & 92 & 22,7 & 36 & 25,5 & 10 & 27,0 & 138 & 23,6 \\
\hline De 50 anos e mais & 56 & 13,8 & 37 & 26,2 & 17 & 45,9 & 110 & 18,8 \\
\hline \multicolumn{9}{|l|}{ Escolaridade $\mathrm{e}^{i * \pi}$} \\
\hline Inferior a ensino superior & 87 & 21,4 & 31 & 22,0 & 5 & 13,5 & 123 & 21,1 \\
\hline Ensino superior completo & 319 & 78,6 & 110 & 78,0 & 32 & 86,5 & 461 & 78,9 \\
\hline Pós-completa ou incompleta & 129 & 31,8 & 57 & 40,4 & 21 & 56,8 & 207 & 35,4 \\
\hline Total & 406 & 100,0 & 141 & 100,0 & 37 & 100,0 & 584 & 100,0 \\
\hline
\end{tabular}

Foram citadas 38 profissões, com maior variedade nos menores municípios (31). Nos municípios médios foram citadas 23 e nos maiores apenas 9. A formação mais frequente foi Enfermagem $(64,9 \%)$, em seguida, com valores bem menores (entre 4,1\% e 3,2\%) são citadas Administração, Área da Saúde sem especificação e Medicina (Tabela 05). Observou-se que mais de 70,0\% dos responsáveis técnicos dos municípios pequenos são enfermeiros, proporção que diminui conforme aumenta o porte populacional. Nos municípios médios e grandes, o profissional de enfermagem é o responsável em 54,8\% e 41,7\% dos municípios, aparecendo em seguida os médicos, com $6,0 \%$ e $20,8 \% \%$, respectivamente. As demais categorias estão listadas no anexo VII - tabela 2A. 
Tabela 05 - Número e proporção de responsáveis técnicos municipais do SIM, segundo formação, por porte populacional, Estado São Paulo, 2015.

\begin{tabular}{|c|c|c|c|c|c|c|c|c|}
\hline \multirow{3}{*}{ Categorias } & \multicolumn{6}{|c|}{ Porte dos Municípios (habitantes) } & & \\
\hline & \multicolumn{2}{|c|}{ Até $\mathbf{3 0 . 0 0 0}$} & \multicolumn{2}{|c|}{$\begin{array}{c}\text { De } 30.001 \text { a } \\
200.000\end{array}$} & \multicolumn{2}{|c|}{$\begin{array}{c}\text { Maior que } \\
200.000\end{array}$} & \multicolumn{2}{|c|}{ Total } \\
\hline & $\mathbf{N}$ & $\%$ & $\mathbf{N}$ & $\%$ & $\mathbf{N}$ & $\%$ & $\mathbf{N}$ & $\%$ \\
\hline Enfermagem & 164 & 71,0 & 46 & 54,8 & 10 & 41,7 & 220 & 64,9 \\
\hline Adminstração & 9 & 3,9 & 2 & 2,4 & 3 & 12,5 & 14 & 4,1 \\
\hline Área Saúde sem especificação & 7 & 3,0 & 3 & 3,6 & 1 & 4,2 & 11 & 3,2 \\
\hline Medicina & 1 & 0,4 & 5 & 6,0 & 5 & 20,8 & 11 & 3,2 \\
\hline Gestão na área da Saúde & 6 & 2,6 & 2 & 2,4 & 0 & 0,0 & 8 & 2,4 \\
\hline Biologia/Ciências biológicas & 3 & 1,3 & 3 & 3,6 & 1 & 4,2 & 7 & 2,1 \\
\hline $\begin{array}{l}\text { Sistemas de informação/ } \\
\text { ciências da computação/ } \\
\text { informatica }\end{array}$ & 5 & 2,2 & 2 & 2,4 & 0 & 0,0 & 7 & 2,1 \\
\hline Pedagogia & 5 & 2,2 & 0 & 0,0 & 1 & 4,2 & 6 & 1,8 \\
\hline Outros & 31 & 13,4 & 21 & 25,0 & 3 & 12,5 & 55 & 16,2 \\
\hline Total & 231 & 100,0 & 84 & 100,0 & 24 & 100,0 & 339 & 100,0 \\
\hline
\end{tabular}

Quanto ao vínculo empregatício do responsável técnico, prevalece o efetivo $(66,1 \%)$, com menor volume nos municípios pequenos e médios $(65,0 \%)$ e maior nos grandes municípios $(81,1 \%)$. O regime CLT é o segundo vínculo mais utilizado (24\%), porém ele apresenta um decréscimo de frequência conforme aumenta o porte populacional chegando a 10,8\% no grupo de municípios maiores. Cerca de 7,9\% dos responsáveis tem cargo em comissão, o que pode indicar permanência transitória no município. As diferenças não foram estatisticamente significantes (Tabela 06).

A função de Diretor/Coordenador/Supervisor foi a mais frequente (40,8\%), com proporção mais elevada nos municípios de médio porte $(43,3 \%)$. A função de Digitador/Auxiliar Administrativo ou similar foi a segunda mais citada $(22,6 \%)$, com frequências decrescentes dos menores municípios $(24,5 \%)$ para os maiores $(13,5 \%)$. Assistentes técnicos ou similares correspondem a $6,7 \%$, sendo mais frequentes nos municípios grandes $(18,9 \%)$. Dos $27,1 \%$ que indicaram outra função predomina o cargo de enfermeiro $(68,5 \%)$ além de 
outros profissionais da saúde e de nível técnico. Neste conjunto destaca-se a presença de dois secretários municipais da saúde.

Quanto ao tempo de atuação no setor público da área de saúde, prevalecem os profissionais com mais de três anos $(88,9 \%)$, ocorre um aumento de percentual à medida que aumenta o porte populacional, partindo de $87,2 \%$ nos municípios menores, chegando a 97,3\% para os maiores, com diferenças estatisticamente significantes.

A maioria dos municípios conta com profissionais experientes na gestão do SIM, 68,1\% deles tem três anos ou mais de atuação, não havendo diferença estatisticamente significante entre os grupos. No entanto, observa-se que cerca de 10,0\% são responsáveis pelo SIM há menos de um ano, sendo 11,6\% nos municípios médios (anexo VII - tabela 1A).

Em relação a ter assinado ou não o Termo de Sigilo e Confidencialidade, observa-se que 48,3\% dos responsáveis técnicos assinaram o termo antes de exercer a função, porém 30,5\% assinaram após o início das suas atribuições em relação ao sistema e destaca-se que 21,2\% não assinaram o referido termo, o que está em desacordo com a Resolução SS nº. 66/2010. Não foram observadas diferenças estatisticamente significantes.

Foi identificado que o acúmulo de responsabilidade com outros sistemas de informação é alto $(83,7 \%)$. Destes, observa-se que os municípios pequenos apresentam maior percentual $(92,4 \%)$, seguido dos de médio porte $(72,3 \%)$ e os municípios maiores apresentam percentual bem menor $(32,4 \%)$. As diferenças entre os grupos foram estatisticamente significantes (Tabela 06). 
Tabela 06 - Número e proporção de responsáveis técnicos municipais pelo SIM, segundo vínculo, função, tempo de trabalho na área de saúde e no SIM, por porte populacional, Estado de São Paulo, 2015.

\begin{tabular}{|c|c|c|c|c|c|c|c|c|}
\hline \multirow{3}{*}{ Variáveis } & \multicolumn{6}{|c|}{ Porte dos Municípios (habitantes) } & & \\
\hline & \multicolumn{2}{|c|}{ Até 30.000} & \multicolumn{2}{|c|}{$\begin{array}{c}\text { De } 30.001 \text { a } \\
200.000\end{array}$} & \multicolumn{2}{|c|}{$\begin{array}{l}\text { Maior que } \\
200.000\end{array}$} & \multicolumn{2}{|c|}{ Total } \\
\hline & $\mathrm{N}$ & $\%$ & $\mathrm{~N}$ & $\%$ & $\mathrm{~N}$ & $\%$ & $\mathrm{~N}$ & $\%$ \\
\hline \multicolumn{9}{|l|}{ Vínculo* } \\
\hline Efetivo & 264 & 65,0 & 92 & 65,2 & 30 & 81,1 & 386 & 66,1 \\
\hline CLT & 102 & 25,1 & 34 & 24,1 & 4 & 10,8 & 140 & 24,0 \\
\hline Cargo em comissão & 30 & 7,4 & 13 & 9,2 & 3 & 8,1 & 46 & 7,9 \\
\hline Outros & 10 & 2,5 & 2 & 1,4 & 0 & 0,0 & 12 & 2,1 \\
\hline \multicolumn{9}{|l|}{ Função } \\
\hline Diretor/Coordenador/Supervisor & 162 & 39,9 & 61 & 43,3 & 15 & 40,5 & 238 & 40,8 \\
\hline $\begin{array}{l}\text { Assistente Técnico, Técnico de } \\
\text { informática ou similar }\end{array}$ & 26 & 6,4 & 15 & 10,6 & 7 & 18,9 & 48 & 8,2 \\
\hline $\begin{array}{l}\text { Digitador/Auxiliar Administrativo ou } \\
\text { similar }\end{array}$ & 99 & 24,4 & 28 & 19,9 & 5 & 13,5 & 132 & 22,6 \\
\hline Outro & 114 & 28,1 & 35 & 24,8 & 9 & 24,3 & 158 & 27,1 \\
\hline \multicolumn{9}{|c|}{ Tempo de trabalho na área de Saúde } \\
\hline Menos de 3 anos & 52 & 12,8 & 12 & 8,5 & 1 & 2,7 & 65 & 11,1 \\
\hline 3 anos ou mais & 354 & 87,2 & 129 & 91,5 & 36 & 97,3 & 519 & 88,9 \\
\hline \multicolumn{9}{|l|}{ Tempo de trabalho no SIM ${ }^{* * * *}$} \\
\hline Menos de 3 anos & 137 & 33,7 & 39 & 27,7 & 10 & 27,0 & 186 & 31,8 \\
\hline 3 anos ou mais & 269 & 66,3 & 102 & 72,3 & 27 & 73,0 & 398 & 68,2 \\
\hline \multicolumn{9}{|c|}{ Assinou o Termo de Sigilo e Confidencialidade ${ }^{* \dot{*} * \dot{*}}$} \\
\hline Não & 93 & 22,9 & 23 & 16,3 & 8 & 21,6 & 124 & 21,2 \\
\hline Sim, antes de exercer o trabalho & 200 & 49,3 & 66 & 46,8 & 16 & 43,2 & 282 & 48,3 \\
\hline Sim, depois de exercer o trabalho & 113 & 27,8 & 52 & 36,9 & 13 & 35,1 & 178 & 30,5 \\
\hline \multicolumn{9}{|l|}{ 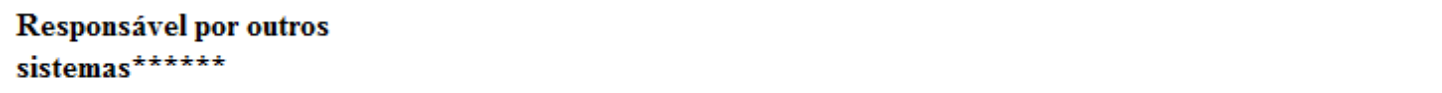 } \\
\hline Não & 31 & 7,6 & 39 & 27,7 & 25 & 67,6 & 95 & 16,3 \\
\hline Sim & 375 & 92,4 & 102 & 72,3 & 12 & 32,4 & 489 & 83,7 \\
\hline Total & 406 & 100,0 & 141 & 100,0 & 37 & 100,0 & 584 & 100,0 \\
\hline
\end{tabular}

Ao iniciar a pesquisa tinha-se a informação (CIVS/SES-SP) de que na quase totalidade dos municípios paulistas o responsável técnico para o SIM era o mesmo para o SINASC, somente 03 municípios tinham responsáveis distintos para cada sistema. Assim, pesquisou-se a responsabilidade simultânea 
por outros sistemas, além do SINASC. Observou-se que, quando há acúmulo de responsabilidade por outros sistemas, os dois mais citados são o SINAN (80,0\%) e Sistema de Informação do Programa Nacional de Imunização (SIPNI) (63,2\%), ligados à vigilância epidemiológica. Em menor grau foram mencionados sistemas ligados à assistência como o SISPRENATAL (37,0\%), SIAB e SIA $(19,4 \%)$. Também foram citados outros sistemas como SIOPS e SISAGUA (Tabela 07).

Tabela 07 - Número de sistemas com responsabilidade conjunta com SIM e SINASC, Estados São Paulo, 2015.

\begin{tabular}{lcc} 
Sistemas & Número & $\mathbf{\%}$ \\
\hline $\begin{array}{l}\text { SINAN - Sistema de informação de Agravos de Notificação } \\
\text { SI-PNI - Sistema de Informação do Programa Nacional de }\end{array}$ & 391 & 80,0 \\
$\begin{array}{l}\text { Imunizações } \\
\text { SISPRENATAL - Sistema de Acompanhamento do Programa de }\end{array}$ & 309 & 63,2 \\
Humanização no Pré-Natal e Nascimento & 181 & 37,0 \\
SLA - Sistema de Informações Ambulatoriais & 95 & 19,4 \\
$\begin{array}{l}\text { SLAB - Sistema de Informações de Atenção Básica } \\
\text { SISSOLO - Sistema de Informação de Vigilância a População }\end{array}$ & 95 & 19,4 \\
$\begin{array}{l}\text { Exposta a Solo Contaminado } \\
\text { SISAGUA -Sistema de Informação de Vigilânciada Qualidade da }\end{array}$ & 84 & 17,2 \\
Agua para o Consumo Humano & 47 & 9,61 \\
SHH - Sistema de Informações Hospitalares & 26 & 5,32 \\
SIOPS - Sistema de Informação sobre Orçamentos Públicos em Si & 12 & 2,45 \\
Outros & 211 & 43,1 \\
\hline Total & $\mathbf{4 8 9}$ & \\
\hline
\end{tabular}

\subsection{Dimensão Estrutura}

A pesquisa aponta que a alocação institucional do SIM está na Vigilância Epidemiológica em 54,1\% dos municípios, com maior proporção em municípios de médio porte $(86,5 \%)$, seguido dos de maior porte $(78,4 \%)$. 
Nos municípios pequenos destaca-se a Unidade de Saúde $(40,1 \%)$ juntamente com a Vigilância Epidemiológica $(40,6 \%)$ em proporções semelhantes. A alocação do SIM no Setor de Informações da SMS foi citada por 12,0\% dos municípios, sendo que $16,2 \%$ são municípios grandes, mas $12,8 \%$ são pequenos. As diferenças entre os grupos de municípios foram estatisticamente significantes. (Tabela 08).

Tabela 08 - Número e proporção de municípios, segundo local onde está alocado o SIM, por porte populacional, Estados São Paulo, 2015.

\begin{tabular}{|c|c|c|c|c|c|c|c|c|}
\hline \multirow{3}{*}{$\begin{array}{l}\text { Setor em que está } \\
\text { alocado o SIM }\end{array}$} & \multicolumn{6}{|c|}{ Porte dos Municípios (habitantes) } & \multirow{2}{*}{\multicolumn{2}{|c|}{ Total }} \\
\hline & \multicolumn{2}{|c|}{ Até 30.000} & \multicolumn{2}{|c|}{$\begin{array}{c}\text { De } 30.001 \text { a } \\
200.000 \\
\end{array}$} & \multicolumn{2}{|c|}{$\begin{array}{c}\text { Maior que } \\
200.000 \\
\end{array}$} & & \\
\hline & $\mathrm{N}$ & $\%$ & $\mathrm{~N}$ & $\%$ & $\mathrm{~N}$ & $\%$ & $\mathrm{~N}$ & $\%$ \\
\hline Unidade de Saúde & 163 & 40,1 & 2 & 1,4 & 1 & 2,7 & 166 & 28,4 \\
\hline Vigilância Epidemiológica & 165 & 40,6 & 122 & 86,5 & 29 & 78,4 & 316 & 54,1 \\
\hline Setor de Informações da SMS & 52 & 12,8 & 12 & 8,5 & 6 & 16,2 & 70 & 12,0 \\
\hline Outros & 26 & 6,4 & 5 & 3,5 & 1 & 2,7 & 32 & 5,5 \\
\hline Total & 406 & 100,0 & 141 & 100,0 & 37 & 100,0 & 584 & 100,0 \\
\hline
\end{tabular}

Para a variável composição da equipe foi considerado a data base de 31 de dezembro de 2014. Em relação ao volume de pessoas que trabalham no SIM, a pesquisa mostrou que $51,4 \%$ dos municípios têm duas pessoas, $24,8 \%$ tem apenas uma pessoa, $15,9 \%$ tem três pessoas, $5,0 \%$ tem quatro pessoas e somente um município tem 15 pessoas na equipe do SIM. Na estratificação por porte populacional, as equipes com duas pessoas tem frequência semelhante nos municípios de médio $(50,4 \%)$ e pequeno porte $(54,4 \%)$. Já $32,4 \%$ dos municípios maiores contam com equipes com cinco pessoas ou mais. Quanto aos municípios que tem um pessoa trabalhando com o SIM, os de pequeno porte apresentaram os maiores percentuais $(30,5 \%)$, decrescendo à medida que aumenta o porte, 12,1\% para médio e 10,0\% para grande, o que chama, neste último caso, atenção dado o volume de trabalho do SIM em municípios com mais de 200 mil habitantes (Tabela 09). 
Tabela 09 - Número e proporção de municípios, segundo número total de pessoas que trabalham no SIM, por porte populacional, Estado São Paulo, 2015.

\begin{tabular}{|c|c|c|c|c|c|c|c|c|}
\hline \multirow{3}{*}{$\begin{array}{l}\text { Número de } \\
\text { pessoas }\end{array}$} & \multicolumn{8}{|c|}{ Porte Populacional } \\
\hline & \multicolumn{2}{|c|}{ Até 30.000} & \multicolumn{2}{|c|}{$\begin{array}{c}\text { De } 30.001 \text { a } \\
200.000\end{array}$} & \multicolumn{2}{|c|}{$\begin{array}{c}\text { Maior que } \\
200.000\end{array}$} & \multicolumn{2}{|c|}{ Total } \\
\hline & $\mathrm{N}$ & $\%$ & $\mathrm{~N}$ & $\%$ & $\mathrm{~N}$ & $\%$ & $\mathrm{~N}$ & $\%$ \\
\hline 1 & 124 & 30,5 & 17 & 12,1 & 4 & 10,8 & 145 & 24,8 \\
\hline 2 & 221 & 54,4 & 71 & 50,4 & 8 & 21,6 & 300 & 51,4 \\
\hline 3 & 48 & 11,8 & 38 & 27,0 & 7 & 18,9 & 93 & 15,9 \\
\hline 4 & 10 & 2,5 & 13 & 9,2 & 6 & 16,2 & 29 & 5,0 \\
\hline 5 ou mais & 2 & 0,5 & 2 & 1,4 & 12 & 32,4 & 16 & 2,7 \\
\hline Ignorado & 1 & 0,2 & 0 & 0,0 & 0 & 0,0 & 1 & 0,2 \\
\hline Total & 406 & 100 & 141 & 100 & 37 & 100 & 584 & 100 \\
\hline
\end{tabular}

Nota: situação em 31/12/2014.

A tabela 10 mostra que $71,4 \%$ dos municípios contém em sua equipe pelo menos um profissional com formação de nível superior na área de saúde, $30,1 \%$ tem um profissional de nível superior na área de tecnologia da informação e 47,1 \% tem um profissional de nível técnico ou ensino médio, $15,1 \%$ tem um profissional de outra área de nível superior. Apenas um município conta com 10 profissionais com nível superior em sua equipe. 47,1\% dos municípios têm um profissional técnico ou de nível médio em sua equipe. Aponta também que 91,8\% não tem nenhum profissional do nível fundamental. 
Tabela 10 - Número e proporção de respondentes, segundo número de pessoas que trabalham com o SIM por nível de instrução, Estado São Paulo, dezembro de 2014

\begin{tabular}{|c|c|c|c|c|c|c|c|c|c|c|c|c|c|c|c|c|}
\hline \multirow{3}{*}{ Nivel de escolaridade } & \multicolumn{16}{|c|}{ Número de pessoas } \\
\hline & \multicolumn{2}{|c|}{0} & \multicolumn{2}{|c|}{1} & \multicolumn{2}{|c|}{2} & \multicolumn{2}{|c|}{3} & \multicolumn{2}{|c|}{4} & \multicolumn{2}{|c|}{5} & \multicolumn{2}{|c|}{10} & \multicolumn{2}{|c|}{ Total } \\
\hline & $\mathrm{N}$ & $\%$ & $\mathrm{~N}$ & $\%$ & $\mathrm{~N}$ & $\%$ & $\mathrm{~N}$ & $\%$ & $\mathrm{~N}$ & $\%$ & $\mathrm{~N}$ & $\%$ & $\mathrm{~N}$ & $\%$ & $\mathrm{~N}$ & $\%$ \\
\hline Superior na área de saúde & 57 & 9,8 & 417 & 71,4 & 92 & 15,8 & 14 & 2,4 & 2 & 0,3 & 1 & 0,2 & 1 & 0,2 & 584 & 100 \\
\hline $\begin{array}{l}\text { Superior na área de Tec. } \\
\text { Informação }\end{array}$ & 485 & 83 & 88 & 15,1 & 8 & 1,4 & 3 & 0,5 & 0 & 0 & 0 & 0 & 0 & 0 & 584 & 100 \\
\hline Superior em outra área & 375 & 64,2 & 176 & 30,1 & 28 & 4,8 & 5 & 0,9 & 0 & 0 & 0 & 0 & 0 & 0 & 584 & 100 \\
\hline Técnico ou ensino médio & 225 & 38,5 & 275 & 47,1 & 66 & 11,3 & 15 & 2,6 & 1 & 0,2 & 2 & 0,3 & 0 & 0 & 584 & 100 \\
\hline Fundamental & 536 & 91,8 & 40 & 6,8 & 7 & 1,2 & 1 & 0,2 & 0 & 0 & 0 & 0 & 0 & 0 & 584 & 100 \\
\hline
\end{tabular}

Nota: situação em 31/12/2014.

Procurou-se identificar quais atividades eram desenvolvidas pelo responsável técnico, pela equipe ou por ambos. Verificou-se que as atividades de rotina de operação do sistema (digitação, backup, retroalimentação, digitação de fichas de investigação, cancelamento de impressos, etc) são aquelas realizadas com mais frequência pelos municípios, já outras atividades mais elaboradas apresentaram menor ocorrência $(<85,0 \%)$. Observa-se que no quesito elaboração de indicadores, $78,6 \%$ dos municípios realizam esta atividade, sendo $100,0 \%$ nos municípios de grande porte, entre os quais o responsável técnico realiza-a em 51,4\%. Observa-se também que 21,4\% não realizam esta atividade, onde os municípios de pequeno porte mostram um maior percentual $(26,4 \%)$ (anexo VII Tabela 3A).

Em relação à analise de dados, a Tabela 11 mostra que esta atividade é compartilhada pelo responsável e pela equipe, com proporções pouco superiores para o primeiro. Não foram observadas diferenças importantes segundo porte populacional por município.

A participação no Comitê de Investigação de Morte Materna e Infantil apresenta um percentual de $72,1 \%$, com destaque para a realização desta atividade pela equipe $(33,9 \%)$, e destes os municípios de grande porte tem maior percentual $(40,5 \%)$. Os municípios de médio porte apresentam dados semelhantes entre o responsável técnico e equipe. Entre os que não realizam esta atividade destaca-se os municípios de pequeno porte com $34,2 \%$. 
Tabela 11 - Número e proporção de municípios, segundo atividades desenvolvidas, por porte populacional, Estado de São Paulo, 2015.

\begin{tabular}{|c|c|c|c|c|c|c|c|c|}
\hline \multirow{2}{*}{ Variáveis } & \multicolumn{6}{|c|}{ Porte Populacional (habitantes) } & \multirow{2}{*}{\multicolumn{2}{|c|}{ Total }} \\
\hline & \multicolumn{2}{|c|}{ Até 30.000} & \multicolumn{2}{|c|}{ De 30.001 a 200.000} & \multicolumn{2}{|c|}{$\begin{array}{c}\text { Maior que } \\
200.000\end{array}$} & & \\
\hline \multicolumn{9}{|c|}{ Elaboração de indicadores } \\
\hline Responsável Técnico & 123 & 30,3 & 55 & 39,0 & 19 & 51,4 & 197 & 33,7 \\
\hline Equipe & 149 & 36,7 & 45 & 31,9 & 12 & 32,4 & 206 & 35,3 \\
\hline Ambos & 27 & 6,7 & 23 & 16,3 & 6 & 16,2 & 56 & 9,6 \\
\hline Não realiza & 107 & 26,4 & 18 & 12,8 & 0 & 0,0 & 125 & 21,4 \\
\hline \multicolumn{9}{|l|}{ Analise de dados } \\
\hline Responsável Técnico & 151 & 37,3 & 55 & 39,0 & 15 & 40,5 & 221 & 37,8 \\
\hline Equipe & 141 & 34,7 & 47 & 33,3 & 12 & 32,4 & 200 & 34,2 \\
\hline Ambos & 35 & 8,6 & 27 & 19,2 & 8 & 21,6 & 70 & 12,0 \\
\hline Não realiza & 78 & 19,2 & 12 & 8,5 & 2 & 5,4 & 92 & 15,8 \\
\hline Ignorado & 1 & 0,2 & 0 & 0,0 & 0 & 0,0 & 1 & 0,2 \\
\hline \multicolumn{9}{|c|}{$\begin{array}{l}\text { Participação em Comitê } \\
\text { De Investigação de morte } \\
\text { materna e infantil }\end{array}$} \\
\hline Responsável Técnico & 109 & 26,8 & 43 & 30,5 & 13 & 35,1 & 165 & 28,3 \\
\hline Equipe & 136 & 33,5 & 47 & 33,3 & 15 & 40,5 & 198 & 33,9 \\
\hline Ambos & 21 & 5,2 & 31 & 22 & 6 & 16,2 & 58 & 9,9 \\
\hline Não realiza & 139 & 34,2 & 30 & 14,2 & 3 & 8,1 & 162 & 27,7 \\
\hline Ignorado & 1 & 0,0 & 0 & 0,0 & 0 & 0,0 & 1 & 0,2 \\
\hline Total & 406 & 100,0 & 141 & 100,0 & 37 & 100,0 & 584 & 100,0 \\
\hline
\end{tabular}

Em relação à quantidade de computadores com o SIM instalado, observou-se uma variação de 1 a 15 computadores, apenas um município informou que não instalou o SIM. Em 92,1\% dos municípios o sistema está instalado em um equipamento, em 4,5\% em dois, Um município informou contar com 15 computadores para operar o SIM (Tabela 12). 
Tabela 12 - Número e proporção de municípios, segundo número de computadores como SIM instalado, por porte populacional, Estado São Paulo, 2015.

\begin{tabular}{|c|c|c|c|c|c|c|c|c|}
\hline \multirow{3}{*}{$\begin{array}{l}\text { Número de } \\
\text { computadores }\end{array}$} & \multicolumn{6}{|c|}{ Porte Populacional } & & \\
\hline & \multicolumn{2}{|c|}{ Até 30.000} & \multicolumn{2}{|c|}{$\begin{array}{c}\text { De } 30.001 \text { a } \\
200.000\end{array}$} & \multicolumn{2}{|c|}{$\begin{array}{c}\text { Maior que } \\
200.000\end{array}$} & \multicolumn{2}{|c|}{ Total } \\
\hline & $\mathrm{N}$ & $\%$ & $\mathrm{~N}$ & $\%$ & $\mathrm{~N}$ & $\%$ & $\mathrm{~N}$ & $\%$ \\
\hline 0 & 1 & 0,2 & 0 & 0,0 & 0 & 0,0 & 1 & 0,2 \\
\hline 1 & 396 & 97,5 & 127 & 90,1 & 15 & 40,5 & 538 & 92,1 \\
\hline 2 & 7 & 1,7 & 11 & 7,8 & 8 & 21,6 & 26 & 4,5 \\
\hline 3 & 2 & 0,5 & 2 & 1,4 & 1 & 2,7 & 5 & 0,9 \\
\hline 4 & 0 & 0,0 & 1 & 0,7 & 6 & 16,2 & 7 & 1,2 \\
\hline 5 & 0 & 0,0 & 0 & 0,0 & 2 & 5,4 & 2 & 0,3 \\
\hline 6 & 0 & 0,0 & 0 & 0,0 & 2 & 5,4 & 2 & 0,3 \\
\hline $7 \mathrm{out}+$ & 0 & 0,0 & 0 & 0,0 & 3 & 8,1 & 3 & 0,5 \\
\hline Total & 406 & 100,0 & 141 & 100,0 & 37 & 100,0 & 584 & 100,0 \\
\hline
\end{tabular}

Para verificar o grau de modernização do parque computacional dos municípios, investigou-se o tipo de sistema operacional instalado nos computadores que operam o SIM. Observou-se que 68,3\% dos municípios tem o Windows XP como sistema operacional para rodar o SIM, versão mais antiga. Em seguida 13,9\% com Windows 7 - 32 Bits, 6,2\% com Windows 7 64 Bits. Nota-se que 5,4\% dos municípios de grande porte tem instalado o Windows 8 - 64 Bits ,sendo este o sistema operacional mais avançado. Cinquenta municípios $(8,6 \%)$ não souberam informar o tipo de sistema operacional utilizado (Tabela 13) . 
Tabela 13 - Número e proporção de municípios, segundo tipo de sistema operacional dos computadores onde está instalado o SIM, por porte populacional, Estado São Paulo, 2015.

\begin{tabular}{|c|c|c|c|c|c|c|c|c|}
\hline \multirow{3}{*}{ Sistema Operacional } & \multicolumn{6}{|c|}{ Porte Populacional } & \multirow{2}{*}{\multicolumn{2}{|c|}{ Total }} \\
\hline & \multicolumn{2}{|c|}{ Até 30.000} & \multicolumn{2}{|c|}{$\begin{array}{c}\text { De } 30.001 \text { a } \\
200.000\end{array}$} & \multicolumn{2}{|c|}{ Maior que 200.000} & & \\
\hline & $\mathbf{N}$ & $\%$ & $\mathbf{N}$ & $\%$ & $\mathbf{N}$ & $\%$ & $\mathbf{N}$ & $\%$ \\
\hline Windows XP & 282 & 69,5 & 100 & 70,9 & 17 & 45,9 & 399 & 68,3 \\
\hline Windows Vista & 2 & 0,5 & 0 & 0,0 & 0 & 0,0 & 2 & 0,3 \\
\hline Windows 7 - 32 Bits & 52 & 12,8 & 22 & 15,6 & 7 & 18,9 & 81 & 13,9 \\
\hline Windows 7 - 64 Bits & 21 & 5,2 & 10 & 7,1 & 5 & 13,5 & 36 & 6,2 \\
\hline Windows 8 - 32 Bits & 4 & 1,0 & 1 & 0,7 & 0 & 0,0 & 5 & 0,9 \\
\hline Windows 8 - 64 Bits & 4 & 1,0 & 3 & 2,1 & 2 & 5,4 & 9 & 1,5 \\
\hline Outro & 0 & 0,0 & 0 & 0,0 & 2 & 5,4 & 2 & 0,3 \\
\hline Nẫo sabe & 41 & 10,1 & 5 & 3,5 & 4 & 10,8 & 50 & 8,6 \\
\hline Total & 406 & 100,0 & 141 & 100,0 & 37 & 100,0 & 584 & 100,0 \\
\hline
\end{tabular}

Dentre os municípios, 73,6\% contam com acesso rápido à internet, seguido de 20,4\% com acesso por link de rádio, 2,9\% por acesso discado, restrito aos municípios pequenos e médios. Outros $2,1 \%$ informaram não ter acesso à internet nos computadores que operam o SIM (Tabela 14).

Tabela 14 - Número e proporção de municípios, segundo acesso a internet, por porte populacional, Estados São Paulo, 2015.

\begin{tabular}{|c|c|c|c|c|c|c|c|c|}
\hline \multirow{3}{*}{$\begin{array}{c}\text { Acesso a } \\
\text { internet }\end{array}$} & \multicolumn{6}{|c|}{ Porte populacional } & & \\
\hline & \multicolumn{2}{|c|}{ Até $\mathbf{3 0 . 0 0 0}$} & \multicolumn{2}{|c|}{$\begin{array}{c}\text { De 30.001 a } \\
200.000\end{array}$} & \multicolumn{2}{|c|}{$\begin{array}{l}\text { Maior que } \\
200.000\end{array}$} & \multicolumn{2}{|c|}{ Total } \\
\hline & $\mathbf{N}$ & $\%$ & $\mathbf{N}$ & $\%$ & $\mathbf{N}$ & $\%$ & $\mathbf{N}$ & $\%$ \\
\hline Não & 10 & 2,5 & 1 & 0,7 & 1 & 2,7 & 12 & 2,1 \\
\hline $\begin{array}{l}\text { Sim, através de } \\
\text { acesso discado }\end{array}$ & 15 & 3,7 & 2 & 1,4 & 0 & 0,0 & 17 & 2,9 \\
\hline $\begin{array}{l}\text { Sim, através de } \\
\text { acesso rápido } \\
\text { (tipo "banda } \\
\text { larga") }\end{array}$ & 291 & 71,7 & 109 & 77,3 & 30 & 81,1 & 430 & 73,6 \\
\hline $\begin{array}{l}\text { Sim, através de } \\
\text { link de rádio }\end{array}$ & 85 & 20,9 & 29 & 20,6 & 5 & 13,5 & 119 & 20,4 \\
\hline Outros & 5 & 1,2 & 0 & 0,0 & 0 & 1,0 & 6 & 1,0 \\
\hline $\begin{array}{r}\text { Total } \\
\end{array}$ & 406 & 100,0 & 141 & 100,0 & 37 & 100,0 & 584 & 100,0 \\
\hline
\end{tabular}

Todo sistema de informação apresenta peculiaridades que exige a ação de profissionais especializados em tecnologia da informação, e para isto levantou-se a disponibilidade de suporte técnico de informática, que mostrou 
que $93,7 \%$ dos municípios contam com este serviço, sem diferença estatisticamente significante entre eles. A diferença existe em relação ao tipo de suporte, 66,0\% dos municípios dispõem de serviço próprio, com frequência acima de $80,0 \%$ nos municípios médios e grandes. Esse serviço é terceirizado em $34,0 \%$ dos municípios, com maior presença nos pequenos $(42,4 \%)$ (Tabela $15)$.

Tabela 15 - Número e proporção de municípios, segundo a disponibilidade de suporte técnico de informática, por porte populacional, Estado São Paulo, 2015.

\begin{tabular}{|c|c|c|c|c|c|c|c|c|}
\hline \multirow{3}{*}{ Variáveis } & \multicolumn{6}{|c|}{ Porte dos Municípios (habitantes) } & \multirow{2}{*}{\multicolumn{2}{|c|}{ Total }} \\
\hline & \multicolumn{2}{|c|}{ Até 30.000} & \multicolumn{2}{|c|}{$\begin{array}{c}\text { De } 30.001 \text { a } \\
200.000\end{array}$} & \multicolumn{2}{|c|}{ Maior que 200.000} & & \\
\hline & $\mathrm{N}$ & $\%$ & $\mathrm{~N}$ & $\%$ & $N$ & $\%$ & $\mathrm{~N}$ & $\%$ \\
\hline \multicolumn{9}{|l|}{$\begin{array}{l}\text { Suporte técnico de } \\
\text { informática }^{\star}\end{array}$} \\
\hline Não & 29 & 7,1 & 7 & 5,0 & 1 & 2,7 & 37 & 6,3 \\
\hline $\operatorname{Sim}$ & 377 & 92,9 & 134 & 95,0 & 36 & 97,3 & 547 & 93,7 \\
\hline Total & 406 & 100,0 & 141 & 100,0 & 37 & 100,0 & 584 & 100,0 \\
\hline \multicolumn{9}{|c|}{ Tipo de Suporte Técnico ${ }^{\star \star}$} \\
\hline Próprio & 217 & 57,6 & 114 & 85,1 & 30 & 83,3 & 361 & 66,0 \\
\hline Tercerizado & 160 & 42,4 & 20 & 14,9 & 6 & 16,7 & 186 & 34,0 \\
\hline Total & 377 & 100,0 & 134 & 100,0 & 36 & 100,0 & 547 & 100,0 \\
\hline
\end{tabular}

O responsável técnico do SIM tem obrigação de zelar pela guarda dos impressos em branco da declaração de óbito. Ao verificar em qual local o município guarda esses impressos, observa-se que 64,5\% utilizam sala fechada, sendo 50,3\% em armários com chave e 14,2\% em armários sem chave; 31,4\% armazenam os impressos em sala aberta, sendo $27,6 \%$ em armários com chave e 3,8\% em armários sem chave; 0,9\% guardam em almoxarifado junto com outros itens e 3,3\% relatam guardar em outros locais (Tabela 16). 
Tabela 16 - Número e proporção de municípios, segundo o local de guarda dos impressos da declaração de óbito em branco, por porte populacional, Estado São Paulo, 2015.

\begin{tabular}{|c|c|c|c|c|c|c|c|c|}
\hline \multirow{3}{*}{$\begin{array}{l}\text { Local de Guarda da } \\
\text { Do }\end{array}$} & \multicolumn{6}{|c|}{ Porte populacional } & \multirow{2}{*}{\multicolumn{2}{|c|}{ Total }} \\
\hline & \multicolumn{2}{|c|}{ Até 30.000} & \multicolumn{2}{|c|}{$\begin{array}{c}\text { De } 30.001 \text { a } \\
200.000\end{array}$} & \multicolumn{2}{|c|}{$\begin{array}{c}\text { Maior que } \\
200.000\end{array}$} & & \\
\hline & $\mathrm{N}$ & $\%$ & $\mathrm{~N}$ & $\%$ & $\mathrm{~N}$ & $\%$ & $\mathrm{~N}$ & $\%$ \\
\hline $\begin{array}{l}\text { Almoxarifado junto com } \\
\text { outros itens }\end{array}$ & 4 & 1,0 & 1 & 0,7 & 0 & 0,0 & 5 & 0,9 \\
\hline $\begin{array}{l}\text { Armário sem chave e em } \\
\text { sala aberta }\end{array}$ & 15 & 3,7 & 6 & 4,3 & 1 & 2,7 & 22 & 3,8 \\
\hline $\begin{array}{l}\text { Armário sem chave e em } \\
\text { sala fechada }\end{array}$ & 65 & 16,0 & 16 & 11,3 & 2 & 5,4 & 83 & 14,2 \\
\hline $\begin{array}{l}\text { Armário com chave e em } \\
\text { sala aberta }\end{array}$ & 93 & 22,9 & 51 & 36,2 & 17 & 45,9 & 161 & 27,6 \\
\hline $\begin{array}{l}\text { Armário com chave e em } \\
\text { sala fechada }\end{array}$ & 218 & 53,7 & 61 & 43,3 & 15 & 40,5 & 294 & 50,3 \\
\hline Outro & 11 & 2,7 & 6 & 4,3 & 2 & 5,4 & 19 & 3,3 \\
\hline Total & 406 & 100,0 & 141 & 100,0 & 37 & 100,0 & 584 & 100,0 \\
\hline
\end{tabular}

\subsection{Dimensão Capacidade Técnica}

O treinamento é uma atividade fundamental para o bom desempenho de sistemas de informações. Em 83,4\% dos municípios os profissionais receberam treinamento institucional para trabalhar com o SIM, com proporções um pouco mais elevadas nos menores. Observa-se também que 16,6\% não receberam treinamento para a função, com proporção mais elevada nos grandes municípios $(21,6 \%)$, porém não houve diferença estatisticamente significante entre os grupos (Tabela 17). O nível estadual é o principal agente de oferta de treinamento, 58,6\% dos municípios receberam treinamentos ministrados pelo GVE, 20,8\% pela Secretaria Estadual de Saúde e 11,7\% receberam de ambos. Em $4,1 \%$ foi o próprio município que treinou o responsável e/ou a equipe, ação que é mais frequente nos maiores municípios (13,8\%) (Tabela 18). 
Tabela 17 - Número e proporção de municípios, segundo treinamento institucional para trabalhar com o SIM, por porte populacional, Estado São Paulo, 2015.

\begin{tabular}{|c|c|c|c|c|c|c|c|c|}
\hline \multirow{3}{*}{$\begin{array}{c}\text { Recebeu } \\
\text { treinamento }\end{array}$} & \multicolumn{6}{|c|}{ Porte dos Municípios (habitantes) } & & \\
\hline & \multicolumn{2}{|c|}{ Até 30.000} & \multicolumn{2}{|c|}{$\begin{array}{c}\text { De } 30.001 \text { a } \\
200.000\end{array}$} & \multicolumn{2}{|c|}{$\begin{array}{c}\text { Maior que } \\
200.000\end{array}$} & \multicolumn{2}{|c|}{ Total } \\
\hline & $\mathrm{N}$ & $\%$ & $\mathrm{~N}$ & $\%$ & $\mathrm{~N}$ & $\%$ & $\mathrm{~N}$ & $\%$ \\
\hline Não & 65 & 16,0 & 24 & 17,0 & 8 & 21,6 & 97 & 16,6 \\
\hline Sim & 340 & 84,0 & 117 & 83,0 & 29 & 78,4 & 486 & 83,4 \\
\hline Total & 405 & 100,0 & 141 & 100,0 & 37 & 100,0 & 583 & 100,0 \\
\hline
\end{tabular}

Tabela 18 - Número e proporção de municípios, segundo instituição que ministrou treinamento para trabalhar com o SIM, por porte populacional, Estado São Paulo, 2015.

\begin{tabular}{|c|c|c|c|c|c|c|c|c|}
\hline \multirow{3}{*}{ Instituição que ministrou treinamento } & \multicolumn{6}{|c|}{ Porte dos Municipios (habitantes) } & \multirow{2}{*}{\multicolumn{2}{|c|}{ Total }} \\
\hline & \multicolumn{2}{|c|}{ Até 30.000} & \multicolumn{2}{|c|}{$\begin{array}{c}\text { De } 30.001 \text { a } \\
200.000\end{array}$} & \multicolumn{2}{|c|}{$\begin{array}{l}\text { Maior que } \\
200.000\end{array}$} & & \\
\hline & $\mathrm{N}$ & $\%$ & $\mathrm{~N}$ & $\%$ & $\mathrm{~N}$ & $\%$ & $\mathrm{~N}$ & $\%$ \\
\hline Grupo de Vigilância Epidemiológica - GVE & 238 & 70,0 & 44 & 37,6 & 3 & 10,3 & 285 & 58,6 \\
\hline Secretaria Estadual de Saúde & 39 & 11,5 & 45 & 38,5 & 17 & 58,6 & 101 & 20,8 \\
\hline $\begin{array}{l}\text { Grupo de Vigiânncia Epidemiológica - GVE } \\
\text { e pela Secretaria Estadual de Saúde }\end{array}$ & 34 & 10,0 & 19 & 16,2 & 4 & 13,8 & 57 & 11,7 \\
\hline Município & 18 & 5,3 & 2 & 1,7 & 4 & 13,8 & 24 & 4,9 \\
\hline Municipio e outra instituição & 6 & 1,8 & 4 & 3,4 & 1 & 3,4 & 11 & 2,3 \\
\hline Outra instituição & 5 & 1,5 & 3 & 2,6 & 0 & 0,0 & 8 & 1,6 \\
\hline Total & 340 & 100,0 & 117 & 100,0 & 29 & 100,0 & 486 & 100,0 \\
\hline
\end{tabular}

A tabela 19 expressa o tipo de treinamento relacionado ao sistema operacional nos dois últimos anos, 45,5\% das equipes municipais receberam treinamento sobre implantação e utilização do sistema local no computador, 43,8\% sobre utilização do balcão, $36,5 \%$ sobre realização de auditoria, retroalimentação, backup e geração de arquivo, 33,2\% sobre operação do Módulo Web Investigação, 29,3\% sobre emissão de relatórios, 29,1\% sobre alimentação de tabelas locais e 39,4\% apontaram que não recebeu nenhum treinamento. Somente um não respondeu a questão. 
Tabela 19 - Número e proporção de municípios, segundo o tipo de treinamento no sistema operacional recebido nos dois últimos anos no SIM, Estado São Paulo, 2015.

\begin{tabular}{lcc}
\hline \multicolumn{1}{c}{ Treinamento } & Número & $\%$ \\
\hline Implantação e utilização do sistema local no computador & 266 & 45,5 \\
Alimentação de tabelas locais & 170 & 29,1 \\
Utilização do balcão & 256 & 43,8 \\
Operação do Módulo Web Investigação & 194 & 33,2 \\
Realização de auditoria, retroalimentação, backup e geração de arquivo & 213 & 36,5 \\
Emissão de relatórios & 171 & 29,3 \\
Nenhum & 230 & 39,4 \\
Não responderam & 1 & 0,2 \\
\hline
\end{tabular}

Ao perguntar sobre o tipo de treinamento recebido os dois últimos anos, observou-se que quase metade dos municípios foram atendidos com curso sobre seleção e codificação de causa básica de morte $(48,1 \%)$, em seguida treinamento de preenchimento da declaração de óbito $(32,4 \%)$, controle de impressos de DO $(26,4 \%)$ e sobre captação de óbitos por um quarto dos municípios $(25,5 \%)$. E 28,9\% dos municípios não receberam nenhum treinamento sobre o SIM. 
Tabela 20 - Número e proporção de municípios, segundo o tipo de treinamento sobre o SIM recebido nos dois últimos anos no SIM, Estado São Paulo, 2015.

\begin{tabular}{lcc}
\hline \multicolumn{1}{c}{ Treinamento } & N & $\mathbf{\%}$ \\
\hline Captação de óbitos & 149 & 25,5 \\
Preenchimento da declaração de óbito & 189 & 32,4 \\
Codificação das causas de morte (CD-10) & 281 & 48,1 \\
Controle de estoque de impressos de DO & 154 & 26,4 \\
Análise dos dados & 113 & 19,3 \\
Nenhum & 169 & 28,9 \\
Ignorado & 1 & 17,0 \\
\hline
\end{tabular}

A fonte principal de informação do sistema SIM é a declaração de óbito, ter seus campos bem preenchidos resulta em indicadores confiáveis e uma das atribuições da equipe responsável pelo sistema é fornecer esse treinamento para as unidades de saúde. No último ano, apenas 17,3\% dos municípios o realizaram, sendo mais frequente nos maiores municípios $(24,3 \%)$ (Tabela 21). Foram observados treinamentos para médicos, enfermeiros, escriturários e outros profissionais. A maioria dos municípios treinou mais de uma categoria profissional, no entanto observa-se predominância de enfermeiros $(58,4 \%)$, seguido de médicos $(30,7 \%)$ e escriturários do setor de admissão hospitalar ou do SAME (23,8\%). Os municípios pequenos e médios treinaram com menos frequência o profissional médico, que é o responsável pelo preenchimento da DO (Figura 02). 
Tabela 21- Número e proporção de municípios que realizaram treinamentos sobre preenchimento de DO no ultimo ano, segundo profissionais, por porte populacional, Estado São Paulo, 2015.

\begin{tabular}{|c|c|c|c|c|c|c|c|c|}
\hline \multirow{3}{*}{$\begin{array}{l}\text { SMS treinou } \\
\text { Unidade de } \\
\text { Saúde }\end{array}$} & \multicolumn{6}{|c|}{ Porte dos Municípios (habitantes) } & \multirow{2}{*}{\multicolumn{2}{|c|}{ Total }} \\
\hline & \multicolumn{2}{|c|}{ Até 30.000} & \multicolumn{2}{|c|}{$\begin{array}{c}\text { De } 30.001 \text { a } \\
200.000\end{array}$} & \multicolumn{2}{|c|}{$\begin{array}{c}\text { Maior que } \\
200.000\end{array}$} & & \\
\hline & $\mathrm{N}$ & $\%$ & $\mathrm{~N}$ & $\%$ & $\mathrm{~N}$ & $\%$ & $\mathrm{~N}$ & $\%$ \\
\hline Não & 332 & 81,8 & 122 & 86,5 & 28 & 75,7 & 482 & 82,5 \\
\hline Sim & 74 & 18,2 & 19 & 13,5 & 9 & 24,3 & 102 & 17,5 \\
\hline Total & 406 & 100,0 & 141 & 100,0 & 37 & 100,0 & 584 & 100,0 \\
\hline
\end{tabular}

Figura 03 - Proporção de municípios que realizaram treinamento para preenchimento da Declaração de Óbito, por tipo de profissional, segundo porte populacional, Estado de São Paulo, 2015

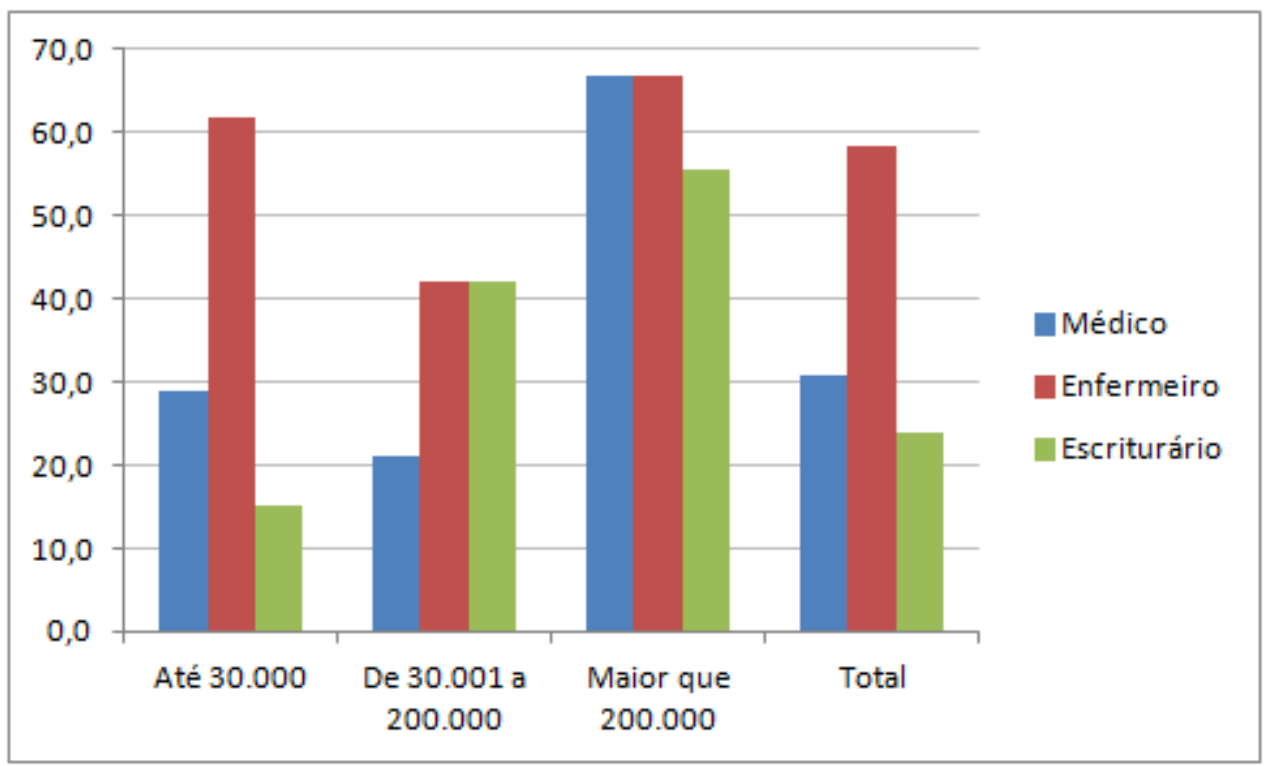

\subsection{Dimensão Processo de Trabalho}

Avaliar como ocorre o processo de trabalho nos municípios pode apontar a absorção de normas e rotinas estabelecidas pelo Estado e pelo Ministério da Saúde. Uma atividade básica do sistema é o controle da distribuição de impressos da DO para estabelecimentos de saúde e para 
profissionais autônomos. Observa-se que 32,5\% dos municípios utilizam o módulo do sistema para tal controle, enquanto $24,8 \%$ a folha de remessa e 19,0\% memorando e ofício. Houve diferença estaticamente significante entre os grupos. Destacam-se na utilização do módulo do sistema os municípios de médio $(51,8 \%)$ e grande $(48,6 \%)$ porte. Para os pequenos, esta modalidade $(24,4 \%)$ tem percentual semelhante ao uso de folha de remessa ou recibo $(24,1 \%)$. Destaca-se ainda que em $12,6 \%$ dos pequenos não utiliza-se nenhum instrumento para esse controle (Tabela 22).

Tabela 22 - Número e proporção de municípios, segundo controle de entrega de impressos de DO a estabelecimentos de saúde e profissionais autônomos, por porte populacional, Estado de São Paulo, 2015.

\begin{tabular}{|c|c|c|c|c|c|c|c|c|}
\hline \multirow{3}{*}{$\begin{array}{c}\text { Controle de entrega } \\
\text { de DO }\end{array}$} & \multicolumn{6}{|c|}{ Porte dos Municipios (habitantes) } & \multirow{2}{*}{\multicolumn{2}{|c|}{ Total }} \\
\hline & \multicolumn{2}{|c|}{ Até 30.000} & \multicolumn{2}{|c|}{$\begin{array}{l}\text { De } 30.001 \text { a } \\
200.000\end{array}$} & \multicolumn{2}{|c|}{$\begin{array}{c}\text { Maior que } \\
200.000\end{array}$} & & \\
\hline & $\mathrm{N}$ & $\%$ & $\mathrm{~N}$ & $\%$ & $\mathrm{~N}$ & $\%$ & $N$ & $\%$ \\
\hline $\begin{array}{l}\text { Não é utilizado } \\
\text { nenhum instrumento }\end{array}$ & 51 & 12,6 & 0 & 0,0 & 0 & 0,0 & 51 & 8,7 \\
\hline $\begin{array}{l}\text { Ficha de controle de } \\
\text { entrega de impressos } \\
\text { do sistema }\end{array}$ & 99 & 24,4 & 73 & 51,8 & 18 & 48,6 & 190 & 32,5 \\
\hline $\begin{array}{l}\text { Folha de remessa ou } \\
\text { recibo }\end{array}$ & 98 & 24,1 & 36 & 25,5 & 11 & 29,7 & 145 & 24,8 \\
\hline Memorando/oficio & 89 & 21,9 & 19 & 13,5 & 3 & 8,1 & 111 & 19,0 \\
\hline Livro de protocolo & 53 & 13,1 & 11 & 7,8 & 5 & 13,5 & 69 & 11,8 \\
\hline Outro & 15 & 3,7 & 2 & 1,4 & 0 & 0,0 & 17 & 2,9 \\
\hline Total & 406 & 100,0 & 141 & 100,0 & 37 & 100,0 & 584 & 100,0 \\
\hline
\end{tabular}

O monitoramento no processo de trabalho permite observar a necessidade de realização de busca ativa de óbitos, e neste quesito observou-se que um pouco mais de 2/3 dos municípios realizam essa atividade, variando de $63,8 \%$ nos municípios pequenos a 81,1\%, nos grandes (Tabela 23). Os municípios indicaram vários lugares de busca, sendo o mais frequente em 
estabelecimentos de saúde $(16,4 \%)$ com predominância para municípios de pequeno $(20,4 \%)$ e grande porte $(17,6 \%)$, seguido do cartório $(15,1 \%)$ também predominante nos pequenos $(17,0 \%)$ e maiores $(14,7 \%)$. A busca tanto em cartórios como em estabelecimentos de saúde representa 9,3\%, com percentual semelhante para os médios $(9,2 \%)$ e pequenos $(9,9 \%)$. Equipe de saúde da família com 6,4\%, sendo que nos municípios menores representa 8,9\% (anexo VII tabela 3A).

Tabela 23 - Número e proporção de municípios, segundo realização de busca ativa de óbitos, por porte populacional, Estado São Paulo, 2015.

\begin{tabular}{|c|c|c|c|c|c|c|c|c|}
\hline \multirow{3}{*}{ Busca Ativa } & \multicolumn{6}{|c|}{ Porte dos Municípios (habitantes) } & \multirow{2}{*}{\multicolumn{2}{|c|}{ Total }} \\
\hline & \multicolumn{2}{|c|}{ Até 30.000} & \multicolumn{2}{|c|}{$\begin{array}{c}\text { De } 30.001 \text { a } \\
200.000\end{array}$} & \multicolumn{2}{|c|}{$\begin{array}{l}\text { Maior que } \\
200.000\end{array}$} & & \\
\hline & $\mathrm{N}$ & $\%$ & $\mathrm{~N}$ & $\%$ & $\mathrm{~N}$ & $\%$ & $\mathrm{~N}$ & $\%$ \\
\hline Não & 147 & 36,2 & 42 & 29,8 & 7 & 18,9 & 196 & 33,6 \\
\hline Sim & 259 & 63,8 & 99 & 70,2 & 30 & 81,1 & 388 & 66,4 \\
\hline Total & 406 & 100,0 & 141 & 100,0 & 37 & 100,0 & 584 & 100,0 \\
\hline
\end{tabular}

$\mathrm{p}=0,057$

Como o sistema é robusto, o processo de trabalho é diversificado e ainda apresentam-se muitas questões relacionadas ao óbito, assim pesquisou-se quais recursos são utilizados pela equipe para o esclarecimento de dúvidas. Observa-se que 95,5\% recorrem aos GVEs, seguido da consulta aos manuais e orientações técnicas $(20,9 \%)$, colegas de equipe $(15,6 \%)$ e de outros municípios $(15,4 \%)$ e 14,6\% recorrem ao nível central da SES (CCD) (Tabela 24). 
Tabela 24 - Número e proporção de municípios, segundo busca de esclarecimento de dúvidas, Estado de São Paulo, 2015.

\begin{tabular}{lcc}
\hline Esclarecimento de Dúvidas & Número & $\mathbf{\%}$ \\
\hline Colegas de equipe & 91 & 15,6 \\
Equipe de informação municipal & 28 & 4,8 \\
Colegas de outros municipios & 85 & 14,6 \\
Equipe do Grupo de Vigilância Epidemiológica - GVE & 558 & 95,5 \\
Equipe da Secretaria Estadual de Saúde - CCD & 90 & 15,4 \\
Profissionais do Ministério da Saúde & 28 & 4,8 \\
Fónum eletrônico de dúvidas do SDM & 30 & 5,1 \\
Manuais e orientações técnicas & 122 & 20,9 \\
Não tem com quem esclarecer & 2 & 0,3 \\
Ignorado & 1 & 0,2 \\
\hline
\end{tabular}

\subsection{Dimensão Gestão}

A qualidade da informação se dá quando todas as etapas do sistema ocorrem de forma harmônica, desde a coleta dos dados iniciais na DO até a disponibilização dos dados produzidos pelo sistema de informação, em tempo ideal. Este processo mostra a efetivação da descentralização da gestão nos municípios. Nesse sentido, a fim de conhecer as características da operacionalização do SIM foram investigados alguns aspectos sobre a gestão do SIM.

Um deles é o monitoramento de eventos ocorridos no município, uma forma de acompanhar é a realização de algum procedimento ao identificar que o volume mensal de eventos registrados no SIM está abaixo do esperado. Neste quesito observa-se um grande percentual de equipes que não fazem nenhum procedimento $(82,9 \%)$. Ao detalhar por porte populacional verifica-se que os 
municípios pequenos tem o maior percentual com $89,7 \%$, diminuindo à medida que aumenta o volume da população e chegando a 56,8\% nos grandes, com diferenças estatisticamente significantes.

Tabela 25 - Número e proporção de municípios, segundo a realização de procedimento ao identificar que o volume mensal de óbitos esta abaixo do esperado, por porte populacional, Estado de São Paulo, 2015.

\begin{tabular}{lcccccccc}
\hline & \multicolumn{9}{c}{ Porte dos Municípios (habitantes) } & \multicolumn{2}{c}{ Total } \\
\cline { 2 - 7 } $\begin{array}{l}\text { Realiza } \\
\text { procedimento }\end{array}$ & \multicolumn{2}{c}{ Até $\mathbf{3 0 . 0 0 0}$} & \multicolumn{2}{c}{$\begin{array}{c}\text { De 30.001 a } \\
\mathbf{2 0 0 . 0 0 0}\end{array}$} & \multicolumn{2}{c}{$\begin{array}{c}\text { Maior que } \\
\mathbf{2 0 0 . 0 0 0}\end{array}$} & & \\
\cline { 2 - 7 } & $\mathrm{N}$ & $\%$ & $\mathrm{~N}$ & $\%$ & $\mathrm{~N}$ & $\%$ & $\mathrm{~N}$ & $\%$ \\
\hline Não & 364 & 89,7 & 99 & 70,2 & 21 & 56,8 & 484 & 82,9 \\
Sim & 41 & 10,1 & 42 & 29,8 & 16 & 43,2 & 99 & 17,0 \\
\hline Total & $\mathbf{4 0 6}$ & $\mathbf{1 0 0 , 0}$ & $\mathbf{1 4 1}$ & $\mathbf{1 0 0 , 0}$ & $\mathbf{3 7}$ & $\mathbf{1 0 0 , 0}$ & $\mathbf{5 8 4}$ & $\mathbf{1 0 0 , 0}$ \\
\hline
\end{tabular}

$\mathrm{p}=0,000$

Outro ponto importante é a questão da completude da DO, pois volume elevado de campos em branco ou incorretos impossibilita a formação de um bom indicador. Foi perguntado se algum técnico/profissional revisa a DO antes de digitar, a fim de identificar campos em branco e/ou preenchidos incorretamente. Observa-se que menos que $15 \%$ dos municípios relataram não realizar $(13,2 \%)$ procedimento algum. Dos que responderam realizar essa revisão, a frequência é menor entre os pequenos $(85,5 \%)$ em relação aos grandes $(91,9 \%)$, porém não houve diferença estatisticamente significante (Tabela 26). 
Tabela 26 - Número e proporção de municípios, segundo a realização de revisão da DO para identificação de campos em brancos ou incorretos antes da digitação, por porte populacional, Estado São Paulo, 2015.

\begin{tabular}{|c|c|c|c|c|c|c|c|c|}
\hline \multirow{3}{*}{$\begin{array}{l}\text { Revisão de } \\
\text { campos }\end{array}$} & \multicolumn{6}{|c|}{ Porte dos Municípios (habitantes) } & \multirow{2}{*}{\multicolumn{2}{|c|}{ Total }} \\
\hline & \multicolumn{2}{|c|}{ Até $\mathbf{3 0 . 0 0 0}$} & \multicolumn{2}{|c|}{$\begin{array}{c}\text { De } 30.001 \text { a } \\
200.000\end{array}$} & \multicolumn{2}{|c|}{$\begin{array}{c}\text { Maior que } \\
200.000\end{array}$} & & \\
\hline & $\mathrm{N}$ & $\%$ & $\mathrm{~N}$ & $\%$ & $\mathrm{~N}$ & $\%$ & $\mathrm{~N}$ & $\%$ \\
\hline Não & 58 & 14,3 & 16 & 11,3 & 3 & 8,1 & 77 & 13,2 \\
\hline Sim & 347 & 85,5 & 125 & 88,7 & 34 & 91,9 & 506 & 86,6 \\
\hline Total & 406 & 100,0 & 141 & 100,0 & 37 & 100,0 & 584 & 100,0 \\
\hline
\end{tabular}

$\mathrm{p}=0,709$

Quanto à utilização de relatórios do sistema para gerar indicadores, observa-se que $72,2 \%$ o fazem, sendo mais elevado nos municípios médios e grandes, com diferença estatisticamente significante. Dos municípios que não utilizam $(27,8 \%)$, duas razões apareceram como principais: falta de treinamento $(61,1 \%)$ e falta de pessoal $(14,8 \%)$, em proporções semelhantes nos três grupos de municípios (anexo VII Tabela 5A).

Tabela 27 - Número e proporção de municípios, segundo a utilização de relatórios do sistema para gerar indicadores, por porte populacional, Estado São Paulo, 2015.

\begin{tabular}{|c|c|c|c|c|c|c|c|c|}
\hline \multirow{3}{*}{$\begin{array}{l}\text { Utilização de } \\
\text { relatórios }\end{array}$} & \multicolumn{6}{|c|}{ Porte dos Municípios (habitantes) } & \multirow{2}{*}{\multicolumn{2}{|c|}{ Total }} \\
\hline & \multicolumn{2}{|c|}{ Até 30.000} & \multicolumn{2}{|c|}{$\begin{array}{c}\text { De } 30.001 \text { a } \\
200.000\end{array}$} & \multicolumn{2}{|c|}{$\begin{array}{c}\text { Maior que } \\
200.000\end{array}$} & & \\
\hline & $\mathrm{N}$ & $\%$ & $\mathrm{~N}$ & $\%$ & $\mathrm{~N}$ & $\%$ & $\mathrm{~N}$ & $\%$ \\
\hline $\operatorname{Sim}$ & 270 & 66,7 & 119 & 84,4 & 32 & 86,5 & 421 & 72,2 \\
\hline Não & 135 & 33,3 & 22 & 15,6 & 5 & 13,5 & 162 & 27,8 \\
\hline Total & 405 & 100,0 & 141 & 100,0 & 37 & 100,0 & 583 & 100,0 \\
\hline
\end{tabular}

$\mathrm{p}=0,000$ 
O Datasus desenvolveu uma ferramenta (Tabwin) para auxiliar as diversas instâncias do SUS na tabulação e tratamento dos dados, bem como produzir mapas e gráficos, além de outras funcionalidades. Observa-se que quase $50 \%$ dos municípios não utilizam esta ferramenta, com predominância entre os de pequeno porte $(57,0 \%)$, as diferenças entre os grupos foram estatisticamente significantes (Tabela 28). Entre os que usam o Tabwin, 87,3\% utilizam as funções básicas, 4,6\% usam com interface com SQL. O módulo de mapas e gráficos e a ferramenta de mapa de fluxo origem-destino são utilizados em apenas três municípios (anexo VII- tabela 4A).

Tabela 28 - Número e proporção de municípios, segundo a utilização do Tabwin do sistema, por porte populacional, Estado de São Paulo, 2015.

\begin{tabular}{|c|c|c|c|c|c|c|c|c|}
\hline \multirow{3}{*}{$\begin{array}{l}\text { Uso do } \\
\text { Tabwin }\end{array}$} & \multicolumn{6}{|c|}{ Porte dos Municípios (habitantes) } & \multirow{2}{*}{\multicolumn{2}{|c|}{ Total }} \\
\hline & \multicolumn{2}{|c|}{ Até 30.000} & \multicolumn{2}{|c|}{$\begin{array}{c}\text { De } 30.001 \text { a } \\
200.000\end{array}$} & \multicolumn{2}{|c|}{$\begin{array}{l}\text { Maior que } \\
200.000\end{array}$} & & \\
\hline & $\mathrm{N}$ & $\%$ & $\mathrm{~N}$ & $\%$ & $\mathrm{~N}$ & $\%$ & $\mathrm{~N}$ & $\%$ \\
\hline Não & 231 & 57,0 & 43 & 30,5 & 3 & 8,1 & 277 & 47,5 \\
\hline $\operatorname{Sim}$ & 174 & 43,0 & 98 & 69,5 & 34 & 91,9 & 306 & 52,5 \\
\hline Total & 405 & 100 & 141 & 100 & 37 & 100 & 583 & 100 \\
\hline
\end{tabular}

$\mathrm{p}=0,000$

Para avaliar o processo de trabalho, foi perguntado sobre o grau de dificuldade encontrada na realização de algumas atividades, numa escala que variou de nenhuma a muita alta dificuldade. Os dados apontam que 20,7\% dos municípios tem alta e muita alta dificuldade na geração de indicadores; 17,8\% na codificação de causas de morte e na instalação do sistema no computador (Anexo VII - Tabela 6A). A figura 04 mostra que o grau de dificuldade para codificação das causas de morte é maior nos pequenos municípios e diminui à medida que aumenta o porte populacional, o mesmo ocorre com a atividade de geração de indicadores. Já em relação à dificuldade de instalação do sistema, os 
três grupos de municípios relataram grau semelhante de muito alta dificuldade; e a proporção de alta dificuldade foi mais elevada nos municípios maiores.

Figura 04 - Municípios segundo grau de dificuldade na realização de algumas atividades do SIM, segundo porte populacional, Estado de São Paulo, 2015.

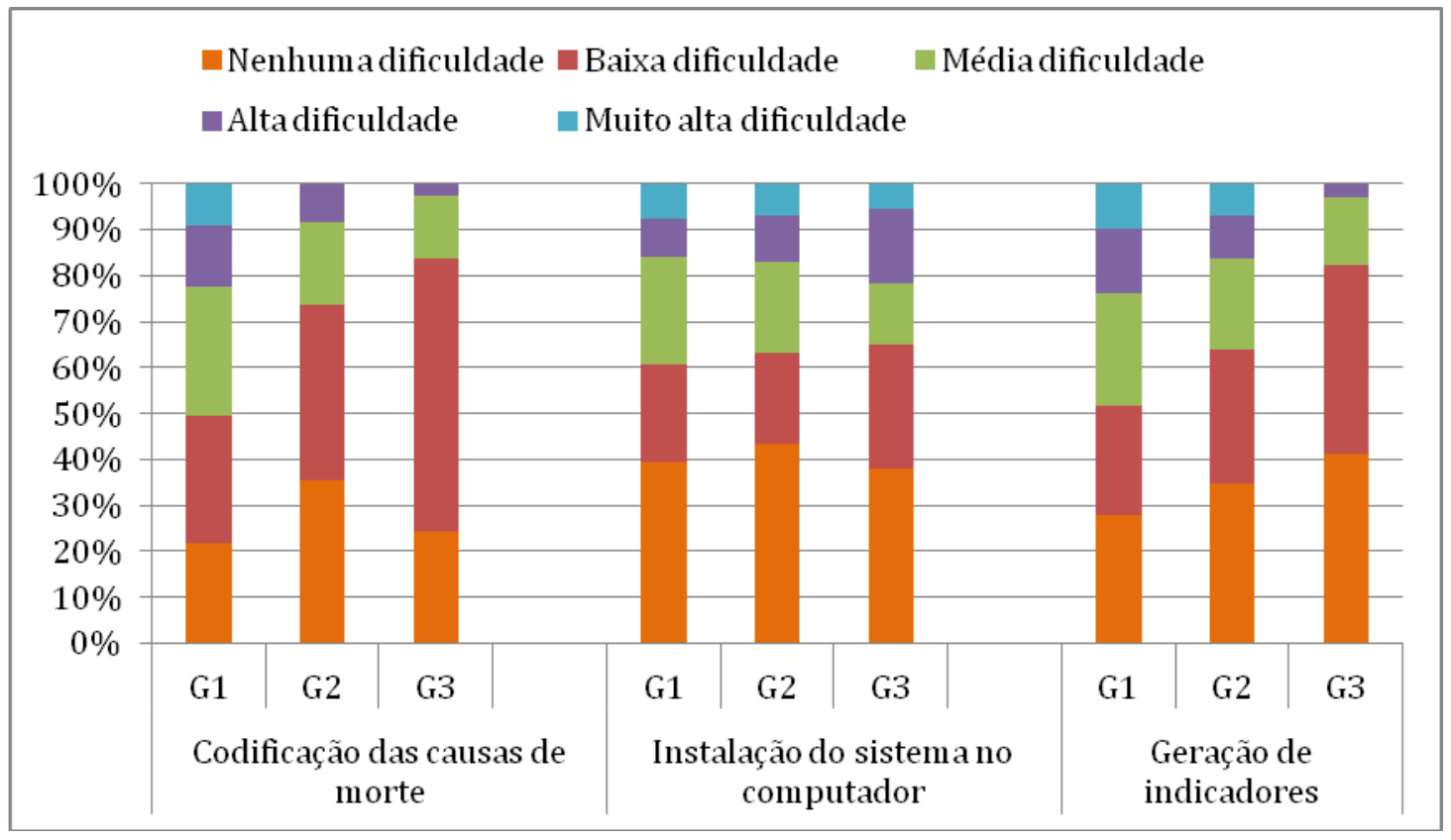

Executar todas as etapas do SIM não basta, é fundamental que estes dados sejam divulgados para diversas instâncias a fim de serem debatidos e utilizados na gestão do sistema de saúde. Neste contexto, pesquisou-se a periodicidade com que o secretário municipal de saúde solicita dados do SIM. Observou-se que em $75 \%$ dos municípios há essa solicitação, com aumento de frequência conforme aumenta o tamanho do município, essas diferenças foram estatisticamente significantes. Para 58,4\% desses municípios não há uma rotina estabelecida, ou seja, não há periodicidade definida, a emissão de relatórios para o secretário ocorre sempre que necessário. Para os que têm periodicidade definida, apenas $11,2 \%$ é mensal (Tabela 29). 
Tabela 29 - Número e proporção de municípios, segundo a solicitação de dados/informações do sistema SIM pelo secretario de Saúde, por porte populacional, Estado São Paulo, 2015.

\begin{tabular}{|c|c|c|c|c|c|c|c|}
\hline \multirow{3}{*}{$\begin{array}{l}\text { Solicitação de dados pelo } \\
\text { secretário de saúde }\end{array}$} & \multicolumn{5}{|c|}{ Porte dos Municipios (habitantes) } & \multirow{2}{*}{\multicolumn{2}{|c|}{ Total }} \\
\hline & Até 30.000 & \multicolumn{2}{|c|}{$\begin{array}{c}\text { De } 30.001 \text { a } \\
200.000\end{array}$} & \multicolumn{2}{|c|}{$\begin{array}{l}\text { Maior que } \\
200.000\end{array}$} & & \\
\hline & $\%$ & N & $\%$ & $\mathrm{~N}$ & $\%$ & $\mathrm{~N}$ & $\%$ \\
\hline
\end{tabular}

\section{Solicitação de dados *}

$\begin{array}{lrrrrrrrr}\text { Não } & 120 & 29,6 & 21 & 14,9 & 4 & 10,8 & 145 & 24,9 \\ \text { Sim } & 285 & 70,4 & 120 & 85,1 & 33 & 89,2 & 438 & 75,1 \\ \text { Total } & 405 & 100,0 & 141 & 100,0 & 37 & 100,0 & 583 & 100,0\end{array}$

\section{Periodicidade Definida ${ }^{\star *}$}

\begin{tabular}{lrrrrrrrr} 
Não & 178 & 62,5 & 62 & 51,7 & 16 & 48,5 & 256 & 58,4 \\
Sim & 107 & 37,5 & 58 & 48,3 & 17 & 51,5 & 182 & 41,6 \\
Total & 285 & 100,0 & 120 & 100,0 & 33 & 100,0 & 438 & 100,0 \\
\hline$*_{p}=0,000 ; * *_{p}=0,064$ & & & & & & & &
\end{tabular}

\subsection{Dimensão Disseminação dos Dados}

Foi perguntado quais as três áreas que mais solicitam dados do SIM, a área de atenção básica foi citada por mais da metade dos municípios $(58,0 \%)$, seguida do secretário de saúde $(48,0 \%)$ e do Comitê de Mortalidade Materna e Infantil (44,1\%). Essa variável mostrou diferença segundo o porte dos municípios, nos pequenos predominam a atenção básica e os comitês de mortalidade, seguida da área de planejamento. Nos médios, foram mais citados o Comitê, a área de atenção básica e o secretário de saúde e nos maiores, em primeiro lugar apareceu o Comitê de Mortalidade, seguido da área de planejamento e do secretário de saúde. As respostas apontam que a disseminação de informação chega aos conselhos de saúde (12,7\%), a imprensa ou mídia local $(3,9 \%)$ e aos prefeitos $(2,4 \%)$. Chama a atenção para 3,6\% de 
respondentes que não sabem sobre a demanda de dados, destacando-se os municípios pequenos $(5,7 \%)$ e médios $(2,8 \%)$ (Tabela 30$)$.

Tabela 30 - Número e proporção de municípios, segundo as três áreas que mais solicitam dados/informações do SIM, por porte populacional, Estado de São Paulo, 2015.

\begin{tabular}{|c|c|c|c|c|c|c|c|c|}
\hline \multirow{3}{*}{ Variáveis } & \multicolumn{6}{|c|}{ Porte dos Municípios (habitantes) } & & \\
\hline & \multicolumn{2}{|c|}{$\begin{array}{l}\text { Até } 30.000 \\
\quad(n=405)\end{array}$} & \multicolumn{2}{|c|}{$\begin{array}{c}\text { De } 30.001 \text { a } \\
200.000 \\
(n=141)\end{array}$} & \multicolumn{2}{|c|}{$\begin{array}{l}\text { Maior que } 200.000 \\
\qquad(n=37)\end{array}$} & \multicolumn{2}{|c|}{$\begin{array}{c}\text { Total } \\
(n=583)\end{array}$} \\
\hline & $\mathrm{N}$ & $\%$ & $\mathrm{~N}$ & $\%$ & $\mathrm{~N}$ & $\%$ & $\mathrm{~N}$ & $\%$ \\
\hline Atenção básica & 272 & 67,2 & 55 & 39,0 & 11 & 29,7 & 338 & 58,0 \\
\hline Secretário de Saúde & 196 & 48,4 & 69 & 48,9 & 15 & 40,5 & 280 & 48,0 \\
\hline Comitê de Mortalidade Materna e Infantil & 140 & 34,6 & 91 & 64,5 & 26 & 70,3 & 257 & 44,1 \\
\hline Planejamento de Ações de Saúde & 95 & 23,5 & 52 & 36,9 & 16 & 43,2 & 163 & 28,0 \\
\hline Saúde da Mulher & 79 & 19,5 & 31 & 22,0 & 8 & 21,6 & 118 & 20,2 \\
\hline Saúde da criança & 68 & 16,8 & 27 & 19,1 & 10 & 27,0 & 105 & 18,0 \\
\hline Conselho Municipal de Saúde & 53 & 13,1 & 21 & 14,9 & 0 & 0,0 & 74 & 12,7 \\
\hline Imprensa ou midia local & 7 & 1,7 & 9 & 6,4 & 9 & 24,3 & 23 & 3,9 \\
\hline Prefeito & 8 & 2,0 & 4 & 2,8 & 2 & 5,4 & 14 & 2,4 \\
\hline Não sabe & 23 & 5,7 & 4 & 2,8 & 0 & 0,0 & 21 & 3,6 \\
\hline
\end{tabular}

Em relação ao uso das informações do SIM, a Tabela 31 apresenta os mais citados pelos municípios. Dentre eles destacam-se pactuação de indicadores (86,1\%), planejamento de ações $(69,6 \%)$ e avaliação e monitoramento das metas estabelecidas $(59,2 \%)$; essas proporções elevam-se conforme aumenta o porte populacional dos municípios. A mídia foi citada por $8,4 \%$, sendo mais frequente nos maiores municípios $(32,4 \%)$, assim com o uso para publicações, com respectivamente $4,5 \%$ e $18,9 \%$. 
Tabela 31 - Número e proporção de municípios, segundo os principais usos das informações do SIM, por porte populacional, Estado de São Paulo, 2015.

\begin{tabular}{|c|c|c|c|c|c|c|c|c|}
\hline \multirow{3}{*}{ Usos das Informações do SIM } & \multicolumn{6}{|c|}{ Porte dos Municípios (habitantes) } & \multirow{2}{*}{\multicolumn{2}{|c|}{$\begin{array}{c}\text { Total } \\
(n=583)\end{array}$}} \\
\hline & \multicolumn{2}{|c|}{$\begin{array}{l}\text { Até } 30.000 \\
\quad(n=405)\end{array}$} & \multicolumn{2}{|c|}{$\begin{array}{c}\text { De } 30.001 \text { a } \\
200.000 \\
(n=141)\end{array}$} & \multicolumn{2}{|c|}{$\begin{array}{c}\text { Maior que } \\
200.000 \\
(n=37)\end{array}$} & & \\
\hline & $\mathbf{N}$ & $\%$ & $\mathbf{N}$ & $\%$ & $\mathbf{N}$ & $\%$ & $\mathbf{N}$ & $\%$ \\
\hline Pactuação de indicadores de saúde & 339 & 83,7 & 129 & 91,5 & 34 & 91,9 & 502 & 86,1 \\
\hline Planejamento de ações & 276 & 68,1 & 101 & 71,6 & 29 & 78,4 & 406 & 69,6 \\
\hline \multicolumn{9}{|l|}{ Avaliação e monitoramento das } \\
\hline metas estabelecidas & 224 & 55,3 & 92 & 65,2 & 29 & 78,4 & 345 & 59,2 \\
\hline Definição de prioridades & 129 & 31,9 & 55 & 39,0 & 19 & 51,4 & 203 & 34,8 \\
\hline Prestação de contas & 91 & 22,5 & 50 & 35,5 & 19 & 51,4 & 160 & 27,4 \\
\hline Midia (Jornal, rádio, TV, etc.) & 12 & 3,0 & 25 & 17,7 & 12 & 32,4 & 49 & 8,4 \\
\hline Publicações & 9 & 2,2 & 10 & 7,1 & 7 & 18,9 & 26 & 4,5 \\
\hline Imprensa/Web & 3 & 0,7 & 5 & 3,5 & 1 & 2,7 & 9 & 1,5 \\
\hline
\end{tabular}

Foi solicitado ao respondente que avaliasse os benefícios da descentralização do SIM para o município, em alguns quesitos, numa escala que variou de nenhum benefício a muito alto benefício. Ao agregarem-se as proporções de alto e muito alto benefício, observa-se que a maioria dos municípios avaliou satisfatoriamente todos os quesitos: aumento da captação de óbitos $(62,4 \%)$, disponibilidade de dados em tempo real $(68,1 \%)$, melhoria da qualidade da informação $(68,6 \%)$, construção dos principais indicadores de saúde $(65,7 \%)$, acesso rápido às informações de evasão de óbitos $(66,6 \%)$, agilização da vigilância em saúde $(68,6 \%)$, permitir tomada de decisões imediatas $(67,6 \%)$, autonomia na gestão do $\operatorname{SIM}(67,2 \%)$, responsabilização do gestor de saúde local $(63,5 \%)$ e disseminação da informação $(64,2 \%$ ) (Anexo VII - tabela 7A). Em todos esses itens, as proporções foram crescentes com o aumento do porte populacional dos municípios (Figura 05). 
Figura 05 - Distribuição dos municípios, segundo avaliação dos benefícios da descentralização do SIM, por porte populacional, Estado de São Paulo, 2015.

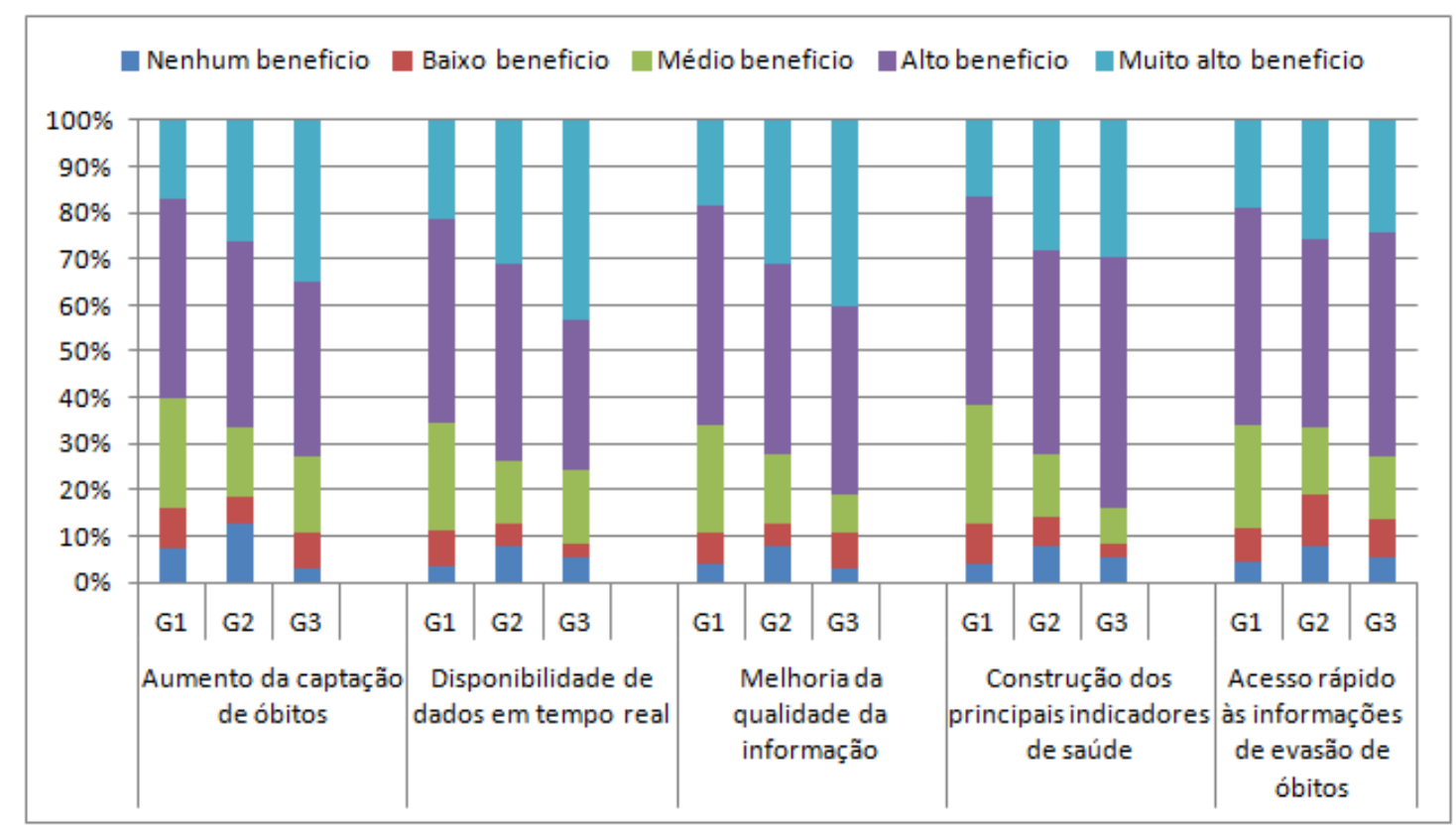

G1: até 30 mil hab. G2: 30.001 a 200.000 hab. G3: <200.000 hab.

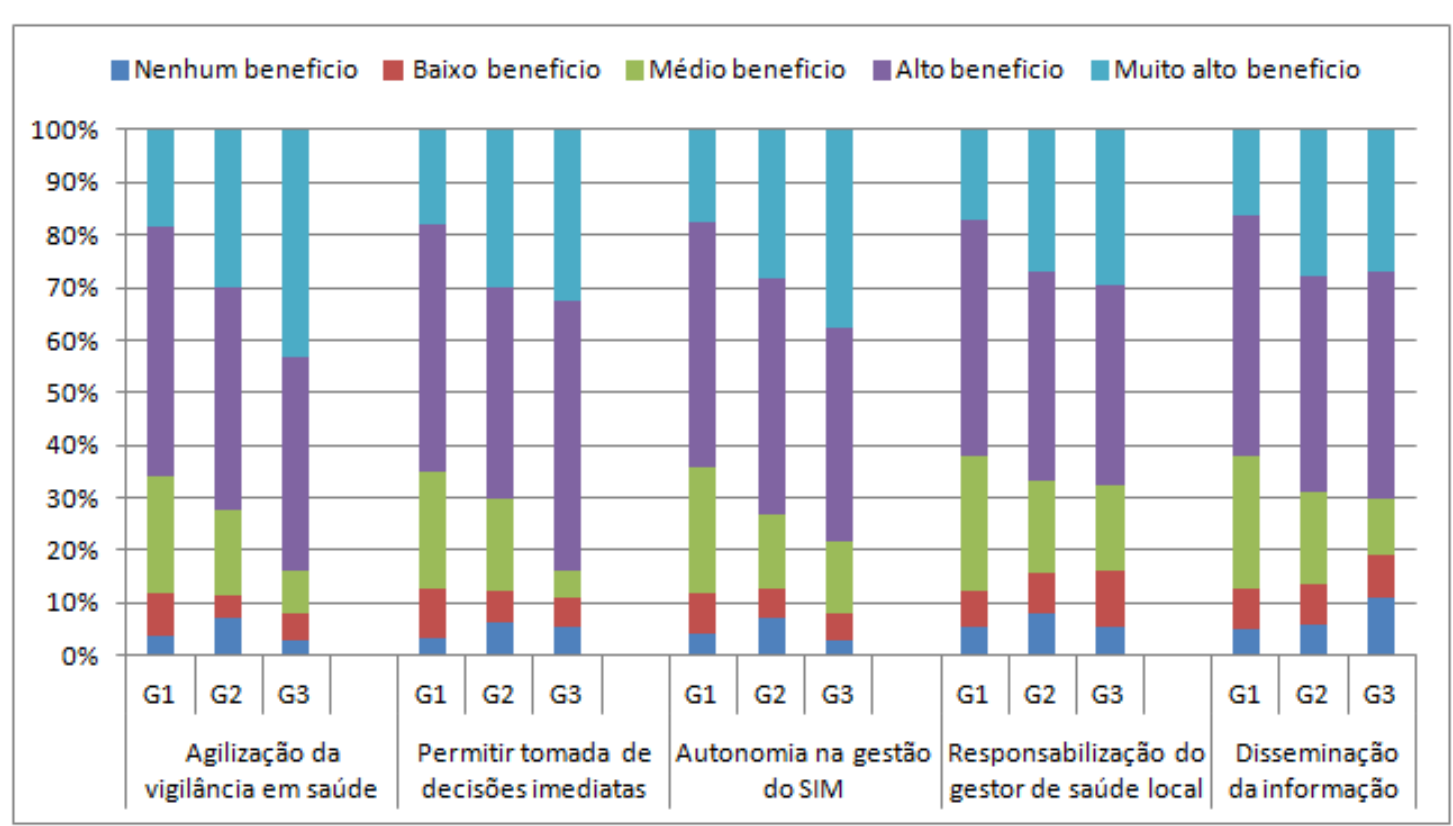




\section{DISCUSSÃO}

Este estudo levantou as características atuais de funcionamento do SIM em 584 municípios do Estado de São Paulo, que representam a quase totalidade dos municípios $(90,5 \%)$, o que permite traçar um panorama da situação no Estado.

O princípio da municipalização de serviços de saúde do SUS alavancou a necessidade de descentralizar os sistemas de informações (ALMEIDA, 1998), o que vem ocorrendo com grandes avanços. Este processo foi orientado por normas e regulamentações elaboradas pelo nível central, o Ministério da Saúde, cabendo a cada esfera de governo aplicar e aprimorar ações que possibilitassem este processo.

No entanto, a efetivação de transferências de ações e serviços para os municípios não está desonerada de dificuldades, muitas dessas são originárias das próprias características dos municípios brasileiros. Para Mendes (1998), dado o modelo de federalismo brasileiro, no qual os municípios são entes federativos com autonomia política, administrativa e financeira e com competências constitucionais e infraconstitucionais bem estabelecidas, era natural que a descentralização do sistema de saúde reservasse para eles papel de protagonista. Não obstante, o autor indica a complexidade que a questão assume quando se observam os altíssimos diferenciais de tamanho, população e desigualdades socioeconômicas entre os milhares de municípios brasileiros. Esses diferenciais, evidentemente, vão se refletir em distintos graus de competências administrativa e gerencial (SILVA e BARRETO, 2004). Assim, a análise por porte populacional possibilita verificar as diferenças encontradas na descentralização do SIM.

\section{Dimensão Profissional do Responsável Técnico}

Em cada município há um responsável técnico pelo SIM, que é responsável por gerenciar o sistema local e estabelecer a interlocução com os estabelecimentos de saúde e o nível regional e estadual. Ao analisar-se seu perfil, observou-se predominância do sexo feminino, o que vai ao encontro do padrão da força de trabalho na área de saúde. Praticamente não existem trabalhos que estudem o perfil 
dos profissionais que atuam na área de informações em saúde, tendo sido encontrados apenas alguns estudos que analisam a força de trabalho na saúde em geral e em atividades ou locais específicos. Estudo que avaliou o perfil do gerente em unidades de saúde de Belo Horizonte obteve resultados semelhantes ao encontrado, e relata que os dados refletem de forma expressiva a tendência da participação da mulher na força de trabalho na saúde (ALVES, 2004). Outro levantamento sobre recursos humanos no setor de saúde de Poços de Caldas também mostra prevalência de trabalhadores do sexo feminino embora em proporções menores (WILIANS, 2010).

O fenômeno da feminização do trabalho em saúde está bem estabelecido há algumas décadas. Estudos com dados do Censo Demográfico identificaram aumento da feminização da força de trabalho em saúde, no período pós-70 e dados dos anos 2000 indicavam predominância de mulheres entre os empregos com escolaridade universitária, e com uma discreta acentuação para o nível técnico e auxiliar (MINISTÉRIO DA SAÚDE, 2006).

Em relação ao perfil etário, observou-se média de idade de 39,3 anos, com um pouco mais da metade concentrada na faixa etária menor de 40 anos, esta proporção é inferior a encontrada no estudo de Guimarães (2011) em relação aos responsáveis técnicos pelo SINASC $(66,0 \%)$ em municípios mineiros.

Os responsáveis técnicos são bem mais jovens nos municípios pequenos do que nos grandes. O elevado percentual de profissionais na faixa etária de mais de 50 anos em municípios maiores pode estar relacionado com uma estrutura de serviço mais sólida, propiciando a permanência do funcionário por mais tempo.

Os responsáveis técnicos tem alta escolaridade, 80,0\% com nível superior completo, sendo menor nos municípios pequenos. Estudo de Guimarães (2011) em municípios mineiros feito com o responsável técnico do SINASC apontou que 70,4\% possuíam mais que 12 anos de estudo, o que não nos permite saber a proporção de respondentes com superior completo.

O Estado de São Paulo, considerando a importância do trabalho que envolve o SIM, a necessidade do conhecimento das questões legais e do cumprimento de atribuições, normatizou o cadastro e acesso de responsável técnico às bases do sistema SIM, e definiu que os municípios deveriam indicar um responsável técnico 
de nível superior, dentre as categorias profissionais de saúde estabelecidas na Resolução do Conselho Nacional de Saúde - CNS - n 287/1998 (SES/Resolução SS $n^{\text {o }}$ 66/2010). Isto pode explicar a elevada proporção de profissionais de nível universitário em todos os municípios. Por outro lado, diante de tal resolução, o percentual de 29,1\% de responsáveis sem nível universitário, especialmente em municípios de pequeno porte, pode indicar dificuldades em alocar este profissional. Isto é corroborado pela literatura que indica maior carência e rotatividade de profissionais em pequenos municípios (GUIMARÃES, 2011; VIDOR, 2011; CAMPOS et al, 2013).

O tipo de vínculo do responsável técnico é uma variável que pode traduzir a possibilidade de consolidação de vínculo junto ao sistema de informação. Ao trabalhar-se com profissionais de vínculo efetivo pode-se diminuir a chance de rotatividade nos serviços. A pesquisa mostra que mais de $60,0 \%$ dos responsáveis técnicos são efetivos, com maior frequência nos municípios de grande porte. Atualmente, uma modalidade muito utilizada para contratação de pessoal no serviço público é o regime CLT, e ele aparece em segundo lugar, com frequência maior em municípios pequenos. Isto ocorre muito provavelmente pela dificuldade administrativa em realizar concurso para cargos efetivos, uma vez que é necessário ter a vaga, esta ser aprovada na câmara municipal juntamente com orçamentário para manutenção de salários. E por outro lado, a contratação no regime CLT é mais ágil, sendo portanto uma opção muito utilizada por municípios pequenos. Os dados aqui levantados mostram resultados semelhantes com pesquisa realizada com funcionários da administração direta dos municípios brasileiros. Nessa pesquisa, predomina o quadro de servidores estatutários $(63,0 \%)$, seguido dos sem vínculo permanente e de CLT (IBGE, 2014).

O quesito função foi levantado a fim de verificar se o responsável técnico tem outras atribuições concomitantes ao SIM. Observa-se um maior percentual de responsáveis com a função de Diretor/Coordenador/Supervisor, o que pode indicar por um lado o acúmulo de função, possivelmente por falta de pessoal, e por outro a valorização da responsabilidade que o SIM assume para o gestor municipal. Avaliase que há um reconhecimento de que o sistema deva funcionar adequadamente, não só pelos insumos para a gestão, como em muitos casos em razão da vinculação 
financeira, pois o município que não atingir o volume de eventos estimados, por dois meses consecutivos ou três intercalados, terá suspensão de recurso financeiro do bloco de vigilância à saúde (Portaria MS/GB nº. 201/2010).

Chama a atenção o fato de mais de 20,0\% dos responsáveis técnicos terem a função de digitador ou auxiliar administrativo, o que está inadequado com a normatização estadual (SES, 2010), uma vez que tal atribuição exige formação apropriada, que supõe conhecimento do sistema de saúde e capacidade de interlocução com os demais agentes, como o nível estadual e regional e estabelecimentos de saúde. O maior percentual ocorre nos municípios pequenos, o que provavelmente está relacionado com a já mencionada falta de pessoal em municípios deste porte (GUIMARÃES, 2011; VIDOR, 211; CAMPOS et al, 2013). Embora este seja um problema mais frequente em menores municípios, observa-se que em cinco municípios de grande porte esta responsabilidade é dada a digitadores, possivelmente pela falta de profissionais na área de informação, ou pela baixa importância dada ao SIM.

Para verificar a experiência do profissional, bem como a rotatividade no trabalho, utilizou-se perguntas sobre o tempo de trabalho no setor público da área de saúde e o tempo de trabalho no SIM. Quase $90 \%$ dos responsáveis atuam a 3 anos ou mais no setor saúde, o que indica baixa rotatividade e, consequentemente, garante profissionais com mais experiência no sistema de saúde.

Já o tempo de trabalho no SIM foi proporcionalmente menor, o que é esperado, pois o funcionário ao ingressar no serviço, geralmente ingressa em atividades assistenciais, passando depois a incorporar atividades na área de informação, isto considerando que o grande volume de profissionais são de formação na área de saúde. Verificou-se também que a rotatividade ocorre principalmente nos municípios de pequeno e médio porte, onde verificou-se maior presença de responsáveis com menos tempo de atuação no SIM.

Prado (2012) aponta, em estudo sobre o processo de descentralização da produção das informações sobre mortalidade e nascidos vivos no Estado de São Paulo, que a rotatividade de profissionais é influenciada por mudanças pós-eleições municipais. Este fato é mais presente em municípios de médio e pequeno porte. 
O estado de São Paulo baseando-se na portaria MS/SVS nº116/2009 e no Código Penal Brasileiro (Art. 153 e 154), que estabelece penas para a violação de sigilo de documentos ou de informações contidas em sistemas de informação, e violação do sigilo profissional, estabeleceu o cadastramento de responsáveis técnicos para acesso às bases de dados do SIM e SINASC com indicação formalizada pelo gestor municipal ou regional acompanhada de documentação Termo de Sigilo e Confidencialidade devidamente preenchido e assinado pelo responsável técnico e pelo Gestor Municipal ou Regional. Verificou-se que menos da metade dos municípios cumpriram essa determinação, seja não assinando o termo ou assinando depois de iniciar o trabalho no SIM. Não houve diferença significativa entre os grupos de municípios. Pode-se pensar em duas hipóteses para este fato, o desconhecimento da portaria e/ou o fato de realizar o trabalho sem que haja descontinuidade, isto porque a falta de alimentação do sistema aponta uma baixa captação de eventos no mês e a possibilidade do município ser indicado para corte de recursos financeiros. Sendo assim, o município só vai sentir necessidade de realizar o cadastro quando ele for retirar impressos de DO (Resolução SS nº. 66/2010).

A fim de entender um pouco sobre as atividades desenvolvidas pelo respondente, foi perguntado se ele trabalhava com outros sistemas além do SIM. Antes de iniciar a pesquisa tinha-se a informação de que em 99,5\% dos municípios o responsável técnico do SIM era o mesmo para SINASC. Além deste, a pesquisa mostrou que há acúmulo de responsabilidade com dois sistemas ligados à vigilância epidemiológica, o SINAN e o SI-PNI, especialmente nos municípios médios e pequenos. Tal achado vai ao encontro dos resultados do estudo de Guimarães (2011) que relata que os profissionais não são exclusivos do SINASC, assumindo mais de um sistema de informação, além de outras funções na área de saúde.

O SIM é um sistema de informação robusto com uma enorme arquitetura de informática, que exige conhecimentos de tecnologia da informação; processo saúdedoença, legislações, sistemas de saúde, além de saber realizar as diversas funcionalidades do sistema operacional a fim ter uma boa cobertura e completude em tempo de cumprimento dos prazos estabelecidos, para tanto quesitos como experiência e baixa rotatividade são pontos fundamentais para o seu 
desenvolvimento. Sua evolução fez com que a esfera federal se organizasse para construir normas e rotinas que suprisse a necessidade de organização a fim de poder descentralizá-lo para os municípios. As iniciativas isoladas de municípios contribuíram muito para esta construção (MELLO JORGE, 2009).

A descentralização do SIM da esfera federal para outras esferas de governo veio acompanhando o movimento da implantação do SUS, havendo uma demanda crescente para descentralizar a produção das informações em saúde. A NOB-96 previa a gestão plena dos serviços de saúde pelos municípios, e a operação dos sistemas de informações constituía um dos seus itens com repasse de recursos financeiros (ALMEIDA, 1998).

O SIM pertenceu a diversos setores do Ministério devido a mudanças em sua estrutura, sendo que em 2003, a Secretaria de Vigilância em Saúde (SVS) assumiu a gestão do SIM (MELLO JORGE, 2009). No nível municipal, observou-se que nos municípios médios e grandes predomina a alocação do SIM na vigilância epidemiológica e no setor de informações da SMS. A alocação na vigilância epidemiológica está relacionada a algumas funções desta: vigilância de óbitos em geral e de doenças de notificação compulsória, repasse de recursos do componente da vigilância e promoção da saúde do bloco da vigilância em saúde atrelado à alimentação do SIM e a necessidade de realização de vigilância de óbito materno e infantil como notificação obrigatória em 48 horas (Portaria MS/GB nº 1272/2014). Para os menores municípios, além destes setores aparece com relevância a alocação em unidade básica, provavelmente devido a pequena estrutura de saúde, baixo número de estabelecimentos, muitas vezes há somente uma unidade de saúde, motivo pelo qual o SIM pode estar neste local. Por outro lado, pode-se verificar que nos municípios maiores há maior frequência de alocação em setores de informação da SMS, possivelmente por estes terem necessidade de uma estrutura específica para desenvolver o trabalho, que exige o processamento de grande volume de informações.

Chama a atenção o fato de que em 8 municípios de pequeno porte o SIM está alocado no gabinete do secretário, situação que pode estar relacionada ao fato deste ser o local que tem estrutura física para o desenvolvimento do sistema, ou também por ser o gestor o responsável técnico ou ainda pelo fato do município ter poucos 
eventos, o que não justificaria estar em outro local e, finalmente, pela importância que as informações que este sistema fornece para tomada de decisão na gestão do município. Estes dados mostram semelhança com o estudo de Guimarães (2011) que observou que os serviços municipais compartilhavam a sala com outros sistemas de informação, ou com a vigilância em saúde, ou com a atenção primária.

Só a existência de um sistema de informação não dá conta de responder bem ao que se pretende, são necessários normatizações, orientações técnicas, portarias e regulamentações, além de formação de recursos humanos para a sua boa operacionalização (MELLO JORGE, 2009). Foi observado que 76,2\% dos municípios relataram ter até duas pessoas trabalhando no SIM, o que mostra uma situação adequada, mesmo nos municípios menores, cujo volume de trabalho é pequeno. Por outro lado, ter somente um profissional no município para desenvolver o trabalho do SIM, atendendo todos os prazos estabelecidos pelo Ministério da Saúde, pode ser comprometedor, principalmente nos meses de férias do profissional ou pelo fato de ter que desenvolver outras atividades. É fato que o volume de eventos ocorridos no município determina o tamanho da equipe, e isto foi observado na compilação dos dados ao registrar no município mais populoso deste estado uma equipe de 15 pessoas. Não se tem um padrão que defina o número de pessoas necessários para a equipe do SIM, o estado de São Paulo resolveu que poderão ser indicados dois profissionais de saúde como responsáveis técnicos, para municípios acima de 500 mil habitantes, sendo obrigatoriamente um para o SIM e outro para o SINASC, mas não sinalizou sobre a composição da equipe (SES, 2010). Para se trabalhar no sistema é preconizado que todo profissional seja cadastrado, a fim de ter um login e senha de acesso. Em estudo realizado por Prado (2012), foi relatado que em 2010 haviam 1.021 pessoas cadastradas, representando uma média de 1,58 pessoas por município. Neste estudo identificou-se um volume maior de profissionais atuando no SIM, o que indica um maior envolvimento das equipes municipais com o sistema.

Branco (1996) define que o sistema de informação em saúde pode ser entendido como um instrumento para adquirir, organizar e analisar dados necessários à definição de problemas e riscos para saúde, avaliar a eficácia, eficiência e influências que os serviços prestados possam ter no estado de saúde da população, 
além de contribuir para a produção de conhecimento acerca da saúde e a ela ligados. O sistema SIM é considerado um dos sistemas mais confiáveis quanto à qualidade de informação, sua cobertura no estado chega a 99,8\%, permite a construção de indicadores para: avaliação das condições e qualidade de vida; monitoramento do desenvolvimento socioeconômico e formulação e avaliação de políticas públicas. Das diversas atividades realizadas nos municípios, destacamos a elaboração de indicadores, a análise de dados e a participação em comitê de investigação de morte materna e infantil.

Nota-se que um grande volume de municípios estão comprometidos com a elaboração de indicadores, sendo a totalidade de municípios de grande porte. Já em um quarto dos municípios de pequeno porte observa-se que esta atividade não é realizada nem pelo responsável técnico e nem pela equipe. Isto é muito preocupante pois é do sistema que se extraem indicadores necessários para elaboração de planos de saúde, para pactuação de serviços e para prestação de contas pelo relatório de gestão. Ao observar a divisão de trabalho, a equipe executa mais a elaboração de indicadores, e a análise compete mais frequentemente ao responsável técnico, provavelmente por este ser um profissional mais preparado e envolvido com questões de pactuações.

A realização de análise de dados também foi relevante, porém os municípios pequenos novamente realizam tal atividade com menos frequência que os demais, pois um município pequeno em cada cinco não analisa os dados de óbito. No entanto, essa situação se mostrou menos desfavorável para os municípios paulistas quando comparados aos municípios gaúchos (VIDOR et al, 2011). Esse tipo de dificuldade em municípios de pequeno porte tem sido atribuída à reduzida disponibilidade de profissionais capacitados para realização de análises dos dados do SIM e a falta de recursos que propiciem sua fixação no município (CAMPOS et al, 2013).

A redução da mortalidade materna e infantil é um dos objetivos de Desenvolvimento do Milênio e todo óbito exige uma investigação a fim esclarecer os fatos que levaram à morte de crianças e/ou mãe e se poderiam ser evitadas ou não. 
A discussão dos casos se dá no Comitê de Investigação de Morte, e o sistema tem um módulo destinado a investigação, onde todas as informações coletadas deverão ser digitadas. O Ministério da Saúde realiza o monitoramento destes dados via relatório do sistema. O responsável técnico é quem permite o acesso ao investigador, e ele é quem monitora localmente toda alimentação dos dados no sistema. Observou-se que em mais de 70,0\% dos municípios, o responsável ou a equipe participam do Comitê, com maior frequência à medida que aumenta o tamanho do município. Em relação aos municípios pequenos é necessário verificar se a resposta negativa se deve ao fato do município não ter o comitê na SMS, ficando as atividades restritas à investigação epidemiológica.

\section{Dimensão Estrutura}

Ao pensar em descentralização entende-se que ocorra um deslocamento de atividade e consequentemente altera-se o papel do município para executor e definidor da política pública, exigindo que haja um diagnóstico de problemas que oriente para intervenções necessárias. Para isto, os serviços devem incorporar algumas práticas dentro de seu cotidiano (DRUMOND, 2003).

Todo e qualquer sistema exige uma estrutura mínima a fim de atingir seus objetivos. No caso do SIM, o Ministério da Saúde orienta o uso de determinadas máquinas (computadores) que possam rodar o sistema, e atrelado a este requisito muitos outros se obrigam, como o número de máquinas versus volume de eventos, sistema operacional, acesso a internet, suporte técnico e guarda adequada para os impressos de DO em branco.

O SIM é uma ferramenta complexa e quando rodado com outros sistema gera incompatibilidade no computador, para tanto ele deve rodar somente com o SINASC, por apresentar a mesma estrutura. O levantamento mostrou que o número de computadores se eleva à medida que aumenta o porte populacional. Ao compararmos com outros estudos, ter pelo menos um computador mostra semelhança com os municípios gaúchos (VIDOR, 2004) e com os mineiros (GUIMARÃES, 2011). 
A tecnologia atualmente evolui com uma enorme velocidade, a indústria e o mercado oferecem sistemas operacionais que fazem com que seus usuários troquem de ferramenta frequentemente e buscou-se identificar o quanto as estruturas municipais estão conseguindo acompanhar esta evolução. Hoje considera-se o Windows 8 com 64 bits o mais atual dos sistemas operacionais e foram identificados somente 18 municípios com este sistema, destacando-se os grandes. Isto pode ocorrer devido à necessidade de máquinas mais rápidas para atender o volume de trabalho, além de terem melhores condições financeiras para aquisição das mesmas. O Windows XP, o mais defasado, está presente em municípios menores justamente pelos motivos opostos aos citados anteriormente.

Atualmente, o acesso a internet no país esta cada vez mais facilitado, e é o que observa-se nos municípios de São Paulo, mais de 70,0\% dispõe de acesso rápido por banda larga. Mas chama a atenção que um quinto dos municípios relatam usar o link de rádio para acessar a internet, além de 17 municípios com acesso discado. Provavelmente tratam-se de municípios com localização distante das grandes metrópoles. Estudo realizado, em 2004, nos municípios gaúchos com menos de 10 mil habitantes mostrou que 94,0\% dispunham de conexão com Internet sendo 52,0\% por acesso discado, 22,0\% por rádio e 19,0\% por conexão de banda larga. Os dados levantados nos municípios pequenos em São Paulo, 10 anos depois, apresentam cobertura pouco maior $(97,9 \%)$ e evidenciam a evolução tecnológica ocorrida com maior acesso por banda larga e diminuição do acesso discado. Já o acesso por rádio manteve o mesmo padrão verificado nos municípios gaúchos em 2004 (VIDOR, 2011).

Para resolução de problemas frequentes que um sistema informatizado pode trazer, ter um suporte de informática é fundamental para manter o desenvolvimento do processo de trabalho. O profissional de TI vem sendo introduzido no quadro de funcionários das SMS, e isto é observado em 16,0\% dos municípios. Apesar disto a quase totalidade dos municípios informou contar com suporte de informática, predominantemente próprio. 


\section{Dimensão Capacitação Técnica}

A base de dados de um sistema de informação pode ser um excelente termômetro para avaliar sua qualidade. Laurenti (2009) relata que na implantação do sistema, na década de 70, foi realizado treinamento de pessoal que abordou desde a sensibilização das autoridades, formação dos médicos, abordando a importância do preenchimento correto da $\mathrm{DO}$, e os responsáveis pelo processamento e análise dos dados. Com a descentralização para os municípios, surgiu uma enorme demanda de capacitação para um contingente expressivo de novos atores na produção das informações de mortalidade no nível local.

Muitos treinamentos foram realizados no estado de São Paulo, principalmente com a versão Windows do sistema a partir de 2006, porém ocorre rotatividade de profissionais que trabalham nos municípios, seja por aposentadorias, seja por alternância do corpo profissional em momento de transição política (PRADO, 2012), sobretudo em municípios pequenos, comprometendo o desenvolvimento do sistema. Para trabalhar no SIM, os técnicos devem conhecer as normas, rotinas, orientações técnicas, o instrumento de coleta, selecionar e codificar as causas de morte, saber operar o sistema, analisar dados e fazer gestão do SIM .

A descentralização do sistema de saúde altera o papel das instâncias de governo, ficando para o estado a função de normatizador e ao município definidor e o executor da política municipal. A divisão administrativa da saúde no estado de São Paulo contribuiu muito para a realização de treinamentos institucionais. Em cada GVE tem um responsável técnico do SIM, com função de dar suporte à toda região de sua abrangência, ponto comprovado com este estudo em que mais da metade dos municípios relatam ter recebido treinamento dos grupos regionais de vigilância epidemiológica ou pelo nível central da SES. Estudo anterior já apontava o papel do estado na capacitação de profissionais dos municípios paulistas (PRADO, 2012).

Por outro lado, verificar que alguns municípios são treinados pelo próprio município $(6,2 \%)$ ou não são treinados $(16,6 \%)$ pode indicar que, mesmo com a 
descentralização ainda há municípios desprovidos, isto devido ao ritmo de mudança de pessoal, grande volume de municípios neste estado ou até mesmo número insuficiente na equipe regional que possa atender todas as necessidades. Nestes dois últimos anos, foi apontado que, nestes treinamentos, pelo menos um profissional de $40,0 \%$ dos municípios pequenos e médios foi treinado e mais de $20,0 \%$ teve dois profissionais para os três grupos de municípios. Este dado mostra que o programa de educação permanente vem ocorrendo neste estado, mas ainda há muito que se ampliar, pois quase $30,0 \%$ dos municípios não tiveram ninguém participando, principalmente dos grandes. Porém nesse caso, isso pode ser atribuído ao fato destes municípios terem equipes mais sedimentadas, ou seja, há mais de dois anos no local não necessitando de novos treinamentos.

O balcão é um local virtual que foi criado e implantado pela SES, a utilização dele aparece como segundo treinamento mais desenvolvido, a necessidade do uso deste instrumento é diário, devido as funções que ele permite. O município utilizavao inicialmente para realização de transferência de lotes quinzenalmente e mensalmente, até novembro de 2014, quando passou a realizar transferências de lotes semanalmente para notificação de mortalidade materna, infantil e fetal. Esta periodicidade pode ter criado a demanda que justificou a realização destes treinamentos, bem como o treinamento do módulo web de investigação materno e infantil.

Outras operações como auditoria, retroalimentação, backup, geração de arquivo também são ações de periodicidade estabelecida desde o início do SIM web, e necessárias para análise de indicadores e principalmente para o restabelecimento de eventos ocorridos em outros municípios. Assim os treinamentos para estas operações favorecem a garantia da integridades dos dados transferidos e da base local, o que explica este treinamento ser o terceiro mais citado.

Apesar do amplo treinamento verificado, 40,0\% dos municípios não realizou nenhum, o que é incompatível com as diversas mudanças ocorridas no sistema nos últimos anos, e que mereceria uma atualização da equipe. É necessário portanto 
identificar em que regiões se encontram estes municípios a fim de suprir esta carência.

Segundo recomendações internacionais apresentadas nas sucessivas revisões da CID é fundamental para a correta codificação da causa de morte. O Centro Brasileiro de Classificação de Doenças (CBCD) é o órgão coordenador no país para realização de curso de formação em codificação. Antes da municipalização, os cursos eram oferecidos anualmente para as Secretarias Estaduais de Saúde, atualmente, a demanda aumentou e fez com que o CBCD optasse por cursos regionais (LAURENTI, 2006).

Em 2010, o estado de São Paulo desenvolveu curso básico em parceria com CBCD, esta ação mostrou-se tímida frente a grande demanda (PRADO, 2012). A partir de 2013, a SES retomou as capacitações nos moldes do CBCD, ou seja, cursos completos para todo o estado de São Paulo. Os dados encontrados neste estudo mostram que quase metade dos municípios relataram ter participado neste tipo de capacitação. Considerando diversos estudos (SANTO, 2001; PEDROSA et al, 2007; LAURENTI et al, 2008) que mostram falta de concordância na codificação das causas de morte, seria necessário ampliar o volume de municípios treinados.

A captação de óbitos é uma ação que leva à melhora da cobertura do sistema no país, validando nacionalmente e internacionalmente a sua qualidade. A introdução de numeração sequencial para a DO em 1976 ocorreu para facilitar o controle quanto à emissão, distribuição, coleta e resgate do documento (LAURENTI, 2006). O atual sistema operacional dispõe de módulo de controle de estoque e distribuição de impressos, que auxilia muito para o aumento da cobertura e no controle do uso indevido das DOs. Tal fato justifica a necessidade de treinamento para estas atividades que, no entanto, atingiram apenas um quarto dos municípios. Este baixo volume de treinamento explica porque apenas um terço dos municípios utilizam o módulo do sistema de distribuição de impressos.

Analisar dados não é uma tarefa trivial, exige conhecimento do conteúdo, métodos e parâmetros para interpretação dos dados e nem sempre esteve presente na formação dos profissionais de saúde. Todo e qualquer dado só tem valor quando analisado, o baixo percentual de treinamento encontrado neste estudo pode ser 
interpretado pela dificuldade que os técnicos do nível estadual e regional tem em realizar esta ação e consequentemente em ofertar treinamentos.

A fonte principal de informação do sistema SIM é a declaração de óbito, ter seus campos bem preenchidos resulta em indicadores confiáveis, e o preenchimento da declaração de óbito envolve prioritariamente o médico, por ser legalmente ele o profissional responsável pelo preenchimento completo do impresso. Há muitos casos onde o médico se limita a preencher apenas o bloco de condições e causas de óbito, deixando para outros profissionais o preenchimento dos demais campos, como relata Schoeps (2012) em estudo realizado no município de São Paulo sobre a qualidade do preenchimento das informações de óbitos perinatais.

Assim, é importante que a SMS realize treinamentos para os profissionais que atuam nas unidades de saúde. Verificou-se que isso foi pouco frequente no último ano e, quando ocorreu, envolveu vários profissionais, sendo que o enfermeiro foi duas vezes mais treinado do que o médico. Isso pode ter acontecido por dificuldade em envolver os médicos nessa atividade, uma vez que estudos relatam que muitos médicos se sentem responsáveis somente pelos campos relativos às condições e causas do óbito e não tem interesse nas atividades de treinamento da DO (SCHOEPS, 2012). Os municípios grandes são os que apresentam maior proporção de treinamento a médicos, isto porque o volume de profissionais é maior, bem como equipes são dedicadas exclusivamente ao SIM, favorecendo a oferta de treinamentos.

Observa-se o predomínio de treinamento para enfermeiros e escriturários com maior frequência em municípios pequenos e médios, o que está de acordo com estudo que identificou que estes profissionais preenchem alguns campos da DO (SCHOPES et al, 2014). O treinamento destes profissionais pode contribuir com a qualidade da informação, uma vez que na prática são eles que de fato preenchem a parte da DO não relacionada às causas de morte.

\section{Dimensão Processo de Trabalho}

Vários elementos concorrem para garantir a qualidade da informação em todo o conjunto de atividades que envolvem um sistema de informação, entre eles incluise as normatizações do processo de trabalho (ALMEIDA,1998; SCHOEPS et al, 
2014). A instituição de normas, rotinas, manuais de instrução e pactuação de fluxos são subsídios para um bom funcionamento do sistema. Para o SIM, o Ministério da Saúde, desde sua implantação, vem traçando normas e rotinas por meio de legislações, porém estas por si só não atendem as necessidades oriundas da descentralização dos sistemas. Os estados e municípios devem traçar suas orientações, mas o que observa-se ainda é o estado com papel normatizador. Por outro lado, municípios de grande porte já têm um embrião de um sistema descentralizado dado o caráter da intervenção necessária em casos potencialmente epidêmicos, ainda que desarticulado, mas com o estabelecimento de rotinas para seu território (DRUMOND, 2011).

O MS preconiza o controle de impressos pelo sistema, pois isto permite o acompanhamento simultâneo do nível federal e estadual, porém somente metade dos municípios o está realizando. Tal fato ocorre por falta de treinamento na utilização do sistema, o que aponta para necessidade dos níveis regionais ampliarem este tipo de treinamento. Guimarães (2011) encontrou fato semelhante no estudo com os municípios mineiros, onde não havia padronização na forma de distribuição do documento do SINASC.

Anteriormente, a distribuição e retorno da DO se dava pelos cartórios do registro civil, pois uma vez registrada a primeira via esta deveria ser retirada pelas secretarias municipais de saúde. Em muitas situações, as agências funerárias ofereciam, entre seus serviços, a DO preenchida por médicos que a assinavam sem ter visto o cadáver e a mesma preenchia os outros dados, incluindo muitas vezes a causa de morte (LAURENTI, 2006). Desde 2009, o MS regulamentou o fluxo de retorno da DO prioritariamente via estabelecimento de saúde, exceto para ocorrências domiciliares, com vistas a monitorar todos os eventos ocorridos e ampliar sua cobertura. O número da DO facilita identificar possíveis casos que não foram inseridos no sistema, permitindo buscá-la nos estabelecimentos para qual foi distribuída.

No estado de São Paulo, o fato de ter um terço dos municípios retornarem a DO via cartórios e funerárias pode ocorrer por desconhecimento deste fluxo por parte dos gestores do SIM, ou por resistência na implantação do atual fluxo. O fluxo oriundo das funerárias deve ser averiguado, considerando que alguns municípios não 
tem serviço funerário público. A busca ativa de eventos é realizada por um grande número de municípios, o mesmo foi encontrado em estudo de Guimarães (2011).

Observou-se que nos municípios que realizam este processo, predomina o fluxo via estabelecimentos de saúde, certamente por serem instâncias em que mais ocorrem eventos, e nos municípios pequenos prevalecem talvez por terem poucos hospitais e facilitar este trabalho.

\section{Dimensão Gestão}

A descentralização da gestão, como discutido anteriormente, transfere ao município o papel decisório e a responsabilidade pelas ações de saúde em seu território. A informação em saúde tem a função de subsidiar técnicos, políticos e a sociedade para melhorar a compreensão do sistema de saúde e sua relação com a saúde da população, avaliar as ações e controlar a produção de serviços e o controle social. Com vistas a este contexto, é imperativo saber se as informações estão contribuindo de forma eficiente para a orientação e planejamento do serviços (VIDOR, 2004).

O monitoramento de volume e regularidade, realizado mensalmente no SIM pelo MS, aponta os municípios que não atingiram a meta de $80,0 \%$ do volume esperado registrado no sistema, transferido até 60 dias após o encerramento do mês de ocorrência, para a finalidade de repasse de verba ao município. Municípios com população inferior a 30.000 habitantes são avaliados pelo envio de notificação positiva ou negativa por mês de ocorrência, já os município com população de 30.000 habitantes ou mais são avaliados pelo volume postado em relação a meta e número de registros esperados.

$\mathrm{O}$ fato de ter encontrado um grande volume de municípios que não realizam procedimentos ao identificar que o volume mensal de óbitos não atingiu a meta, principalmente nos município abaixo de 30.000 habitantes, pode ser porque o monitoramento se dá somente pela notificação positiva ou negativa e não de fato pelo número de casos esperados. Outras possibilidades são: por não acreditar que o município terá sua verba cortada; pelo desconhecimento do gestor municipal deste 
monitoramento; ou até pela pouca importância atribuída a ação que envolva um sistema de informação e não a assistência dispensada diretamente ao paciente.

Analisar a consistência das informações, no nível municipal e antes da digitação, permite verificar inconsistências, como conteúdos discrepantes e campos em branco, possibilitando a correção que venha melhorar a qualidade dos dados em tempo mais próximo em relação a ocorrência do evento (ALMEIDA,2006). Avaliar a qualidade de dados de um sistema de informação sobre a completude dos registros das variáveis do documento de coleta de dados é a primeira etapa de uma avaliação (SCHOEPS, 2012). Ainda que os resultados tenham mostrado alto percentual de municípios que revisam os campos em branco da DO, há muitos estudos que relatam sobre a incompletude dos dados, como de Mello (1993), Almeida (2006) e Schoeps (2012), e sobre a necessidade de uma boa gestão a fim de diminuir este problema.

Municípios grandes tem sempre maiores necessidades de realizar esta ação, possivelmente por trabalhar com maior frequência com indicadores, e por terem mais profissionais em sua equipe e rotinas já traçadas. Esta hipótese sobre as normatizações do preenchimento dos documentos, também foi levantada no estudo de Schoeps e colaboradores (2012) sobre a qualidade da informação de óbitos no município de São Paulo. Outra possibilidade é a fragmentação do preenchimento da informação por vários profissionais, pois mesmo com a orientação do manual de preenchimento da DO de que o médico não deve deixar nenhum campo em branco ou deixá-la assinada em branco, pois todas as informações contidas no documento são de reponsabilidade do mesmo, é sabido que em muitos locais esta divisão no preenchimento ocorre.

O SIM dispõe de relatórios que geram indicadores com vistas ao apoio a gestão, a utilização destes pelos municípios grandes e médios se dá em maior proporção possivelmente por alguns fatores, como ter uma equipe maior, ser mais demandado pelo gestor municipal e equipe e ter profissionais treinados. Observa-se que municípios pequenos tem menores percentuais por falta destes fatores citados. Guimarães (2011) observou em seu estudo com municípios mineiros que, apesar da 
estrutura e o processo de produção de dados terem avançado, aspectos do gerenciamento das informações não ocorreram, pois para gerenciar informações, como identificar volume, análise de indicadores e outros, é necessário ter conhecimento a importância dessas ações para a qualidade dos dados.

Outra ferramenta que facilita a geração de indicadores é o Tabwin disponível dentro do SIM. O fato de quase metade dos municípios não o utilizarem, sendo este percentual maior nos menores, tem a ver com os mesmos fatores descritos para emissão de relatórios. Para operar o Tabwin, além da necessidade de treinamento, é preciso conhecer todos os arquivos de definição de dados e as finalidades da sua operacionalização. Há grande chance que este fato seja atribuído à falta de treinamento e conhecimento da ferramenta. Já o alto percentual de utilização em municípios maiores ocorre por estes terem uma necessidade premente de gerar indicadores e ampliar o uso para muitos técnicos das secretarias municipais.

Municípios grandes tomaram a iniciativa de utilizar o Tabwin antes mesmo da implantação no SIM, bancos eram preparados para serem utilizados nesta ferramenta, fato que contribuiu com a iniciativa do Ministério da Saúde em implantar para o resto do país. Estudos sobre a utilização dos programas Tabwin e Tabnet como ferramentas de apoio à disseminação das informações em saúde apontam a falta de planejamento central e de uma programação permanente de capacitação de técnicos dos níveis municipais na utilização dessas ferramentas de forma a descentralizar o seu uso (SILVA, 2009).

Dentre as dificuldades apontadas pelos respondentes, foi citada a geração de relatórios, tal fato pode estar relacionado com a não utilização da ferramenta do Tabwin. A codificação de causas de morte aparece mais premente em municípios menores, seguido de geração de indicadores. Estas três dificuldades podem estar relacionadas a falta de capacitação, ao corpo técnico reduzido e ao acúmulo de atribuições além do SIM. As equipes que trabalham com os sistemas de informação, atualmente, são compostas por profissionais que já se encontravam na administração municipal com diversas formações, principalmente atuando na assistência, sendo que 
na maioria dos casos foram deslocados para trabalharem com informação, sem que tenham construído uma área especifica para tal.

\section{Dimensão Disseminação de Dados}

Realizar um bom processo de coleta e processamento de dados não é o suficiente, estes dados devem ser estruturados em indicadores e levados ao conhecimento das autoridades, a partir do secretário municipal de saúde. Antes da descentralização, esta atribuição era competência do Ministério da Saúde, pois era na esfera federal onde se dava o processamento final dos dados. Alguns estados e municípios, principalmente os de grande porte, realizavam suas análises e divulgavam para os municípios menores. Atualmente, com as novas versões do SIM, seus fluxos, prazos e internet, facilitou muito a divulgação dos dados, pois propicia com que o município possa realizar análises em curto tempo.

Contudo disseminar informações não depende exclusivamente da condição de ter acesso aos dados, mas também pelo conhecimento que os profissionais tem em lidar com todas as atividades e produtos gerados e, que segundo Guimarães (2011), ainda é insuficiente para gerenciamento de informações nos municípios pequenos.

A periodicidade com que os gestores solicitam os dados do SIM variou entre os municípios, para os grandes que apresentaram percentuais iguais no período mensal e quadrimestral, pode se explicar pelo fato de que mensalmente pode ser realizado monitoramento dos eventos com enfoque na captação e também com vistas a assistência. Já a divulgação quadrimestral pode estar associada ao monitoramento de qualidade de ações de vigilância em saúde e nos indicadores de pactuações, cuja periodicidade é a cada quatro meses. Para os municípios de médio porte a periodicidade trimestral pode ser devido também ao acompanhamento de pactuação, onde os gestores realizam as mesmas em reuniões de colegiado de gestão regional.

O grande volume de municípios em que não há periodicidade de solicitação dos dados pelo secretário pode indicar a falta de rotina, ou seja, que o gestor solicita 
os dados apenas quando quer realizar alguma tomada de decisão, sem monitoramento periódico dos indicadores.

Ainda chama a atenção haver um quarto dos municípios onde o secretário não solicita as informações de óbito de seu território, com predominância de municípios pequenos e médios, o que pode ser atribuído a pouca importância dada a esta informação, seja apela falta de conhecimento, seja pela falta de rotina. Quanto aos grandes municípios, o fato de aparecer um percentual de gestores que não solicita esses dados pode ser por razões diferentes das anteriores: ter uma estrutura maior em relação a equipe, o que propicia que ele venha tomar conhecimento por outras áreas técnicas da secretaria, como área da saúde da mulher, criança, planejamento ou outras, ou também porque possui acesso automático aos dados.

Além do gestor de saúde municipal, as áreas que mais solicitam esta informação são a atenção básica e o Comitê de Mortalidade Materna e Infantil. Na descentralização do sistema, a atenção básica ficou com a responsabilidade pelo munícipe, seja no modelo de atenção do programa de saúde de família, seja no modelo de procura espontânea, necessitando realizar um monitoramento frequente. Outro ponto é o fato do SIM estar alocado em unidades de saúde nos municípios pequenos, proporcionando maior proximidade com os profissionais que lá trabalham. Além disso, na grande maioria dos municípios pequenos, que não possuem hospitais, é esta área que assume a linha de frente na assistência no território e, consequentemente, tem a necessidade do conhecimento dos dados de mortalidade.

Quanto ao Comitê de Investigação, sua atuação tem se intensificado devido aos Objetivos de Desenvolvimento do Milênio e as metas estabelecidas nos planos municipais de redução de mortalidade. Para este monitoramento, os casos devem ser analisados a partir da DO. O prazo de fechamento da investigação do caso é de até 120 dias (PORTARIA MS no 1119/2008 e $\mathrm{n}^{\circ}$ 72/2010), o que impulsionou municípios e estados para uma atuação mais intensa. Agregado a isto, cabe lembrar que muitas das informações contidas na declaração de óbito permitem uma análise minuciosa para área da saúde da mulher e da criança, além de gerar os coeficientes específicos (MELLO JORGE, 1993). 
A pactuação de indicadores de saúde e planejamento das ações são as atividades que mais demandam o uso das informações do SIM, certamente por serem os dados de mortalidade os mais utilizados para formulação de indicadores que permitem mensurar as metas traçadas nestas ações. A hipótese da utilização para pactuação é a obrigatoriedade oriunda da realização dos planos de saúde, recomendados pelo processo de descentralização da assistência. Foi verificado que os dados são utilizados para planejamento, possivelmente para propor ações de saúde com base nas informações de mortalidade, e esta prática realmente é mais comum de ocorrer em municípios maiores, que tem histórico de formação de políticas de saúde, fato também encontrado em estudo realizado nos municípios mineiros (GUIMARÃES, 2011).

Por outro lado, ver que a informação é usada para divulgação na mídia, ainda que em um percentual pequeno, pode ser bastante animador, pois é uma forma de reconhecimento dos dados e fortalecimento do sistema, e isto ocorre em maior volume nos municípios grandes.

A maioria identificou benefícios com a descentralização, porém percebe-se que para o grupo de pequenos municípios isto ocorreu com menos intensidade, e pode estar associado às dificuldades que estes encontram em realizar as atividades, seja pela falta de recursos humanos, falta de capacitação, ou por terem estruturas mais deficientes, diminuindo assim sua autonomia e desenvolvimento que a descentralização pode oferecer. Ainda em decorrência do deslocamento de funções pela descentralização do sistema, podem surgir dúvidas tanto no instrumental como no gerencial (DRUMOND, 2003). À medida que aumenta o porte populacional aumenta o grau de benefício identificado, provavelmente porque o SIM possa estar mais sedimentado quanto ao sistema e suas ações frente ao gestor e equipe de saúde. 


\section{CONCLUSÃO}

Este estudo permitiu conhecer com detalhes o SIM, sobre a ótica dos responsáveis técnicos dos municípios do estado de São Paulo. A grande adesão de resposta se deu com o apoio dos GVEs que incentivaram a participação. Durante a aplicação do questionário muitos municípios estavam atravessando uma epidemia de Dengue, o que dificultou a participação no início da coleta. $\mathrm{O}$ fato de o instrumento ser aplicado pela web propiciou maior participação .

O grupo de municípios pequenos de até 30.000 habitantes apresentou responsáveis técnicos do SIM com predominância do sexo feminino, mais da metade com idade inferior a 40 anos, predomínio da escolaridade com ensino superior e formação de enfermagem, um grupo de efetivos menor que nos grandes municípios, porém um quarto tem a função de digitador e/ou auxiliar administrativo, que trabalham na saúde há mais de 3 anos, mas um terço deles estão no SIM menos de 3 anos, e quase um quarto não assinaram o Termo de Sigilo e Responsabilidade. Em quase sua totalidade os responsáveis técnicos respondem por outros sistemas, onde o SI-PNI prevalece, talvez pela predominância da formação de enfermagem. A alocação do sistema está em mais de 3/4 em unidade de saúde ou vigilância epidemiológica e as equipes se resumem a um ou no máximo dois profissionais.

$\mathrm{Na}$ estrutura, a maioria tem um computador, com sistema operacional mais antigo, acesso por banda larga e com suporte de informática. Mais de $80 \%$ relatam ter sido capacitados pela GVE ou SES-SP, porém mais da metade não recebeu treinamentos sobre implantação e utilização do sistemas. Já para preenchimento da DO, eles priorizaram treinar os enfermeiros.

No processo de trabalho, mais de $80 \%$ controlam a entrega dos impressos, porém somente um quarto utilizam o sistema preconizado. Ainda um terço deles não realizam busca ativa, e as dúvidas são esclarecidas pelas GVEs. Na gestão do SIM, quase $90 \%$ deste grupo não realiza procedimentos ao detectar baixo volume de registros. Quanto a utilização dos dados observou-se que mais de um terço não utilizam os relatórios do sistema e mais de $50 \%$ não utilizam o Tabwin. Suas maiores dificuldades são na codificação de causas de 
morte, instalação do sistema e geração de indicadores. Os dados são utilizados mais pela Atenção Básica e para pactuação dos indicadores $\mathrm{Na}$ descentralização do SIM, os municípios indicaram benefício em todos os itens, mas em menor percentual comparado com outros grupos.

Os municípios de médio porte se comportam acompanhando o perfil profissional dos municípios pequenos, para escolaridade, formação em enfermagem, vínculo efetivo e tempo de trabalho na saúde, já a idade é de 40 a 49 anos em mais de 50\%, predomina a função de Diretor/Coordenador/Supervisor, e quase metade começou a desenvolver o trabalho antes de assinar o Termo de Sigilo. Os responsáveis tem responsabilidades por outros sistemas, mas em menor percentual que nos municípios pequenos. A alocação do SIM encontra-se nas vigilâncias epidemiológicas, e suas equipes tem em média dois ou três profissionais. Contam na maioria com um computador, com sistema operacional em versões mais novas do que nos pequenos. Quanto à realização de treinamentos, a SESSP compartilha a atividade de órgão formador com a GVE. No treinamento realizado pelo município para preenchimento de DO, a população alvo foi enfermeiros e escriturários, sendo o médico o menos treinado. Em mais de $80 \%$ do municípios, há revisão de campos em branco e utilizam-se dados através de relatórios do sistema. Quanto ao uso do Tabwin, este grupo utiliza mais do que os pequenos, o grau de dificuldade é menor para codificação de causa de morte, mas para instalação do sistema e geração de indicadores é o mesmo que nos municípios pequenos.

Neste grupo prevalece o Comitê de Morte Materna e Infantil e o Secretário de Saúde como maiores solicitantes dos dados, que são utilizados para pactuação de indicadores, planejamento de ações e avaliação e monitoramento das metas estabelecidas. Quanto aos benefícios da descentralização do SIM, todos os itens foram avaliados com grande percentual de alto e muito alto, com exceção para o acesso rápido às informações de óbitos ocorridos fora do município de residência e o aumento de captação de óbitos onde os percentuais para nenhum beneficio e médio beneficio foram mais de $30 \%$. 
O grupo de municípios de grande porte em número absoluto é o menor, porém são responsáveis por mais de $70 \%$ dos óbitos do estado. Este grupo apresenta municípios com população superior a 200.001, até um com aproximadamente 11 milhões de habitantes, o maior do país. O perfil profissional deste grupo apresenta média de idade acima de 50 anos, profissionais com formação em nível superior e pós graduação, nas áreas de enfermagem, medicina e administração, mais de $80 \%$ efetivos, função de diretor e assistente técnico, com mais de 3 anos atuando na saúde e no SIM e sem responsabilidade por outros sistemas. Estão alocados na vigilância epidemiológica e no setor de informação da SMS, suas equipes variam de dois a mais de cinco profissionais, tem de um a mais de sete computadores, e seus sistemas operacionais são mais novos. O acesso predominante é por banda larga e tem suporte de informática próprio. Receberam treinamentos para atuarem com o SIM, fornecido pela SES-SP e pelo próprio município, já os treinamentos para preenchimento de DO foram ofertados tanto para médicos como para enfermeiros e foi o grupo de municípios que mais investiu para isto. No processo de distribuição de impressos, são os que mais utilizam o sistema, bem como os que mais realizam: busca ativa de óbitos; procedimentos ao verificar que o volume de eventos está abaixo do esperado; revisão de campos em branco da DO, utilizam relatórios do sistema e o Tabwin. As informações são mais solicitadas pelo Comitê de Morte Materna e Infantil, seguida do Planejamento de Ações de Saúde e do Secretário de Saúde.

Apresentam baixa ou nenhuma dificuldade para as atividades pesquisadas. Já para os benefícios da descentralização, o grupo apresentou mais de $70 \%$ de alto e muito alto, com exceção da responsabilidade do gestor de saúde local.

Foi possível verificar que cada município absorveu o SIM de forma diferente, com alocação do sistema em locais diversos, recursos humanos comprometidos com muitas outras funções, infra estrutura de computadores, impressoras, telefone e materiais, que ainda que suficientes apresentam divergências entre si. 
As etapas de formulação e análise de indicadores mostraram-se vulneráveis, sendo a rotatividade de $\mathrm{RH}$ fator que pode interferir muito, pois o tempo em capacitar o profissional para desenvolver todas as atividades fica limitado e não ocorre a sedimentação do trabalho, principalmente em municípios pequenos.

A interlocução realizada pela GVE e SES-SP demonstra peso importante no desenvolvimento do SIM nos municípios, muitas vezes através dela amplia-se o vínculo e a comunicação entre as partes, aprimorando o trabalho.

Por outro lado, nos municípios grandes isto não ocorre com tanta velocidade, pois parte-se do princípio que a alta demanda de trabalho no SIM faz com que tenham equipes do nível central mais bem preparadas tanto pela estrutura como pelo vínculo predominante de efetivos. Mas ao olharmos para a coleta da informação isto pode não ocorrer, pois há uma grande rotatividade de profissionais nos hospitais.

A descentralização dos sistema se deu com flexibilidade para que os municípios realizem ajustes em seu sistema de saúde, mas com as diferenças encontradas neste estudo observa-se que nem todos tinham condições de caminhar e evoluir sozinhos da forma como foi concebido, seja por falta de recursos financeiros ou por ter outras prioridades que não o sistema. Ainda se vê os sistemas de informação muito frágeis frente a outras atividades nos municípios, que contando com equipes reduzidas priorizam questões assistenciais, conforme verificado no momento da adesão à esta pesquisa.

A descentralização do SIM para os municípios se mostrou uma decisão acertada, pois favoreceu o acesso imediato a informações de mortalidade que são essenciais para o diagnóstico de saúde da população. A heterogeneidade dos municípios paulistas naturalmente implicou numa heterogeneidade do processo de descentralização, com os municípios menores apresentando maiores limitações, o que reforça o papel do gestor estadual no aprimoramento desse processo, visando tornar a informação eficiente, eficaz e adequada às necessidades não só do município, mas das três esferas de atuação no SUS. 
Como considerações finais recomenda-se medidas que possam diminuir a rotatividade neste trabalho, principalmente em municípios de pequeno e médio porte, como criação de uma carreira e cargos, porém é necessário ampliar o estudo a fim de sugerir a implantação de uma estrutura organizacional mais sólida nos municípios. Ampliar a interlocução entre o estado e os municípios e estabelecer maior vínculo. Proporcionar mais treinamentos para operacionalizar o SIM e, por fim, sensibilizar os diversos setores internos das SMSs, inclusive os gestores municipais, para a importância do trabalho do SIM, com vista para além de uma simples coleta e digitação de dados. 


\section{REFERÊNCIAS BIBLIOGRÁFICAS}

1. Almeida MF, Alencar GP. Informações em Saúde: Necessidade de Introdução de Mecanismos de Gerenciamento dos Sistemas. Inf Epidemiol SUS 2000; 9(4): 241-9.

2. Almeida, MF de. Descentralização de Sistemas de Informação e o uso das informações a nível municipal. Inf. Epidemiol. SUS.1998; v. 2, n. 3.

3. Alves M, Penna CMM, Brito MJM. Perfil dos Gerentes de Unidades Básicas de Saúde. Revista Brasileira Enfermagem, Brasília, v 57(4):441446, 2004.

4. Arts et al. Defining and Improving Data Quality in Medical Registries: A Literature Review, Case Study, and Generie Framework. Journal of the American Medical Informatics Association. 2002; v. 9 n. 6.

5. Barreira RB. Elaboração e Validação de Questionários para Coleta de Dados Sobre Serviços Especializados e Pacientes com Imunodeficiências Primárias. 2007. 166 f. Dissertação de mestrado - Instituto Fernandes Figueira - Fundação Oswaldo Cruz, Rio de Janeiro, 2007.

6. Branco MAF, Sistemas de Informação em saúde no nível local. Cad. Saúde Pública. 1996 v. 12, n. 2.

7. Branco MAF. Informação e saúde: uma ciência e suas políticas em uma nova era. Rio de Janeiro: Editora Fiocruz; 2006.

8. Brasil, Ministério da Saúde. Rede de Observatórios de Recursos Humanos em Saúde. Analise da Força de Trabalho do Setor Saúde no Brasil: focalizando a feminização. Rio de Janeiro, 2006.

9. Brasil. Lei Orgânica da Saúde 8.080 de 19 de setembro de 1990. Dispõe sobre as condições para a promoção, proteção e recuperação da saúde, a organização e o funcionamento dos serviços correspondentes e dá outras providências. Diário Oficial da União. 20 de setembro de 1990. Seção 1:018055.

10. Brasil. Ministério da Saúde. A Experiência Brasileira em Sistemas de Informação em Saúde./ Ministério da Saúde; Organização Pan-Americana 
da Saúde; Fundação Oswaldo Cruz In: Almeida, MF et al.. Sistema de Avaliação de Nascidos Vivos - SINASC: Uma avaliação de sua trajetória. (Série B. Textos Básicos de Saúde). Brasilia: Editora do Ministério da Saúde, 2009. 1v. p. 11-38.

11. Brasil. Ministério da Saúde. Declaração de óbito: documento necessário e importante / Ministério da Saúde, Conselho Federal de Medicina, Centro Brasileiro de Classificação de Doenças. - Brasília: Ministério da Saúde, 2006. 40 p.: il. - (Série A. Normas e Manuais Técnicos).

12. Brasil. Ministério da Saúde. Gabinete do Ministro Portaria n ${ }^{\circ}$ 1271, de 06 de junho de 2014. Define a Lista Nacional de Notificação Compulsória de doenças, agravos e eventos de saúde pública nos services de saúde públicos e privados em todo o territorio nacional, nos termos do anexo, e dá outras providências. Diário Oficial da União. 07 de junho.

13. Brasil. Ministério da Saúde. Gabinete do Ministro. Portaria ${ }^{\circ} 1119$, de 05 de junho de 2008. Regulamenta a Vigilância de Óbitos, 2008.

14. Brasil. Ministério da Saúde. Gabinete do Ministro. Portaria $\mathrm{n}^{\circ} 1271$, de 11 de janeiro de 2010. Define a Lista Nacional de Notificação Compulsória de doenças, agravos e eventos de saúde pública nos serviços de saúde públicos e privados em todo o território nacional, nos termos do anexo, e dá outras providências. Diário Oficial do Estado de São Paulo. 06 de junho 2014; Seção 1:68.

15. Brasil. Ministério da Saúde. Gabinete do Ministro. Portaria $n^{\circ} 72$, de 11 de janeiro de 2010. Estabelece que a vigilância do óbito infantil e fetal é obrigatória nos serviços de saúde (públicos e privados) que integram o Sistema Único de Saúde (SUS). Diário Oficial do Estado de São Paulo. 12 de janeiro 2010; Seção 1:29.

16. Brasil. Ministério da Saúde. Manual de Instrução Para Preenchimento da Declaração de Óbito,

17. Brasil. Ministério da Saúde. Manual do Instalador do Sistema de Mortalidade. DATASUS. - Brasília: Secretaria de Vigilância em Saúde, Ministério da Saúde, 2005. 
18. Brasil. Ministério da Saúde. Portal da Saúde [homepage na internet]. Brasil [acesso em 21 de maio2015]. Disponivel em: http://www2.datasus.gov.br/DATASUS/index.php?area=060701

19. Brasil. Ministério da Saúde. Portal da Saúde [homepage na internet]. Brasil [acesso em 15 de abril 2014]. Disponivel em: http://www2.datasus.gov.br/DATASUS/index.php?area=01

20. Brasil. Ministério da Saúde. Secretaria de Vigilância em Saúde. Departamento de Análise de Situação de Saúde. Manual de Instruções para o preenchimento da Declaração de Óbito / Ministério da Saúde, Secretaria de Vigilância em Saúde, Departamento de Análise de Situação de Saúde. Brasília: Ministério da Saúde, 2011.54 p.: il. (Série A. Normas e Manuais Técnicos).

21. Brasil. Ministério da Saúde. Secretaria de Vigilância em Saúde. Portaria nº 116 de 11 de fevereiro de 2009, Regulamenta a coleta de dados, fluxo e periodicidade de envio das informações sobre óbitos e nascidos vivos para o Sistema de Informações em Saúde. Diário Oficial da União, 12 de fevereiro 2009; Seção1:29.

22. Brasil. Ministério da Saúde. Secretaria de Vigilância em Saúde. Portaria nº 201, de 03 de novembro de 2010. Regulamenta as atividades da vigilância epidemiológica com relação à coleta, fluxo e a periodicidade de envio de dados da notificação de mortalidade e doenças de notificação compulsória. Diário Oficial da União. 04 de novembro 2010; Seção 1:88.

23. Campos, Deise et al. Sistema de Informações sobre Mortalidade em municípios de pequeno porte de Minas Gerais: concepções dos profissionais de saúde. Ciênc. saúde coletiva 2013, vol.18, n.5, pp. 14731482. .

24. Cohn A, Westphal MF, Elias PE. Informação e Decisão Política em Saúde. Rev Saúde Pública. 2005;39(1):114-121.

25. Drumond Jr M. Epidemiologia nos Municípios - Muito Além das Normas. 2. ed. São Paulo: Hucitec; 2003. 
26. Ferreira JSA et al . Avaliação da qualidade da informação: linkage entre SIM e SINASC em Jaboatão dos Guararapes (PE). Ciência \& Saúde Coletiva, 16(Supl. 1):1241-1246, 2011.

27. Guimarães EAA et al. A descentralização do Sinasc e a completude das variáveis da declaração de nascido vivo em municípios mineiros de 1998 a 2005. Rev. bras. crescimento desenvolv. hum. [online]. 2011, v. 21, n. $3,832-840$.

28. Guimarães EAA et al. Avaliação da Implantação do Sistemas de Informação sobre Nascidos Vivos em Municípios de Minas Gerais, Cadernos de Saúde Pública, Rio de Janeiro. 2013; 29(10):2105-2118.

29. IBGE. Pesquisa de Informações Básicas Municipais - Perfil dos Municípios Brasileiros. Rio de Janeiro, 2014.

30. Lagaurdia J. et al. Sistema de informação de Agravos de Notificação em Saúde (Sinan): desafios no desenvolvimento de um sistema de informação em saúde. Epidemiologia. Serv. Saúde v.13 n.3. 2004.

31. Laurenti R, Mello Jorge MHP, Gotlieb SLD. O Sistema de Informação sobre Mortalidade: Passado, Presente, Futuro. Centro Colaborador da OMS para a Família de Classificações. Centro Brasileiro de Classificação de Doenças. MS/USP/OPAS/OMS. São Paulo: 2006.

32. Mello Jorge MHP, Gotileb SLD, Soboll MLMS, Almeida MF, Latorre MRD. Avaliação do sistema de informações sobre nascidos vivos e o uso de seus dados em epidemiologia e estatísticas de saúde. Rev. saúde pública 1993; 27(1):1-44.

33. Mello Jorge MHP, Gotlieb SLD, Soboll, MLMS, Baldijião, MFA, Latorre, MRDO. O Sistema de Informação sobre Nascidos Vivos - SINASC. Centro Brasileiro de Classificação de Doenças. MS/USP/OPAS/OMS. São Paulo: 1992.

34. Mello Jorge MHP, Laurenti R, Goltlib SLD. O Sistema de Informações sobre Mortalidade - SIM Concepção, Implantação e Avaliação. In Ministério da Saúde. A experiência brasileira em sistemas de informação em saúde. MS/OPAS, Fundação Oswaldo Cruz. - Brasília: Editora do Ministério da Saúde; 2009; v. 1. 
35. Mello Jorge MHP, Laurenti R, Gotlieb SLD. Análise da qualidade das estatísticas vitais brasileiras: a experiência de implantação do SIM e do SINASC. Cien Saúde Colet. 2007; 12(3):643-654.

36. Mendes JDV, Bittar OJN. Saúde Pública no Estado de São Paulo com Implicações no Planejamento de Programas e Serviços. Boletim Eletrônico Paulista - BEPA 2010; Edição Especial; 5-71.

37. Moraes IHS. Política, tecnologia e informação em saúde: a utopia da emancipação. Salvador: Ed. Casa da Qualidade; 2003.

38. Messas, JT. Análise do Ambiente Educacional: Construção e Validação de um instrumento de Avaliação para Graduação em Enfermagem. Dissertação São Paulo, Escola de Enfermagem - Universidade de São Pualo, 2013.

39. Mota E, Carvalho DM. Sistemas de informação em saúde. In: Rouquayrol MZ, Almeida Filho N, editores. Epidemiologia e saúde. Rio de Janeiro: MEDSI; 2003.

40. Nakajime H. Epidemiology and the future of World Health. The Robert Crinchshank Lecture. Int. Journal of Epidemiology. 1991; 20(3):589-94.

41. OMS, Organização Mundial da Saúde/Organização Pan-americana de Saúde. Sistema de informação e tecnologia de informação em saúde: desafios e soluções para a América Latina e Caribe. Brasil: OPAS/OMS, 1998.120p.

42. Pereira, CCB ; VIDAL SA ; CARVALHO PI ; FRIAS PG. Avaliação da Implantação do Sistema de Informações sobre Nascidos Vivos (Sinasc) em Pernambuco. Revista Brasileira de Saúde Materno Infantil (Impresso), v. 13, p. 39-49, 2013.

43. Prado MF, Marques CCA. Sistemas de Informações em Saúde: uma experiência da descentralização da produção das informações sobre mortalidade e nascidos vivos para o uso em vigilância à saúde no estado de São Paulo. Boletim Eletrônico Paulista - BEPA 2012; 9(100):4-15.

44. Ribeiro, F.F.S. Um passo em direção a um sistema de informações de nascidos vivos de múltiplas interface. Tese (doutorado) - Faculdade de Saúde Pública, Universidade de São Paulo.2003. 
45. Santos A H. Avaliação da qualidade da codificação das causas de morte no Estado de São Paulo. Inf. Epidemiol. Sus v.9 n.3 Brasília. 2000.

46. São Paulo. Secretaria da Saúde do Estado de São Paulo. Coordenadoria de Controle de Doenças. Comunicado Orientação Técnica CIVS 01/2013 Auditoria de Arquivos dos Sistemas SIM e SINASC do ano de 2011. Diário Oficial do Estado de São Paulo. 11 de janeiro 2013; Seção 1:33.

47. São Paulo. Secretaria da Saúde do Estado de São Paulo. Resolução nº 66 de 03 de maio de 2010. Disciplina o cadastro e acesso de Responsáveis Técnicos e usuários às bases de dados dos Sistemas de Informações de MortalidadeSIM e sobre Nascidos Vivos-SINASC, no âmbito do Estado de São Paulo e dá outras providencias. Diário Oficial do Estado de São Paulo. 04 de maio 2010; Seção 1:29.

48. São Paulo. Secretaria da Saúde do Estado. Plano Estadual de Saúde do Estado de São Paulo 2012-2015. Política de Saúde; 2012.

49. São Paulo. Secretaria da Saúde do Estado. Portaria CCD n. 17 de 05 de maio de 2010. Regulamenta os procedimentos para a gestão de formulários de Declaração de Óbito e Declaração de Nascidos Vivos. Diário Oficial do Estado de São Paulo. 07 de maio 2010; Seção 1:32.

50. São Paulo. Secretaria da Saúde do Estado. Resolução n. 67 de 03 de maio de 2010. Descentraliza o processo de gestão dos formulários de Declaração de Óbito e Declaração de Nascidos Vivos, no âmbito do Estado de São Paulo e dá outras providencias. Diário Oficial do Estado de São Paulo. 04 de maio 2010; Seção 1:30.

51. Schoeps D. O Papel dos Profissionais de Saúde na Qualidade de Informações de Óbitos Perinatais e Nascidos Vivos no Município de São Paulo [tese na internet].São Paulo: Faculdade de Saúde Pública da USP; 2012.

52. Schoeps D. et al. Representações Sociais de Médicos Obstetras e Neonatologistas Sobre Declaração de Óbito Fetal e Neonatal Precoce no Município de São Paulo. Revista Brasileira Epidemiologia, 2014; 105-118. 
53. Solomon DJ, Henry RC, Hogan JG, Van Amburg GH, Taylor J. Evaluation and implementation of public health registries. Public Health Rep.1991;106:141-150.

54. Stansfiel SK et al. Information to Improve Decision Making for Health. Disease Control Priorities in Developing Countries. 2000. P. 1017-1030.

55. Vasconcellos MM, Moraes IHS, Cavalcante MT. Política de saúde e potencialidades de uso das tecnologias de informação. Saúde debate 2002.

56. Viacava F, Ramos CL. A experiência brasileira em sistemas de informação em saúde. Ministério da Saúde, Organização Pan-Americana da Saúde, Fundação Oswaldo Cruz. Brasília: Editora do Ministério da Saúde, 2009, v. 2.

57. Vidor AC, Fischer PD, Bordin R. Utilização dos Sistemas de Informações em Saúde em Municípios Gaúchos de Pequeno Porte. Rev Saúde Pública. 2011;45(1):24-30.

58. Waldvogel BC, Ferreira CEC. Estatísticas da Vida. São Paulo em Pespectiva. 2003;17(3-4):55-66;

59. WHO-World Health Organization. Developing health management information systems: a practical guide for developing countries. WHO, 2004.

60. Williams MCRP, et al. Recursos Humanos em Saúde no Município de Poços de Caldas, MG. Revista de Investigação v.10, p.60-68, 2010. 


\section{ANEXOS}

Anexo I: Modelo da DO

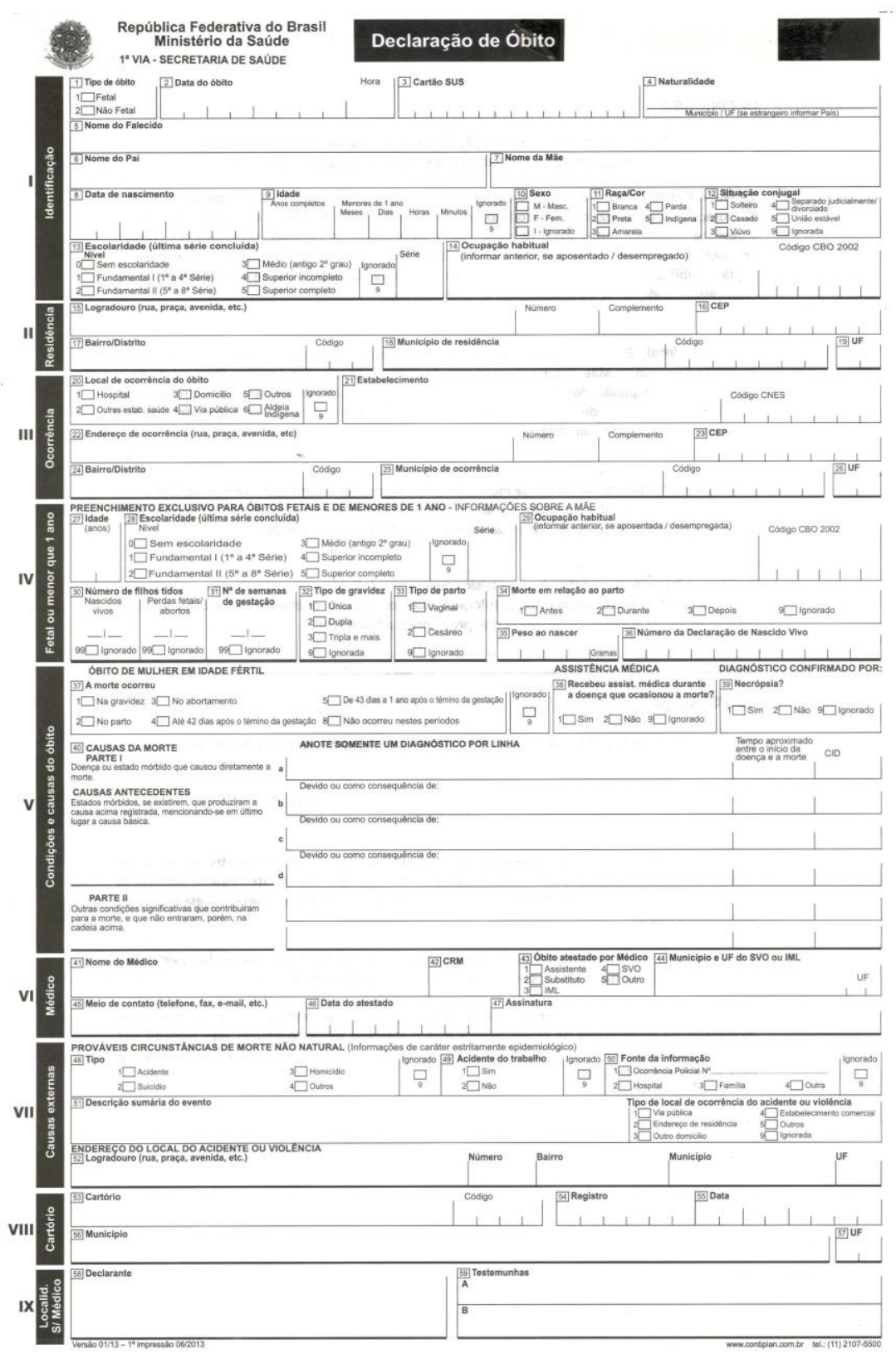


Anexo II : Fluxo das vias da DO

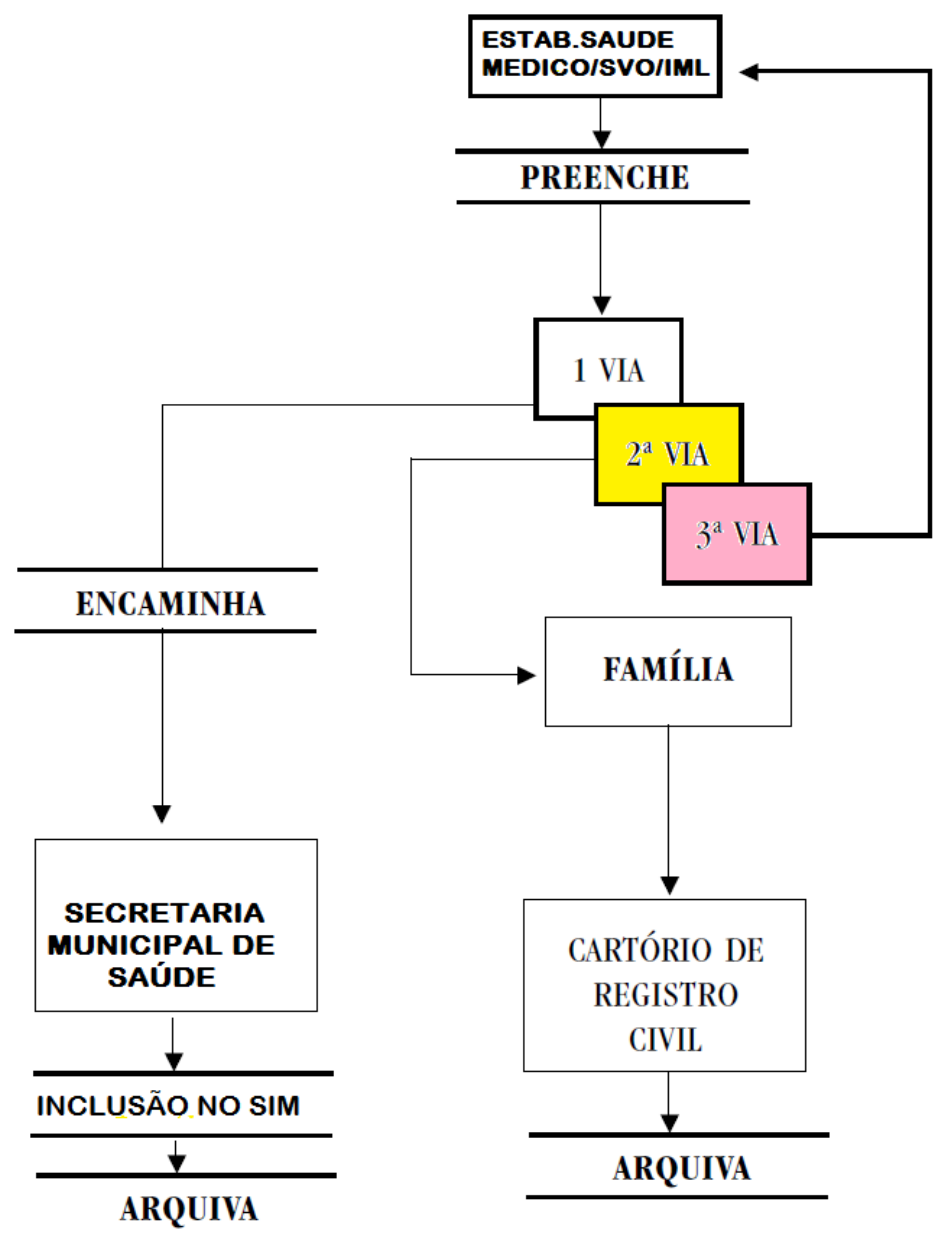




\title{
Anexo III: Termo de Sigilo e Confidencialidade
}

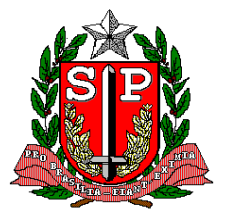

\author{
SECRETARIA DE ESTADO DA SAÚDE \\ COORDENADORIA DE CONTROLE DE DOENÇAS - CCD \\ CENTRO DE INFORMAÇÕES ESTRATÉGICAS DE VIGILÂNCIA À SAUDE
}

Av. Dr. Arnaldo, 351 - Sala 131, 1 o andar - SP/SP - CEP: 01246-901

Fone: (11) 3066-8912/8843

\section{TERMO DE SIGILO E CONFIDENCIALIDADE}

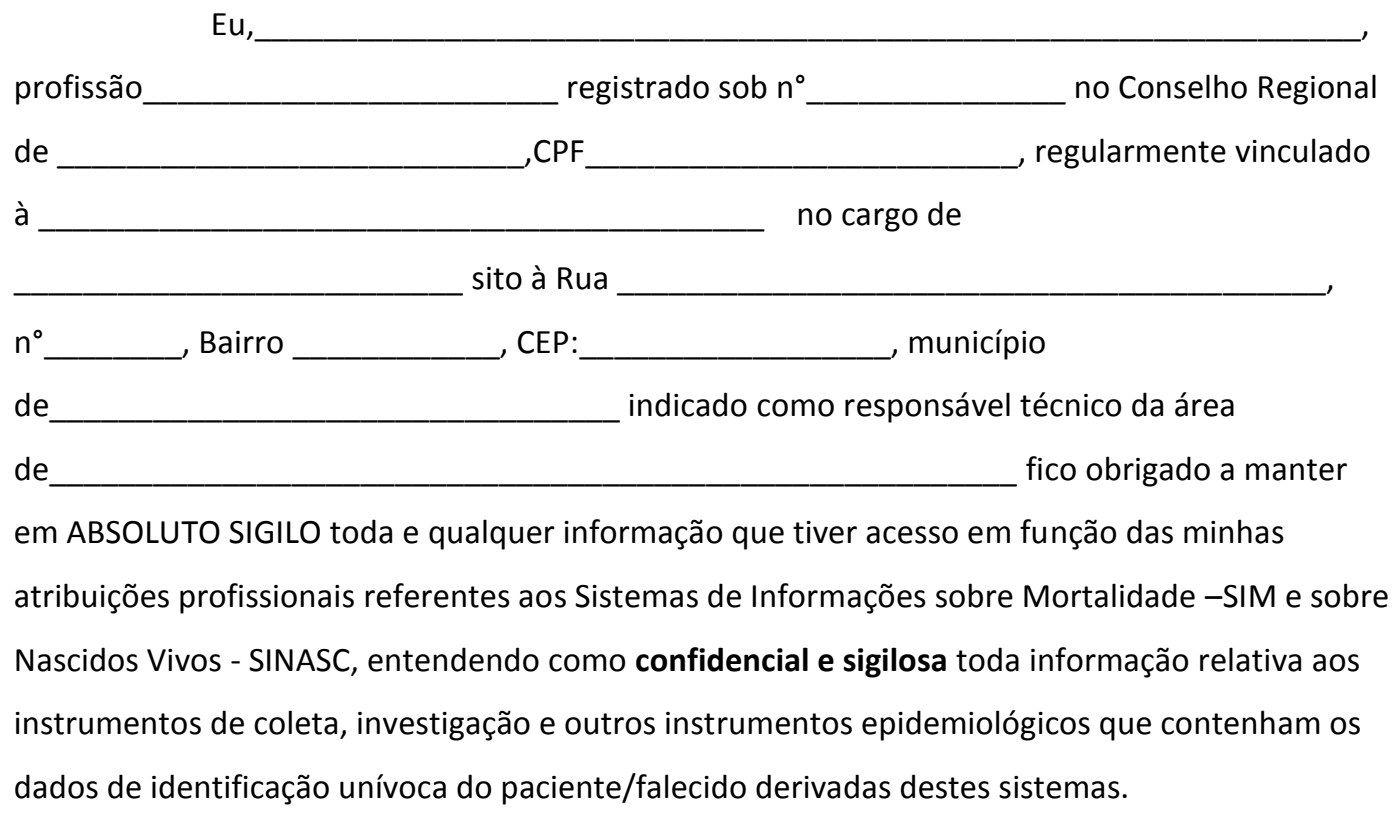

Para tanto, concordo e comprometo-me à:

1. Manter sigilo escrito e verbal de todos os dados, informações técnicas e administrativas obtidas ou não com minha participação.

2. Não divulgar ou publicar quaisquer dados ou informações que tenha tomado conhecimento ou elaborado no decorrer de minhas atividades sem a prévia autorização institucional.

3. Utilizar os dados de acesso restrito mantendo a necessária cautela quando da exibição de dados em tela, impressora ou gravação em meios eletrônicas, a fim de evitar que deles venham tomar ciência, pessoas não autorizadas.

4. Não fazer cópias, registros escritos ou em mídias eletrônicas de quaisquer dados ou informações que não sejam necessários, por força de minhas atribuições e 
responsabilidades, assim como tomar precauções e as devidas medidas de segurança, para que no âmbito de minhas atribuições e responsabilidades, tais dados e informações não sejam copiados, revelados, ou venham a ser usados indevidamente ou sem autorização.

5. Não praticar qualquer medida fora de minhas atribuições com a finalidade de obter para mim ou terceiros, direitos, vantagens pessoais ou financeiras relativas às informações que tenho acesso.

6. Não ausentar-me da estação de trabalho sem encerrar a sessão de uso dos sistemas, garantindo assim a impossibilidade de acesso indevido por terceiros.

7. Não revelar minha senha de acesso ao(s) sistema(s) a outros, cuidando para que a mesma seja somente de meu conhecimento.

8. Alterar minha senha de acesso quando da possibilidade de violação ou conhecimento de terceiros e, não utilizar combinações óbvias ou de fácil acesso à mesma.

9. Cadastrar e permitir acesso a tais sistemas somente a profissionais que tenham definidas na sua função ou cargo atribuições inerentes aos referidos sistemas e, mediante Termo de Sigilo e Confidencialidade devidamente assinado.

10. Notificar imediatamente a Coordenadoria de Controle de Doenças da Secretaria de Estado da Saúde através do Grupo de Vigilância Epidemiológica da minha região quando do eventual desligamento das funções de responsável técnico por tais sistemas.

11. Observar e cumprir as boas práticas de segurança da informação e das diretrizes preconizadas por tais sistemas de informações.

Declaro ainda estar ciente de que o não cumprimento de tais normas caracterizará infração ética podendo acarretar punição nas esferas penal, civil e administrativa de acordo com a legislação vigente.

Sem mais, 
como subsídio para planejamento de ações e tomadas de decisão. $\mathrm{O}$ objetivo desse projeto é conhecer as características estruturais (recursos humanos, infraestrutura, informática), processo de trabalho e uso das informações na gestão nos municípios do Estado do São Paulo. Com isso pretende-se gerar novos conhecimentos que possibilitem ações para o aprimoramento desses sistemas de informações.

sim, esclarecemos que sua participação é de ema importância, a fim de contribuir para strução de evidências científicas referentes a este ia.

Você será esclarecido(a) sobre a pesquisa em qualquer aspecto que desejar e é livre para recusarse a participar, retirar seu consentimento ou interromper a participação a qualquer momento. $A$ sua participação é voluntária e a recusa em participar não irá acarretar problema de qualquer natureza.

Os pesquisadores irão tratar a sua identidade com padrões profissionais de sigilo. Os resultados da pesquisa serão disponibilizados de forma agregada, sem identificação do respondente ou do município e permanecerão confidenciais. Você não será identificado(a) em nenhuma publicação que possa resultar deste estudo. Uma cópia deste consentimento poderá ser impresso ao final do preenchimento do questionário.

A participação no estudo não acarretará custos para você e não será disponível nenhuma compensação financeira adicional.

Este é um projeto em parceria entre a 
Secretaria de Estado da Saúde de São Paulo e a Faculdade de Saúde Pública da USP, com apoio do Conselho Nacional de Desenvolvimento Científico e Tecnológico - CNPq.

Em caso de dúvidas, você poderá chamar a estudante Cátia Martinez Minto ou a professora orientadora, nos telefones (11) 99666-6094, (11) 3061-7930 ou no Comitê de Ética em Pesquisa da Faculdade de Saúde Pública da Universidade de São Paulo, sito à Av. Dr. Arnaldo, 715, Cerqueira César São Paulo, SP, no telefone (11) 3066-7779.

"Eu fui informado(a) dos objetivos da pesquisa acima de maneira clara e detalhada e esclareci minhas dúvidas. Sei que, em qualquer momento, poderei solicitar novas informações $e$ modificar minha decisão se assim o desejar. A professora orientadora Dra. Zilda Pereira da Silva, da Universidade de São Paulo, Faculdade de Saúde Pública, certifica-me de que todos os dados desta pesquisa serão confidenciais.

Declaro que concordo em participar desse estudo. Recebi uma cópia deste termo de consentimento livre e esclarecido e me foi dada a oportunidade de ler e esclarecer as minhas dúvidas. "

* Preenchimento Obrigatório

Clique aqui em caso de dúvidas relativas a este formulário.

1) Declaro que concordo em participar desse estudo: *

Aceito

Identificação do Respondente

2) GVE: *

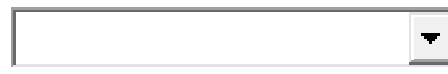

4) Nome: 
Telefone: $*$

Informe ddd e número - apenas números

6) E-mail : *

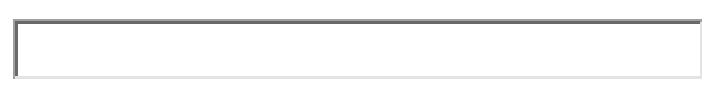

7) Sexo: *

\begin{tabular}{c|c}
$C$ & Masculino \\
$C$ & Feminino
\end{tabular}

8) Idade: *

Anos

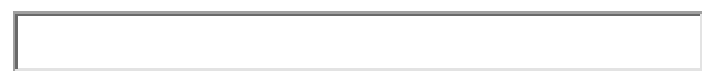

9) Escolaridade: *

Ensino Fundamental incompleto

Ensino Fundamental completo

Ensino Médio incompleto

Ensino Médio completo

Superior incompleto

S Superior completo

Pós Graduação incompleta

C. Pós Graduação completa

11) Vínculo: *
(C) Efetivo
C CLT
C. Contratado periódico
Cargo em comissão
Estagiário
Outro

13) Qual a sua função?

Diretor/Coordenador/Supervisor

Assistente Técnico ou similar

(C) Digitador/Auxiliar Administrativo ou similar 


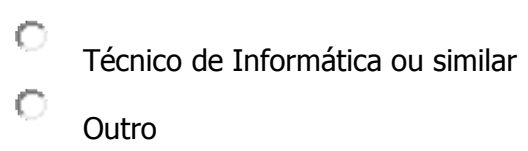

15) Há quanto tempo o Sr.(a) trabalha no setor público da área de saúde?

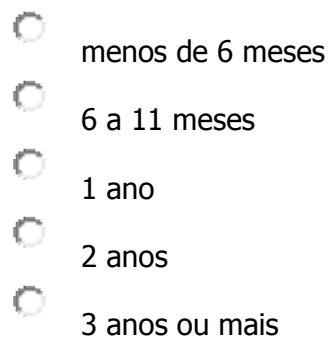

16) O Sr.(a) é responsável por outros sistemas? *

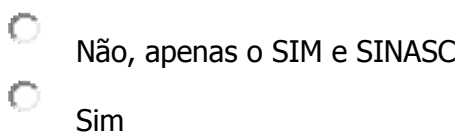

18) Há quanto tempo o Sr.(a) trabalha com o SIM e com o SINASC ? *

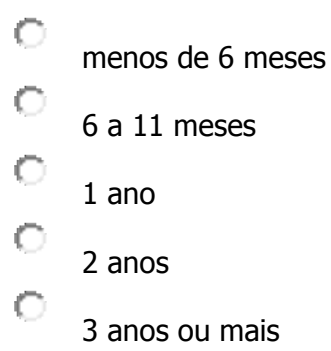

19) O Sr.(a) assinou o Termo de Confidencialidade e Sigilo, para trabalhar com os Sistemas de Informações de Mortalidade e de Nascidos Vivos?
Não
Sim, antes de exercer o trabalho
Sim, depois de exercer o trabalho

\section{Estrutura}

20) Em qual setor está alocado o SIM e o SINASC? *

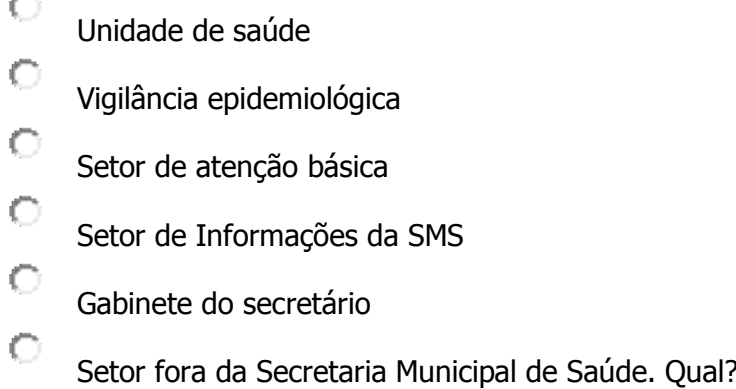


Outro. Especifique:

23) Indique quantas pessoas trabalhavam no TOTAL no Sistema SIM e SINASC, em 31/12/2014:

completar em números e utilizar o 0 (zero) para nenhum

24) Indique quantas pessoas, de nível superior de formação da área de saúde, trabalhavam no Sistema SIM e SINASC, em 31/12/2014:

completar em números e utilizar o 0 (zero) para nenhum

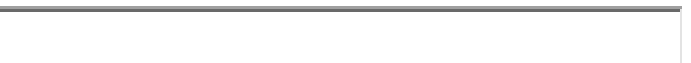

25) Indique quantas pessoas, de nível superior de formação da área de Tecnologia da Informação trabalhavam no Sistema SIM e SINASC, em 31/12/2014: *

completar em números e utilizar o 0 (zero) para nenhum

26) Indique quantas pessoas, de outra área de Nível Superior de formação trabalhavam no Sistema SIM e SINASC, em 31/12/2014: *

completar em números e utilizar o 0 (zero) para nenhum

27) Indique quantas pessoas, de Nível Técnico ou ensino médio trabalhavam no Sistema SIM e SINASC, em 31/12/2014: * completar em números e utilizar o 0 (zero) para nenhum

28) Indique quantas pessoas, de Nível Fundamental trabalhavam no Sistema SIM e SINASC, em 31/12/2014:

completar em números e utilizar o 0 (zero) para nenhum

29) Indique as atividades que o Sr.(a) e/ou sua equipe realizam:

\begin{tabular}{|l|c|c|c|}
\hline & \multicolumn{2}{c|}{$\begin{array}{c}\text { Sr(a } \\
\text { Equi }\end{array}$} & $\begin{array}{c}\text { Não } \\
\text { realiza }\end{array}$ \\
\hline $\begin{array}{l}\text { 30) Distribuição e controle de impressos da DO e } \\
\text { DNV: * }\end{array}$ & $\Gamma$ & $\Gamma$ & $\Gamma$ \\
\hline 31) Digitação: * & $\Gamma$ & $\Gamma$ & $\Gamma$ \\
\hline $\begin{array}{l}\text { 32) Backup, retroalimentação, arquivos de } \\
\text { transferências e outros: } *\end{array}$ & $\Gamma$ & $\Gamma$ & $\Gamma$ \\
\hline $\begin{array}{l}\text { 33) Cancelamento de impressos de DO e DNV no } \\
\text { sistema: } *\end{array}$ & $\Gamma$ & $\Gamma$ & $\Gamma$ \\
\hline $\begin{array}{l}\text { 34) Classificação e codificação de doenças: * } \\
\text { 35) Digitação de ficha de investigação } \\
\text { epidemiológica no sistema: * }\end{array}$ & $\Gamma$ & $\Gamma$ & $\Gamma$ \\
\hline 36) Elaboração de indicadores: * & $\Gamma$ & $\Gamma$ & $\Gamma$ \\
\hline 37) Análise dos dados: * & $\Gamma$ & $\Gamma$ & $\Gamma$ \\
\hline
\end{tabular}


38) Participação do Comitê de Investigação de Morte Materna e Infantil:

39) Indique quantas pessoas atuavam na Digitação, em 31/12/2014:

completar em números e utilizar o 0 (zero) para nenhum

40) Indique quantas pessoas atuavam na Classificação e codificação de doenças, em 31/12/2014: *

completar em números e utilizar o 0 (zero) para nenhum

41) Em quantos computadores estão instalados o Sistema SIM e SINASC? *

completar em números

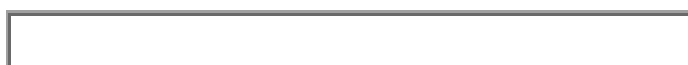

42) Indique qual o sistema operacional que esta instalado no(s) computador(es) que opera o SIM e SINASC:

Para saber clicar em Painel de Controle e depois em Sistemas

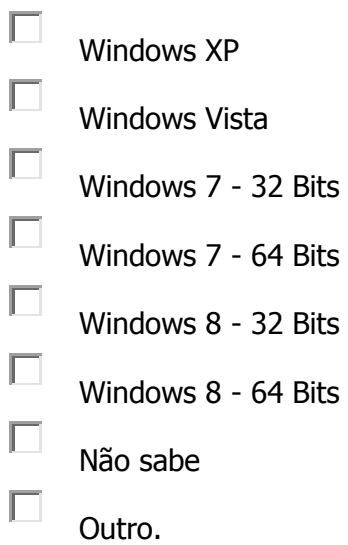

44) Nestes computadores, há outros sistemas de informação de saúde instalados? *

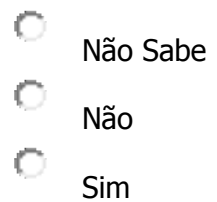

46) Há conexão com internet nos computadores que operam o SIM e o SINASC? *

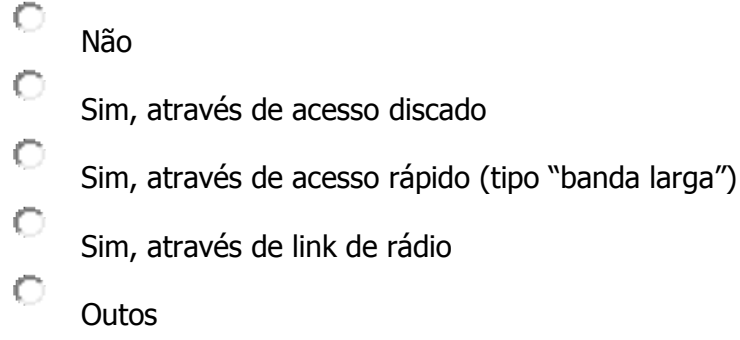


48) Há impressora para uso do SIM e SINASC? *

(C) Não

Sim, de uso exclusivo

S Sim, de uso coletivo

49) Existe computador para backup dos dados dos sistemas SIM e SINASC? *

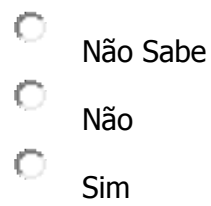

50) $\mathbf{O}$ (s) computador(es) de backup do SIM e SINASC armazenam dados de outros sistemas? *
Não Sabe
(C) Não
(C) $\operatorname{Sim}$

52) O município dispõe de suporte técnico de informática? *
Não
Sim, serviço próprio
S Sim, serviço tercerizado

55) Em que local são guardados os impressos de DO e DNV em branco? *

Almoxarifado junto com outros itens

Armário sem chave e em sala aberta

Armário sem chave e em sala fechada

(C) Armário com chave e em sala aberta

Armário com chave e em sala fechada

O Outro

57) Avalie a disponibilidade de materiais para operar os sistemas SIM e SINASC:

\begin{tabular}{|c|c|c|}
\hline & Sufici & Insufic \\
\hline 58) CD/DVD/pen-drive: * & $C$ & $C$ \\
\hline 59) Telefone: * & $\mathrm{C}$ & 0 \\
\hline 60) Computador: * & $\mathrm{C}$ & 0 \\
\hline 61) Impressora: * & $C$ & $\mathrm{C}$ \\
\hline
\end{tabular}


62) Tinta para impressora: *

63) Impressos da DO: *

64) Impressos da DNV: *

65) Avalie a disponibilidade de outros materiais para operar os sistemas SIM e SINASC:

Descreve o material e indique se for suficiente ou insuficiente.

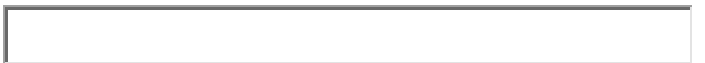

Capacitação Profissional

66) $\mathbf{O}$ (a) Sr.(a) e/ou sua equipe receberam treinamento institucional para trabalhar com o sistema SIM e SINASC? *

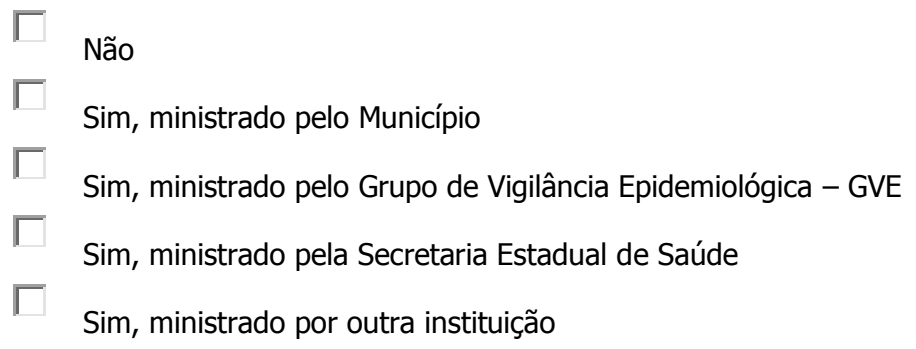

68) Do total de integrantes da equipe, quantos foram treinados nos últimos dois anos? ${ }^{*}$

número de profissionais treinados, completar em números e utilizar o 0 (zero) para nenhum

69) Indique o(s) tipo(s) de treinamento(s) recebido(s), sobre o Sistema Operacional , nos dois últimos anos: *

Implantação e utilização do sistema local no computador

- Alimentação de tabelas locais

ए Utilização do balcão

- Operação do Módulo Web Investigação

Г Realização de auditoria, retroalimentação, backup e geração de arquivo

$\Gamma$

Emissão de relatórios

ए Nenhum

70) Indique o(s) tipo(s) de treinamento(s) recebido(s), sobre SIM e SINASC, nos dois últimos anos:

$\Gamma$

Captação de óbitos e nascimentos

- Preenchimento da declaração de óbito e de nascimento

- Codificação das causas de morte (CID-10) 


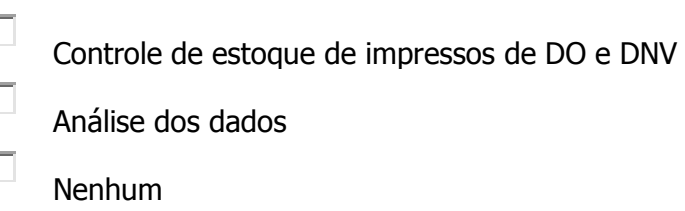

71) No último ano, a Secretaria Municipal de Saúde realizou treinamento para profissionais das unidades de saúde, para preenchimento da DO? *

Cão

Sim, para Médicos

Sim para Enfermeiros

- Sim para Escriturários do setor de admissão hospitalar/SAME

ГSim para Outros profissionais

72) No último ano, a Secretaria Municipal de Saúde realizou treinamento para profissionais das unidades de saúde, para preenchimento da DNV? *

Não

ГSim, para Médicos

T Sim, para Enfermeiros

Г Sim, para Escriturários do setor de admissão hospitalar/SAME

Г Sim para Outros profissionais

Processo de Trabalho

73) Indique o tipo de controle realizado na entrega dos impressos de DO e DNV para os estabelecimentos de saúde/profissionais: *

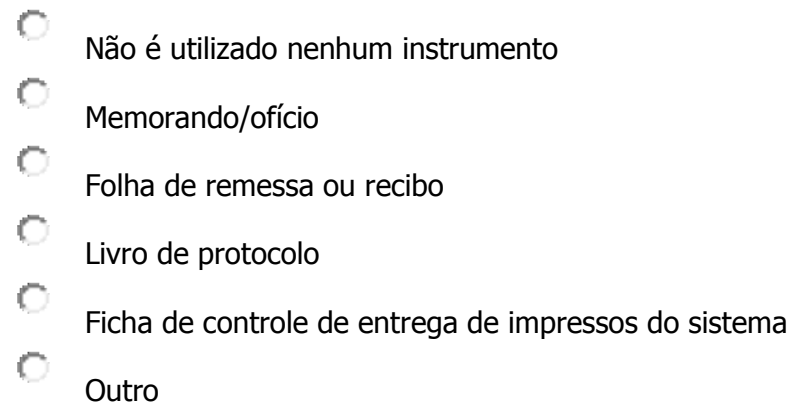

75) Indique qual o local que os profissionais retiram DO e DNV nos finais de semanas e feriados, quando necessário:

Nenhum, a retirada ocorre apenas durante a semana

Em hospital ou pronto socorro

- Na Secretaria Municipal de Saúde

ए No cartório 


$$
\begin{aligned}
& \text { Гa funerária } \\
& \Gamma \quad \text { Outro }
\end{aligned}
$$

77) Indique as instituições que enviam para a SMS a via branca da DO, de óbitos ocorridos em estabelecimentos de saúde:

$$
\begin{aligned}
& \Gamma \text { Estabelecimentos de saúde ( hospital/PS/ PA) } \\
& \Gamma \quad \text { Cartórios } \\
& \square \text { Serviço Funerário Público } \\
& \Gamma \quad \text { Funerárias } \\
& \Gamma \quad \text { Médicos } \\
& \Gamma \quad \text { Família } \\
& \Gamma \quad \text { Outros }
\end{aligned}
$$

78) Indique as instituições que enviam para a SMS a via branca preenchida da DNV, de nascimentos ocorridos em estabelecimentos de saúde: *

$$
\begin{aligned}
& \text { Г Estabelecimentos de saúde (hospital/PS/ PA) } \\
& \square \text { Cartórios } \\
& \Gamma \quad \text { Médicos } \\
& \Gamma \quad \text { Enfermeiro/Obstetriz } \\
& \Gamma \quad \text { Parteira Tradicional } \\
& \square \quad \text { Família } \\
& \Gamma \quad \text { Outros } \\
& \Gamma \quad \text { Não distribui formulário }
\end{aligned}
$$

79) Indique as instituições que enviam para SMS a via branca preenchida da DO, de óbitos domiciliares: *

Estabelecimentos de saúde (hospital/PS/ PA)

Cartórios

Г Serviço Funerário Público

Funerárias

Г Médicos

- Família

Г Outros

80) Indique as instituições que enviam para SMS a via branca preenchida da DNV, de nascimentos domiciliares: *

Г Estabelecimentos de saúde (hospital/PS/ PA) 


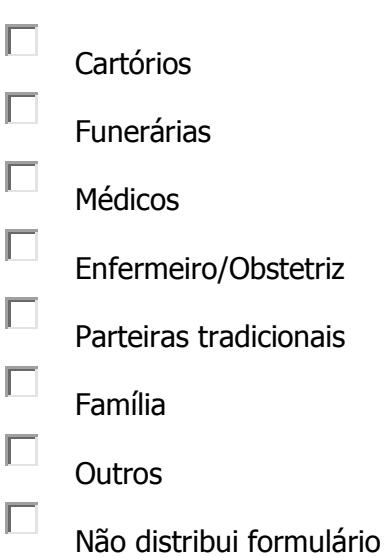

81) 0 município realiza busca ativa de óbitos? *

$\Gamma$

Não

Sim, em Estabelecimentos de saúde

Sim, em Cartórios

Sim, em Funerárias

Sim, em IML/SVO

Sim, em Delegacia

Sim, em Cemitérios

Sim, em Equipe de Saúde da Família

- Sim, em Outros locais

83) 0 município realiza busca ativa de nascimentos? *

$\Gamma$ Não

$\Gamma$

Sim, em Estabelecimentos de saúde

$\Gamma$

Sim, em Cartórios

$\Gamma$

Sim, em Equipe de saúde da família

Sim, em Outros locais

85) 0 município utiliza o Módulo WEB de investigação? *
Não
C. Sim

86) Ao se deparar com alguma dúvida na operação do SIM e SINASC, com quem a equipe busca auxílio? *

Colegas de equipe

Equipe de informação municipal

Colegas de outros municípios 


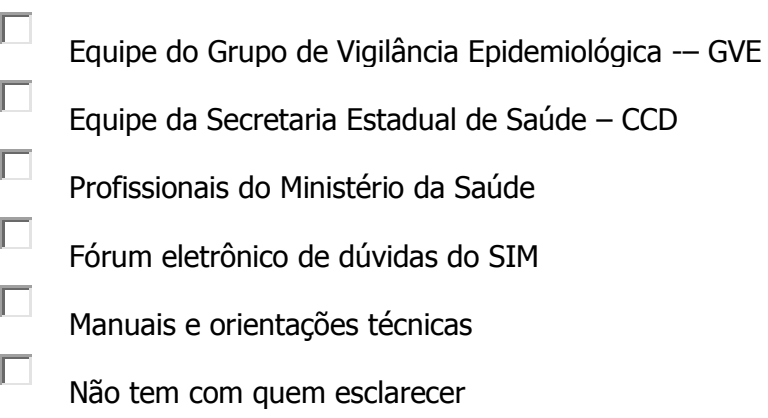

87) É realizado algum procedimento ao identificar que o volume mensal de eventos registrados no SIM está abaixo do esperado?

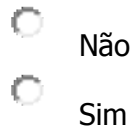

89) É realizado algum procedimento ao identificar que o volume mensal de eventos registrados no SINASC está abaixo do esperado? *

$$
\text { Sim }
$$

91) Algum técnico/profissional revisa as DOs antes de digitar, a fim de identificar campos em branco (sem preenchimento) e/ou preenchimento incorreto? ${ }^{*}$

$$
\begin{array}{l|l}
\text { C. Não } \\
\text { Sim }
\end{array}
$$

94) Algum técnico/profissional revisa as DNVs antes de digitar, a fim de identificar campos em branco (sem preenchimento) e/ou preenchimento incorreto? *

$$
\begin{aligned}
& \text { Não } \\
& \text { Sim }
\end{aligned}
$$

97) 0 município utiliza os relatórios do sistema para gerar indicadores? ${ }^{*}$

$$
\text { Tim }
$$

Não, por falta de treinamento

Não, por falta pessoal

Não, os relatórios não atendem à necessidade do município

Não, por outros motivos

99) Os indicadores de óbitos gerados no sistema atendem às necessidades do município? ${ }^{*}$ 


$$
\begin{array}{l|l}
\text { S } & \text { Sim, completamente } \\
& \text { Sim, parcialmente } \\
& \text { Não } \\
1 & \text { Não são gerados indicadores }
\end{array}
$$

100) Os indicadores de nascimentos gerados no sistema atendem às necessidades do município?
Sim, completamente
S. Sim, parcialmente
(C) Não
Não são gerados indicadores

101) A equipe utiliza o Tabwin do sistema SIM e SINASC ? *

\begin{tabular}{|c|c|c|c|c|c|}
\hline & $\begin{array}{c}0- \\
\text { Nenhuma } \\
\text { dificuldad } \\
\text { e }\end{array}$ & $\begin{array}{c}1 \text { - Baixa } \\
\text { dificuldad } \\
\text { e }\end{array}$ & $\begin{array}{c}2 \text { - Média } \\
\text { dificuldad } \\
\text { e }\end{array}$ & $\begin{array}{c}3 \text { - Alta } \\
\text { dificuldad } \\
\text { e }\end{array}$ & $\begin{array}{l}4 \text { - Muito } \\
\text { alta } \\
\text { dificuldad } \\
\text { e }\end{array}$ \\
\hline $\begin{array}{l}\text { 103) Distribuição } \\
\text { de formulários: * }\end{array}$ & $C$ & 0 & 0 & $C$ & $C$ \\
\hline $\begin{array}{l}\text { 104) } \\
\text { Preenchimento das } \\
\text { DOs: * }\end{array}$ & $C$ & $C$ & 0 & $C$ & 0 \\
\hline $\begin{array}{l}\text { 105) } \\
\text { Coleta/captação } \\
\text { das DOs: * }\end{array}$ & $C$ & 0 & 0 & 0 & $C$ \\
\hline $\begin{array}{l}\text { 106) Codificação } \\
\text { das causas de } \\
\text { morte: } *\end{array}$ & 0 & $C$ & 0 & $C$ & $C$ \\
\hline $\begin{array}{l}\text { 107) Instalação do } \\
\text { sistema no } \\
\text { computador: * }\end{array}$ & $C$ & $C$ & $C$ & $C$ & $C$ \\
\hline 108) Digitação: * & $C$ & $C$ & 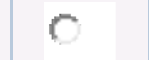 & $C$ & $C$ \\
\hline $\begin{array}{l}\text { 109) Falhas } \\
\text { operacionais da } \\
\text { ferramenta na } \\
\text { digitação } \\
\text { (travamento): * }\end{array}$ & 0 & $\mathrm{C}$ & $C$ & $C$ & $C$ \\
\hline
\end{tabular}

$$
\begin{aligned}
& \text { ए Não } \\
& \text { Г Sim, utiliza funções básicas } \\
& \text { Г Sim, utiliza módulo de mapas e gráficos } \\
& \ulcorner\text { Sim, utiliza ferramenta de mapa de fluxo origem-destino } \\
& \text { - Sim, utiliza interface Tabwin - SQL }
\end{aligned}
$$

102) Avalie o grau de dificuldade encontrado em cada etapa de operação do SIM: 
110) Checagem de inconsistência dos dados digitados: *

111) Fechamento e transmissão de lotes: *

112) Geração de indicadores: *

\begin{tabular}{|c|c|c|c|c|}
\hline$C$ & $r$ & $C$ & $C$ & $C$ \\
\hline$C$ & $C$ & $r$ & $C$ & $r$ \\
\hline$C$ & $C$ & $r$ & $C$ & $r$ \\
\hline
\end{tabular}

113) Avalie o grau de dificuldade encontrada em cada etapa de operação do SINASC:

\begin{tabular}{|c|c|c|c|c|c|c|}
\hline & $\begin{array}{c}0 \text { - } \\
\text { Nenhuma } \\
\text { dificuldad } \\
\text { e }\end{array}$ & $\begin{array}{c}1 \text { - Baixa } \\
\text { dificulda } \\
\text { de }\end{array}$ & $\begin{array}{c}2 \text { - Média } \\
\text { dificulda } \\
\text { de }\end{array}$ & $\begin{array}{c}3 \text { - Alta } \\
\text { dificulda } \\
\text { de }\end{array}$ & $\begin{array}{c}4 \text { - Muito } \\
\text { alta } \\
\text { dificuldad } \\
\text { e }\end{array}$ & $\begin{array}{l}\text { Não } \\
\text { se } \\
\text { aplic } \\
\text { a }\end{array}$ \\
\hline $\begin{array}{l}\text { 114) } \\
\text { Distribuição dos } \\
\text { formulários: * }\end{array}$ & $C$ & $C$ & $C$ & 0 & $C$ & $C$ \\
\hline $\begin{array}{l}\text { 115) } \\
\text { Preenchimento } \\
\text { das DNVs: * }\end{array}$ & $C$ & $C$ & $C$ & 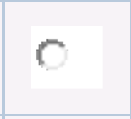 & $C$ & 0 \\
\hline $\begin{array}{l}\text { 116) } \\
\text { Coleta/captação } \\
\text { das DNVs: * }\end{array}$ & $C$ & $C$ & $C$ & $C$ & $C$ & 0 \\
\hline $\begin{array}{l}\text { 117) Codificação } \\
\text { das anomalias } \\
\text { congênitas: * }\end{array}$ & 0 & 0 & 0 & 0 & 0 & $C$ \\
\hline $\begin{array}{l}\text { 118) Instalação } \\
\text { do sistema no } \\
\text { computador: * }\end{array}$ & 0 & 0 & 0 & 0 & $C$ & 0 \\
\hline 119) Digitação: & 0 & $C$ & $C$ & $C$ & $C$ & 0 \\
\hline $\begin{array}{l}\text { 120) Falhas } \\
\text { operacionais da } \\
\text { ferramenta na } \\
\text { digitação } \\
\text { (travamento): * }\end{array}$ & $C$ & $C$ & $C$ & $C$ & $C$ & $C$ \\
\hline $\begin{array}{l}\text { 121) Checagem } \\
\text { de inconsistência } \\
\text { dos dados } \\
\text { digitados: * }\end{array}$ & 0 & $C$ & $C$ & $C$ & 0 & $C$ \\
\hline $\begin{array}{l}\text { 122) } \\
\text { Fechamento e } \\
\text { transmissão de } \\
\text { lotes: * }\end{array}$ & $C$ & $C$ & 0 & 0 & 0 & 0 \\
\hline $\begin{array}{l}\text { 123) Geração } \\
\text { de indicadores: * }\end{array}$ & $C$ & $C$ & $C$ & $C$ & 0 & $C$ \\
\hline
\end{tabular}

\section{Disseminação de Dados:}

124) O Secretário de Saúde municipal solicita relatório com os dados/informações do sistema? *
Não
S. Sim, com periodicidade Mensal 
r.

Sim, com periodicidade Trimestral

Sim, com periodicidade Quadrimestral

r

Sim, com periodicidade Anual

S Sim sempre que necessário, sem periodicidade definida

125) Aponte as três áreas que mais solicitam dados /informações do SIM, no município: *

- Atenção Básica

- Área de saúde da criança

— Área de saúde da mulher

- Área de saúde do adulto

Comitê de mortalidade materna e infantil

- Área de planejamento de ações de saúde

- Imprensa ou mídia local

- Secretário de Saúde

ए Prefeito

Conselho municipal de saúde

Não sei

ए Outros

127) Aponte as três áreas que mais solicitam dados/informações do SINASC, no município: *

Atenção Básica

- Área de saúde da criança

- Área de saúde da mulher

- Comitê de mortalidade materna e infantil

- Área de planejamento de ações de saúde

Г Imprensa ou mídia local

\Secretário de Saúde

ए Prefeito

ए Conselho municipal de saúde

ए Não sei

ए Outros

129) Indique quais os principais usos das informações de mortalidade geradas pelo município: * 


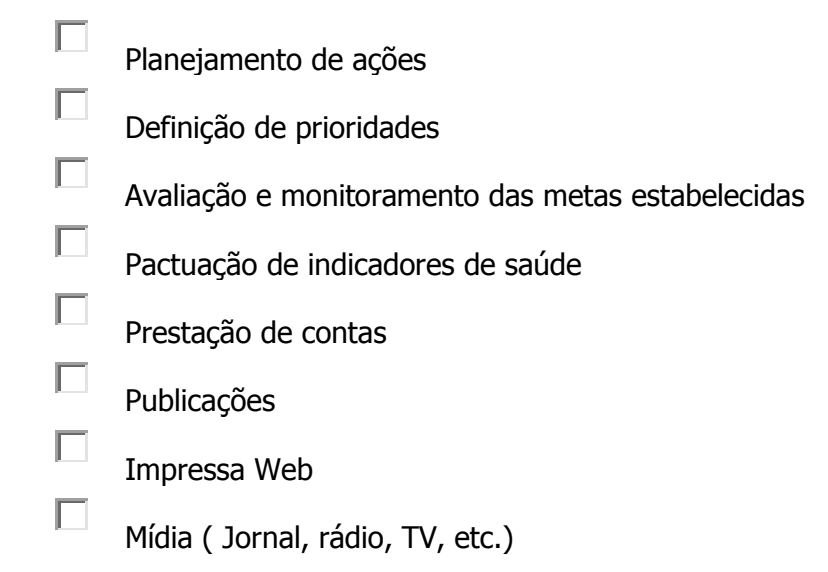

130) Indique quais os principais usos das informações de nascimentos geradas pelo município: *

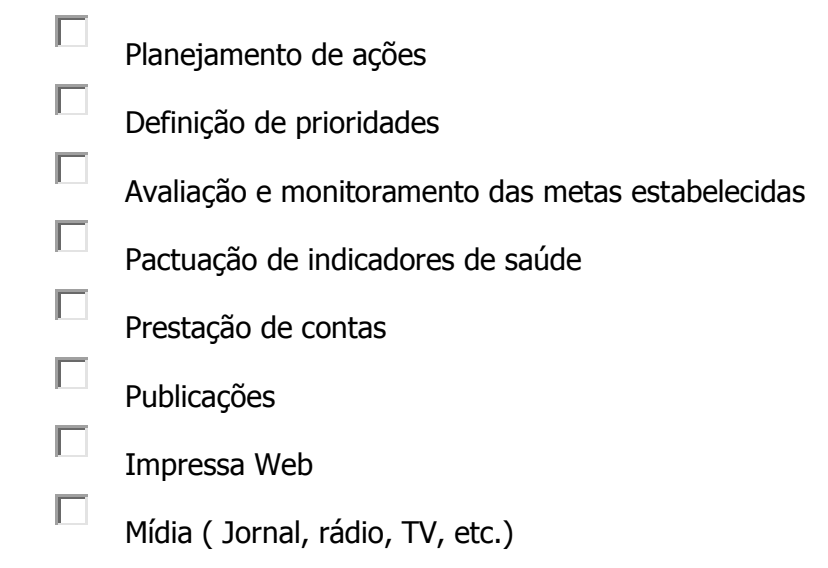

\section{Avaliação}

131) Avalie o benefício ocorrido com a descentralização do SIM para o município:

\begin{tabular}{|c|c|c|c|c|c|}
\hline & $\begin{array}{c}0 \text { - } \\
\text { Nenhum } \\
\text { beneficio }\end{array}$ & $\begin{array}{c}1- \\
\text { Baixo } \\
\text { benefici } \\
0\end{array}$ & $\begin{array}{c}2 \text { - } \\
\text { Médio } \\
\text { benefici } \\
0\end{array}$ & $\begin{array}{c}3 \text { - Alto } \\
\text { benefici } \\
0\end{array}$ & $\begin{array}{l}4 \text { - Muito } \\
\text { alto } \\
\text { beneficio }\end{array}$ \\
\hline $\begin{array}{l}\text { 132) Aumento da } \\
\text { captação de óbitos: * }\end{array}$ & $C$ & $C$ & $C$ & 0 & 0 \\
\hline $\begin{array}{l}\text { 133) Disponibilidade de } \\
\text { dados em tempo real: } *\end{array}$ & $C$ & $C$ & $C$ & $C$ & 0 \\
\hline $\begin{array}{l}\text { 134) Melhoria da } \\
\text { qualidade da informação: } \\
\text { * }\end{array}$ & $C$ & $C$ & $C$ & $C$ & $C$ \\
\hline $\begin{array}{l}\text { 135) Construção dos } \\
\text { principais indicadores de } \\
\text { saúde: } *\end{array}$ & 0 & $C$ & $C$ & $C$ & 0 \\
\hline $\begin{array}{l}\text { 136) Agilização da } \\
\text { vigilância em saúde: * }\end{array}$ & 0 & 0 & 0 & 0 & $C$ \\
\hline $\begin{array}{l}\text { 137) Permitir tomada de } \\
\text { decisões imediatas: } *\end{array}$ & $C$ & $C$ & $C$ & $C$ & $C$ \\
\hline $\begin{array}{l}\text { 138) Autonomia na } \\
\text { gestão do SIM: * }\end{array}$ & 0 & 0 & $C$ & 0 & 0 \\
\hline
\end{tabular}


139) Acesso rápido às informações de óbitos de residentes ocorridos em outros municípios : *

140) Responsabilização do gestor de saúde local: *

141) Disseminação da informação: *

\section{2) Avalie o benefício ocorrido com a descentralização do} SINASC para o município:

\begin{tabular}{|c|c|c|c|c|c|}
\hline & $\begin{array}{c}0 . \\
\text { Nenhum } \\
\text { beneficio }\end{array}$ & $\begin{array}{c}\text { 1. Baixo } \\
\text { benefici } \\
0\end{array}$ & $\begin{array}{l}\text { 2. Médio } \\
\text { benefici } \\
0\end{array}$ & $\begin{array}{l}\text { 3. Alto } \\
\text { benefici } \\
0\end{array}$ & $\begin{array}{l}\text { 4. Muito } \\
\text { alto } \\
\text { beneficio }\end{array}$ \\
\hline $\begin{array}{l}\text { 143) Aumento da } \\
\text { captação de nascimentos: } \\
\text { * }\end{array}$ & $C$ & $C$ & $C$ & $C$ & $C$ \\
\hline $\begin{array}{l}\text { 144) Melhoria da } \\
\text { qualidade da informação: } \\
\text { * }\end{array}$ & $C$ & $C$ & $C$ & $C$ & $C$ \\
\hline $\begin{array}{l}\text { 145) Disponibilidade de } \\
\text { dados em tempo real: } *\end{array}$ & 0 & $C$ & $C$ & $C$ & $C$ \\
\hline $\begin{array}{l}\text { 146) Construção dos } \\
\text { principais indicadores de } \\
\text { saúde: * }\end{array}$ & $C$ & $C$ & 0 & $C$ & $C$ \\
\hline $\begin{array}{l}\text { 147) Agilização da } \\
\text { vigilância em saúde: * }\end{array}$ & $C$ & $C$ & $C$ & $C$ & $C$ \\
\hline $\begin{array}{l}\text { 148) Permitir tomada de } \\
\text { decisões imediatas: } *\end{array}$ & 0 & $C$ & $C$ & $C$ & $C$ \\
\hline $\begin{array}{l}\text { 149) Autonomia na } \\
\text { gestão do SINASC: * }\end{array}$ & $C$ & $C$ & $C$ & $C$ & $C$ \\
\hline $\begin{array}{l}\text { 150) Acesso rápido às } \\
\text { informações de } \\
\text { nascimentos de residentes } \\
\text { ocorridos em outros } \\
\text { municípios : * }\end{array}$ & 0 & $C$ & $C$ & $C$ & $C$ \\
\hline $\begin{array}{l}\text { 151) Responsabilização } \\
\text { do gestor de saúde local: } \\
\text { * }\end{array}$ & $C$ & $C$ & $C$ & $C$ & $C$ \\
\hline $\begin{array}{l}\text { 152) Disseminação da } \\
\text { informação: * }\end{array}$ & $C$ & $C$ & $C$ & $C$ & $C$ \\
\hline
\end{tabular}

\section{3) Caso deseje, inclua comentários adicionais:}

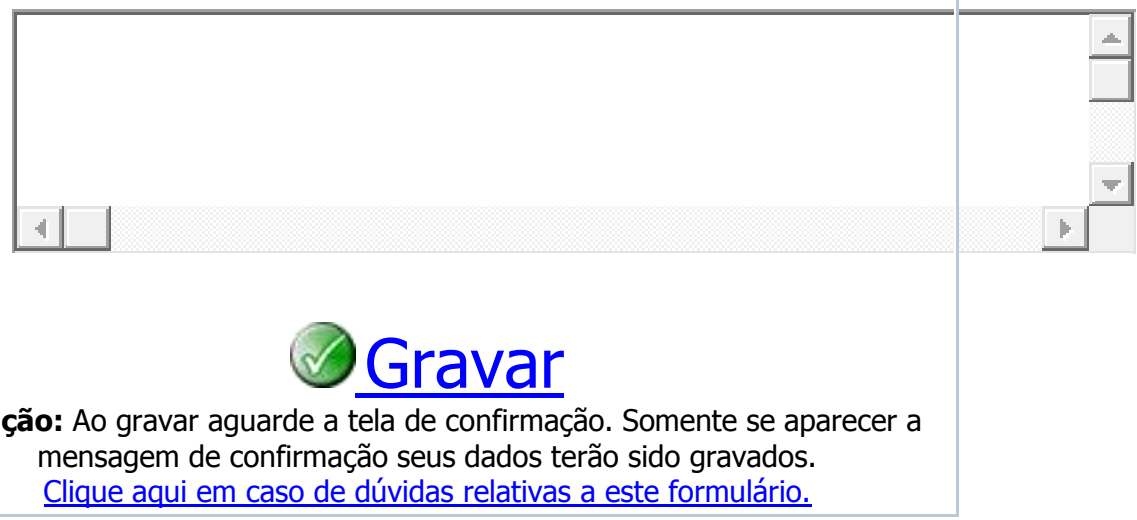


Anexo V: Questionário SIM

\begin{tabular}{l} 
Acesso \\
\hline Cmartinez@saude. \\
sp.gov.br \\
\hline Sair \\
\hline Opções \\
\hline Dados Pessoais \\
\hline Formulários \\
\hline Campos \\
\hline Notícia \\
\hline Cores e Estilos \\
\hline LOG \\
\hline FormSus \\
\hline$\underline{\text { Sobre FormSus }}$ \\
\hline Manual
\end{tabular}

Questionário de Formulário | Resultado | Busca Ficha | Altera Ficha | Pesquisa 2 SIM Imprimir Formuláric

\section{(?)}

BEM VINDOS!

Antes de mais nada, muito obrigada pela oportunidade de apresentar o projeto. Meu nome é CÁTIA MARTINEZ, sou aluna no mestrado do Programa de Pós-Graduação da Faculdade de Saúde Pública (FSP) da Universidade de São Paulo (USP).

Você está sendo convidada (o) a participar da pesquisa que integra o projeto de "Descentralização dos Sistemas de Informação em Saúde nos Municípios do Estado de São Paulo".

O questionário é de fácil preenchimento, com uma duração média de 20 minutos. Por favor, leia o Termo de Consentimento Livre e Esclarecido antes de iniciar o preenchimento.

\section{TERMO DE CONSENTIMENTO LIVRE E ESCLARECIDO}

Prezado (a) Senhor (a):

Você está sendo convidado (a) como voluntário (a) a participar da pesquisa sobre Diagnóstico Situacional do Sistema de Informação sobre Mortalidade e Nascidos Vivos nos municípios do Estado de São Paulo. O motivo que nos leva a estudar o sistema de informações de mortalidade (SIM) e o sistema de informações de nascidos vivos (SINASC) é a importância das Estatísticas de Saúde como subsídio para planejamento de ações e tomadas de decisão. O objetivo desse projeto é conhecer as características estruturais (recursos humanos, infraestrutura, informática), processo de trabalho e uso das informações na gestão nos municípios do Estado do São Paulo. Com isso pretende-se gerar novos conhecimentos que possibilitem ações para o aprimoramento desses sistemas de informações. 
Assim, esclarecemos que sua participação é de extrema importância, a fim de contribuir para construção de evidências científicas referentes a este tema.

Você será esclarecido (a) sobre a pesquisa em qualquer aspecto que desejar e é livre para recusar-se a participar, retirar seu consentimento ou interromper a participação a qualquer momento. A sua participação é voluntária e a recusa em participar não irá acarretar problema de qualquer natureza.

Os pesquisadores irão tratar a sua identidade com padrões profissionais de sigilo. Os resultados da pesquisa serão disponibilizados de forma agregada, sem identificação do respondente ou do município e permanecerão confidenciais. Você não será identificado (a) em nenhuma publicação que possa resultar deste estudo. Uma cópia deste consentimento poderá ser impresso ao final do preenchimento do questionário.

A participação no estudo não acarretará custos para você e não será disponível nenhuma compensação financeira adicional.

Este é um projeto em parceria entre a Secretaria de Estado da Saúde de São Paulo e a Faculdade de Saúde Pública da USP, com apoio do Conselho Nacional de Desenvolvimento Científico e Tecnológico - CNPq.

Em caso de dúvidas, você poderá chamar a estudante Cátia Martinez Minto ou a professora orientadora, nos telefones (11) 99666-6094, (11) 30617930 ou no Comitê de Ética em Pesquisa da Faculdade de Saúde Pública da Universidade de São Paulo, sito à Av. Dr. Arnaldo, 715, Cerqueira César - São Paulo, SP, no telefone (11) 3066-7779.

"Eu fui informado (a) dos objetivos da pesquisa acima de maneira clara e detalhada e esclareci minhas dúvidas. Sei que, em qualquer momento, poderei solicitar novas informações e modificar minha decisão se assim o desejar. A professora orientadora Dra. Zilda Pereira da Silva, da Universidade de São Paulo, Faculdade de Saúde 
Pública, certifica-me de que todos os dados desta pesquisa serão confidenciais.

Declaro que concordo em participar desse estudo. Recebi uma cópia deste termo de consentimento livre e esclarecido e me foi dada a oportunidade de ler e esclarecer as minhas dúvidas."

* Preenchimento Obrigatório

Clique aqui em caso de dúvidas relativas a este formulário.

1) Declaro que concordo em participar desse estudo: *

Aceito

Identificação do Respondente

2) Qual GVE pertence? *

3) Município:

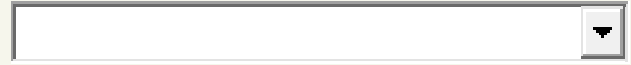

4) Nome: *

Informe ddd e número - apenas números

6) E-mail: *

7) Sexo: *
Masculino
C. Feminino

8) Idade: *

Anos

9) Escolaridade: *

Ensino Fundamental incompleto

C

Ensino Fundamental completo

C

Ensino Médio incompleto

C

Ensino Médio completo 


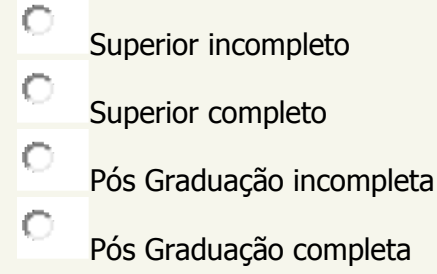

11) Vínculo: *

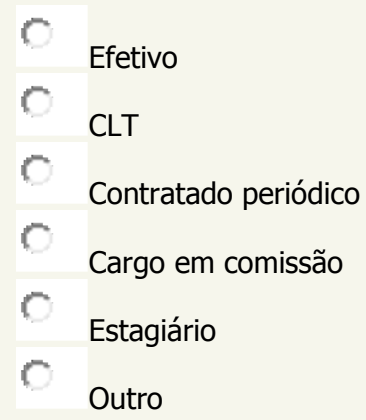

13) Qual a sua função? *

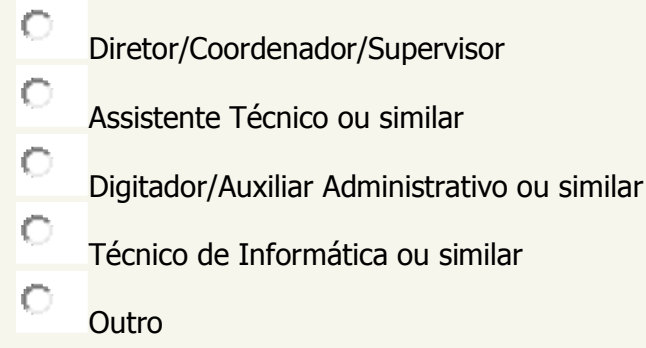

15) Há quanto tempo o Sr.(a) trabalha no setor público da área de saúde? *
menos de 6 meses
(2)
6 a 11 meses
1 ano
(C) 2 anos
(C) 3 anos ou mais

16) O Sr.(a) é responsável por outros sistemas? : *

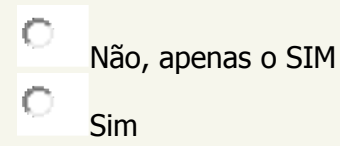

18) Há quanto tempo o Sr.(a) trabalha com o SIM ? *
C menos de 6 meses
r 6 a 11 meses
r 1 ano
2 anos 


\section{(1) 3 anos ou mais}

19) O Sr.(a) assinou o Termo de Confidencialidade e Sigilo, para trabalhar com os Sistemas de Informações de Mortalidade? ${ }^{*}$

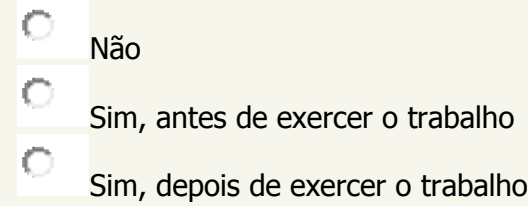

Estrutura

20) Em qual setor está alocado o SIM ? : *

Unidade de saúde

C.

Vigilância epidemiológica

Setor de atenção básica

Setor de Informações da SMS

(C)

Gabinete do secretário

(C)

Setor fora da Secretaria Municipal de Saúde. Qual?

C

Outro. Especifique:

23) Indique quantas pessoas trabalhavam no TOTAL no Sistema SIM, em 31/12/2014: : *

completar em números e utilizar o 0 (zero) para nenhum

24) Indique quantas pessoas, de nível superior de formação da área de saúde, trabalhavam no Sistema SIM, em 31/12/2014: * completar em números e utilizar o 0 (zero) para nenhum

25) Indique quantas pessoas, de outra área de Nível Superior de formação trabalhavam no Sistema SIM, em 31/12/2014: * completar em números e utilizar o 0 (zero) para nenhum

26) Indique quantas pessoas, de Nível Técnico ou ensino médio trabalhavam no Sistema SIM, em 31/12/2014: *

completar em números e utilizar o 0 (zero) para nenhum

27) Indique quantas pessoas, de Nível Fundamental trabalhavam no Sistema SIM, em 31/12/2014: *

completar em números e utilizar o 0 (zero) para nenhum

28) Indique as atividades que o Sr.(a) e/ou sua equipe realizam: 


\begin{tabular}{|l|l|l|l|}
\hline & ) & e & realiza \\
\hline 29) Distribuição e controle de impressos da DO : * & $\Gamma$ & $\Gamma$ & $\Gamma$ \\
\hline 30) Digitação: * & $\Gamma$ & $\Gamma$ & $\Gamma$ \\
\hline $\begin{array}{l}\text { 31) Backup, retroalimentação, arquivos de } \\
\text { transferências e outros: * }\end{array}$ & $\Gamma$ & $\Gamma$ & $\Gamma$ \\
\hline $\begin{array}{l}\text { 32) Cancelamento de impressos de DO no } \\
\text { sistema: * }\end{array}$ & $\Gamma$ & $\Gamma$ & $\Gamma$ \\
\hline $\begin{array}{l}\text { 33) Classificação e codificação de doenças: * } \\
\text { 34) Digitação de ficha de investigação } \\
\text { epidemiológica no sistema: * }\end{array}$ & $\Gamma$ & $\Gamma$ & $\Gamma$ \\
\hline 35) Elaboração de indicadores: * & $\Gamma$ & $\Gamma$ & $\Gamma$ \\
\hline 36) Análise dos dados: * & $\Gamma$ & $\Gamma$ & $\Gamma$ \\
\hline $\begin{array}{l}\text { 37) Participação do Comitê de Investigação de } \\
\text { Morte Materna e Infantil: * }\end{array}$ & $\Gamma$ & $\Gamma$ & $\Gamma$ \\
\hline
\end{tabular}

38) Indique quantas pessoas atuavam na Digitação, em 31/12/2014: *

completar em números e utilizar o 0 (zero) para nenhum

39) Indique quantas pessoas atuavam na Classificação e codificação de doenças, em 31/12/2014: *

completar em números e utilizar o 0 (zero) para nenhum

40) Em quantos computadores está instalado o Sistema SIM ? * completar em números

41) Indique qual o sistema operacional que esta instalado no(s) computador(es) que opera o SIM: : *

Para saber clicar em Painel de Controle e depois em Sistemas

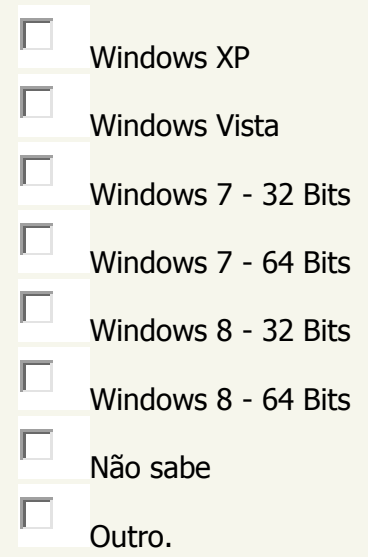

43) Nestes computadores, há outros sistemas de informação de saúde instalados? *

C

Não Sabe 


$$
\begin{aligned}
& \text { N. Não } \\
& \text { Sim }
\end{aligned}
$$

45) Há conexão com internet nos computadores que operam o SIM? : *

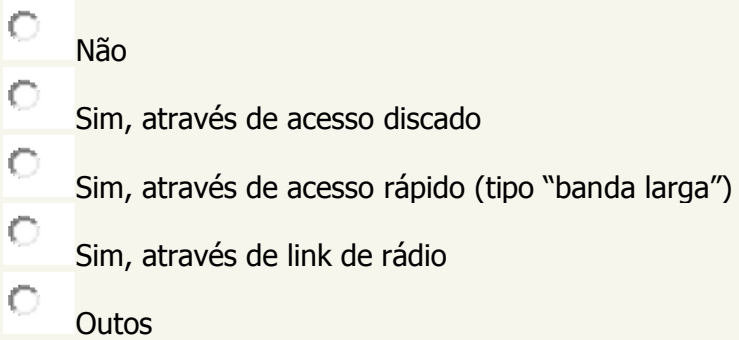

47) Há impressora para uso do SIM? : *

$$
\begin{array}{l|l}
\text { (C) Não } \\
\text { S Sim, de uso exclusivo } \\
\text { Sim, de uso coletivo }
\end{array}
$$

48) Existe computador para backup dos dados do sistema SIM?
Não Sabe
(C) Não
(C) Sim

49) $\mathbf{O}$ (s) computador(es) de backup do SIM armazenam dados de outros sistemas? : *

$$
\begin{array}{l|l}
\text { C Não Sabe } \\
\text { Não } \\
\text { Sim }
\end{array}
$$

51) O município dispõe de suporte técnico de informática? *

$$
\begin{array}{l|l}
\text { Não } \\
\text { C Sim, serviço próprio } \\
\text { Sim, serviço tercerizado }
\end{array}
$$

52) Este serviço é de fácil acesso? *
(C) Não
(C) Sim

53) Este serviço é resolutivo? *

C Não 


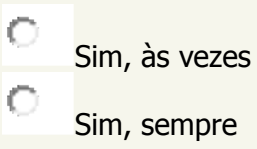

54) Em que local são guardados os impressos de DO em branco? Almoxarifado junto com outros itens

Armário sem chave e em sala aberta

Armário sem chave e em sala fechada

Armário com chave e em sala aberta

Armário com chave e em sala fechada

Outro

56) Avalie a disponibilidade de materiais para operar o sistema SIM: :

\begin{tabular}{|c|c|c|}
\hline & Sufici & Insufic \\
\hline 57) CD/DVD/pen-drive: * & $C$ & $C$ \\
\hline 58) Telefone: * & $C$ & $C$ \\
\hline 59) Computador: * & $C$ & $C$ \\
\hline 60) Impressora: * & $C$ & $C$ \\
\hline 61) Tinta para impressora: * & $C$ & $C$ \\
\hline 62) Impressos da DO: * & $C$ & $C$ \\
\hline
\end{tabular}

63) Avalie a disponibilidade de outros materiais para operar o sistema SIM: :

Descreve o material e indique se for suficiente ou insuficiente.

\section{Capacitação Profissional}

64) $\mathbf{O}$ (a) Sr.(a) e/ou sua equipe receberam treinamento institucional para trabalhar com o sistema SIM? : *

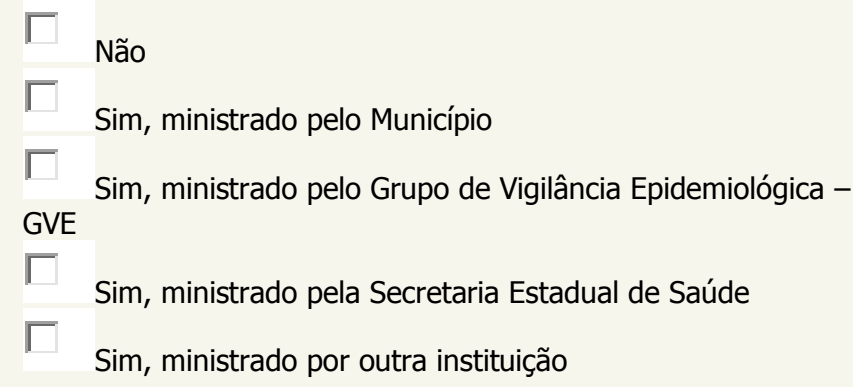

66) Do total de integrantes da equipe, quantos foram treinados nos últimos dois anos? $*$

número de profissionais treinados, completar em números e utilizar o 0 (zero) para nenhum 
67) Indique o(s) tipo(s) de treinamento(s) recebido(s), sobre o Sistema Operacional, nos dois últimos anos: *

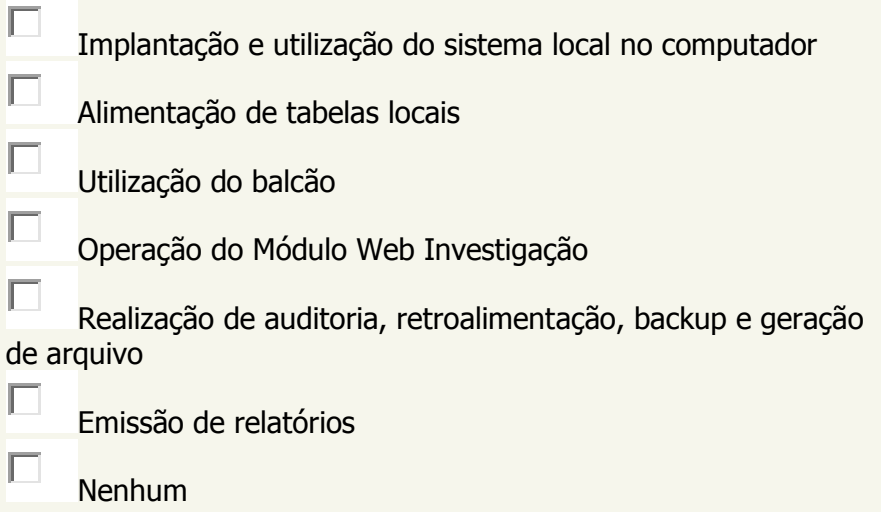

68) Indique o(s) tipo(s) de treinamento(s) recebido(s), sobre SIM, nos dois últimos anos: : * Captação de óbitos Preenchimento da declaração de óbito Codificação das causas de morte (CID-10) Controle de estoque de impressos de DO Análise dos dados<smiles>[Tl]</smiles>
Nenhum

69) No último ano, a Secretaria Municipal de Saúde realizou treinamento para profissionais das unidades de saúde, para preenchimento da DO? *

Não

Sim, para Médicos

$\Gamma$ Sim para Enfermeiros

Cim para Escriturários do setor de admissão hospitalar/SAME Sim para Outros profissionais

Processo de Trabalho

70) Indique o tipo de controle realizado na entrega dos impressos de DO para os estabelecimentos de saúde/profissionais: : * Não é utilizado nenhum instrumento

r Memorando/ofício

C. Folha de remessa ou recibo 


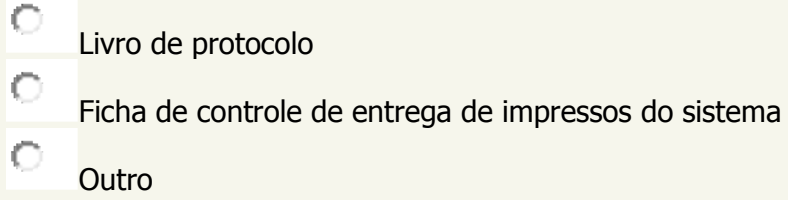

72) Indique qual o local que os profissionais retiram DO nos finais de semanas e feriados, quando necessário: :

$\Gamma$ Nenhum, a retirada ocorre apenas durante a semana

Em hospital ou pronto socorro

- Na Secretaria Municipal de Saúde

No cartório

Г Na funerária

$\Gamma$ Outro

74) Indique as instituições que enviam para a SMS a via branca da DO, de óbitos ocorridos em estabelecimentos de saúde: *

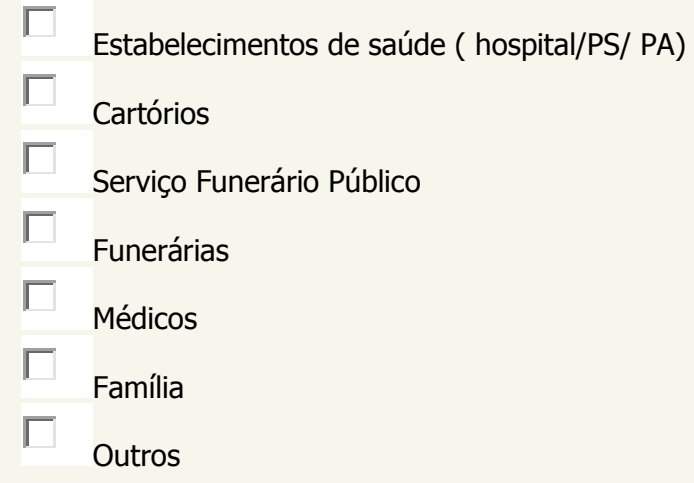

75) Indique as instituições que enviam para SMS a via branca preenchida da DO, de óbitos domiciliares: *

Estabelecimentos de saúde (hospital/PS/ PA)

Cartórios

Serviço Funerário Público

$\Gamma$

Funerárias

Médicos

Família

Г Outros

76) 0 município realiza busca ativa de óbitos? *

กão

- Sim, em Estabelecimentos de saúde

Sim, em Cartórios 
Sim, em IML/SVO

Sim, em Delegacia

Sim, em Cemitérios Sim, em Equipe de Saúde da Família

Sim, em Outros locais

78) $O$ município utiliza o Módulo WEB de investigação? *

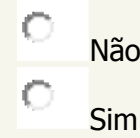

79) Ao se deparar com alguma dúvida na operação do SIM, com quem a equipe busca auxílio? : *

Colegas de equipe

Equipe de informação municipal

Colegas de outros municípios

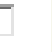

Equipe do Grupo de Vigilância Epidemiológica -- GVE

Equipe da Secretaria Estadual de Saúde - CCD

Profissionais do Ministério da Saúde

$\Gamma$

Fórum eletrônico de dúvidas do SIM

ए Manuais e orientações técnicas

$\Gamma$ Não tem com quem esclarecer

Gestão

80) É realizado algum procedimento ao identificar que o volume mensal de eventos registrados no SIM está abaixo do esperado? *

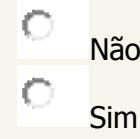

82) Algum técnico/profissional revisa as DOs antes de digitar, a fim de identificar campos em branco (sem preenchimento) e/ou preenchimento incorreto? *

$$
\text { (C) Não }
$$

83) Ao detectar problemas, é feito algum procedimento? *<smiles>[Mg][Mg]</smiles> 


\section{(C) Sim}

85) O município utiliza os relatórios do sistema para gerar indicadores? $*$

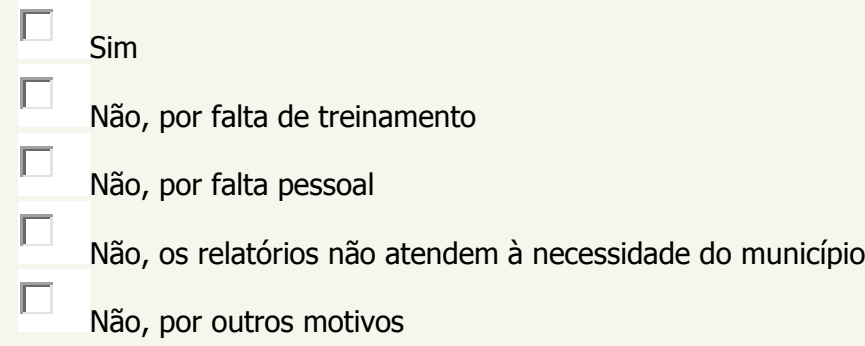

87) Os indicadores de óbitos gerados no sistema atendem às necessidades do município?

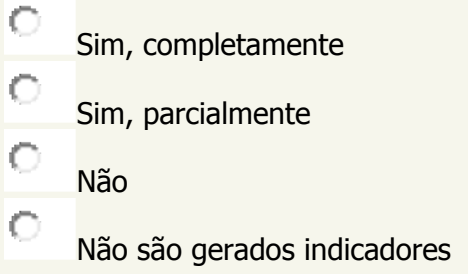

88) A equipe utiliza o Tabwin do sistema SIM? : *

Não

「 Sim, utiliza funções básicas

Sim, utiliza módulo de mapas e gráficos

- Sim, utiliza ferramenta de mapa de fluxo origem-destino

Г Sim, utiliza interface Tabwin - SQL

89) Avalie o grau de dificuldade encontrado em cada etapa de operação do SIM:

\begin{tabular}{|c|c|c|c|c|c|}
\hline & $\begin{array}{c}0- \\
\text { Nenhuma } \\
\text { dificuldad } \\
\text { e }\end{array}$ & $\begin{array}{c}1 \text { - Baixa } \\
\text { dificuldad } \\
\mathrm{e}\end{array}$ & $\begin{array}{c}2 \text { - Média } \\
\text { dificuldad } \\
\mathrm{e}\end{array}$ & $\begin{array}{c}3 \text { - Alta } \\
\text { dificuldad } \\
\mathrm{e}\end{array}$ & $\begin{array}{l}4 \text { - Muito } \\
\text { alta } \\
\text { dificuldad } \\
\text { e }\end{array}$ \\
\hline $\begin{array}{l}\text { 90) Distribuição } \\
\text { dos formulários: * }\end{array}$ & 0 & 0 & 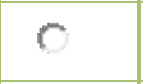 & $C$ & 0 \\
\hline $\begin{array}{l}\text { 91) } \\
\text { Preenchimento } \\
\text { das DOs: } *\end{array}$ & $C$ & $C$ & $C$ & 0 & $C$ \\
\hline $\begin{array}{l}\text { 92) } \\
\text { Coleta/captação } \\
\text { das DOs: * }\end{array}$ & $C$ & 0 & $C$ & 0 & $C$ \\
\hline $\begin{array}{l}\text { 93) Codificação } \\
\text { das causas de } \\
\text { morte: } *\end{array}$ & $C$ & $C$ & 0 & 0 & $C$ \\
\hline $\begin{array}{l}\text { 94) Instalação do } \\
\text { sistema no } \\
\text { computador: * }\end{array}$ & 0 & $C$ & $C$ & $C$ & $C$ \\
\hline
\end{tabular}




\begin{tabular}{|c|c|c|c|c|c|}
\hline 95) Digitação: * & $C$ & $C$ & $C$ & $C$ & $r$ \\
\hline $\begin{array}{l}\text { 96) Falhas } \\
\text { operacionais da } \\
\text { ferramenta na } \\
\text { digitação } \\
\text { (travamento): * }\end{array}$ & $C$ & $C$ & $C$ & $C$ & $r$ \\
\hline $\begin{array}{l}\text { 97) Checagem de } \\
\text { inconsistência dos } \\
\text { dados digitados: } \\
*\end{array}$ & $C$ & $C$ & $C$ & $C$ & $r$ \\
\hline $\begin{array}{l}\text { 98) Fechamento } \\
\text { e transmissão de } \\
\text { lotes: } *\end{array}$ & $C$ & $C$ & $C$ & $C$ & $C$ \\
\hline $\begin{array}{l}\text { 99) Geração de } \\
\text { indicadores: * }\end{array}$ & $C$ & $C$ & 0 & 0 & $C$ \\
\hline
\end{tabular}

Disseminação de Dados:

100) O Secretário de Saúde municipal solicita relatório com os dados/informações do sistema? *

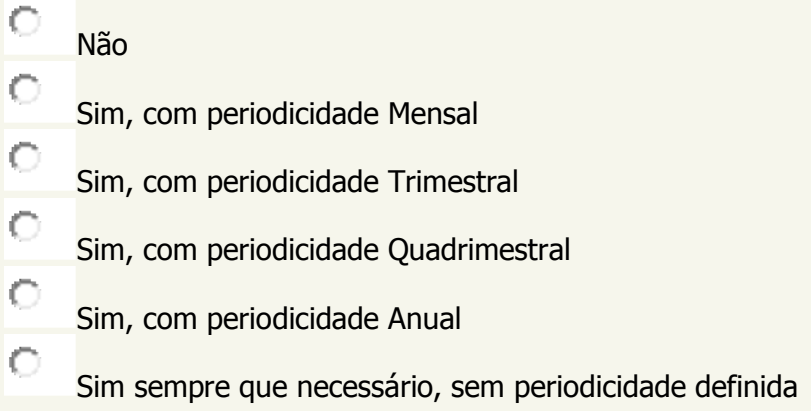

101) Aponte as três áreas que mais solicitam dados /informações do SIM, no município: * Atenção Básica

Área de saúde da criança

Área de saúde da mulher

Área de saúde do adulto Comitê de mortalidade materna e infantil Área de planejamento de ações de saúde Imprensa ou mídia local

Г Secretário de Saúde

ए Prefeito

Conselho municipal de saúde

$\Gamma$ Não sei

Г Outros 
103) Indique quais os principais usos das informações de mortalidade geradas pelo município: *

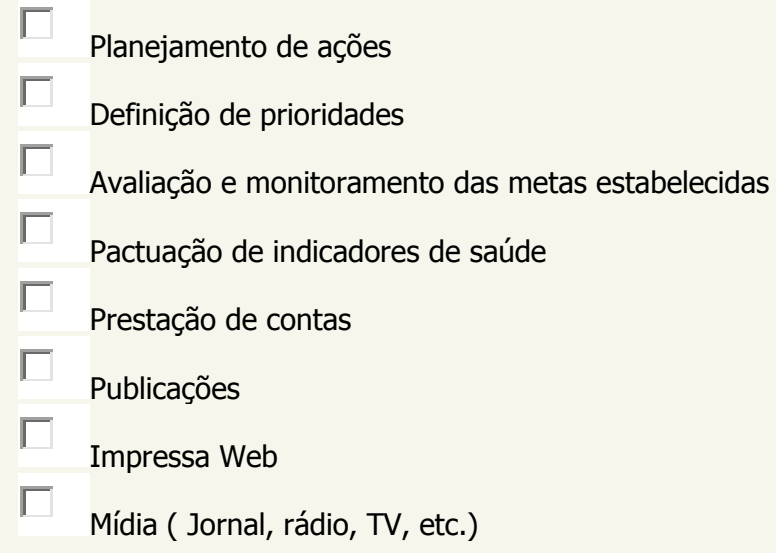

\section{Avaliação}

104) Avalie o benefício ocorrido com a descentralização do SIM para o município:

\begin{tabular}{|c|c|c|c|c|c|}
\hline & $\begin{array}{c}0- \\
\text { Nenhum } \\
\text { beneficio }\end{array}$ & $\begin{array}{c}1- \\
\text { Baixo } \\
\text { benefici } \\
0\end{array}$ & $\begin{array}{c}2- \\
\text { Médio } \\
\text { benefici } \\
0\end{array}$ & $\begin{array}{c}3 \text { - Alto } \\
\text { benefici } \\
0\end{array}$ & $\begin{array}{l}4 \text { - Muito } \\
\text { alto } \\
\text { beneficio }\end{array}$ \\
\hline $\begin{array}{l}\text { 105) Aumento da } \\
\text { captação de óbitos: * }\end{array}$ & $r$ & 0 & 0 & $C$ & $C$ \\
\hline $\begin{array}{l}\text { 106) Disponibilidade de } \\
\text { dados em tempo real: * }\end{array}$ & $r$ & $C$ & $C$ & 0 & $C$ \\
\hline $\begin{array}{l}\text { 107) Melhoria da } \\
\text { qualidade da } \\
\text { informação: * }\end{array}$ & $C$ & 0 & $C$ & 0 & $C$ \\
\hline $\begin{array}{l}\text { 108) Construção dos } \\
\text { principais indicadores } \\
\text { de saúde: * }\end{array}$ & $C$ & $C$ & 0 & 0 & 0 \\
\hline $\begin{array}{l}\text { 109) Agilização da } \\
\text { vigilância em saúde: * }\end{array}$ & $r$ & 0 & $C$ & $C$ & $C$ \\
\hline $\begin{array}{l}\text { 110) Permitir tomada } \\
\text { de decisões imediatas: } \\
*\end{array}$ & $C$ & $C$ & 0 & $C$ & 0 \\
\hline $\begin{array}{l}\text { 111) Autonomia na } \\
\text { gestão do SIM: } *\end{array}$ & $C$ & $C$ & $C$ & $c$ & $C$ \\
\hline $\begin{array}{l}\text { 112) Acesso rápido às } \\
\text { informações de óbitos } \\
\text { de residentes ocorridos } \\
\text { em outros municípios : } \\
*\end{array}$ & $C$ & 0 & $c$ & $C$ & $C$ \\
\hline $\begin{array}{l}\text { 113) Responsabilização } \\
\text { do gestor de saúde } \\
\text { local: * }\end{array}$ & 0 & $r$ & $C$ & 0 & $C$ \\
\hline $\begin{array}{l}\text { 114) Disseminação da } \\
\text { informação: * }\end{array}$ & $c$ & 0 & $C$ & $C$ & $C$ \\
\hline
\end{tabular}

115) Caso deseje, inclua comentários adicionais: * 
Anexo VI: Carta de apresentação da Pesquisa

CARTA DE APRESENTAÇÃO DA PESQUISA

Prezado (a) Senhor(a),

Sou aluna de pós-graduação - mestrado da Faculdade de Saúde Pública do Departamento de Epidemiologia - e apresento a pesquisa intitulada "Diagnóstico Situacional dos Sistemas de Informação de Nascidos Vivos e Mortalidade nos Municípios do Estado de São Paulo", cujo objetivo principal é conhecer condições estruturais e operacionais dos Sistemas de Informação de Nascidos Vivos (SINASC) e de Mortalidade (SIM) nos municípios do Estado de São Paulo, bem como dificuldades enfrentadas pelos municípios.

Espera-se gerar conhecimentos que possibilitem ações para o aprimoramento desses sistemas de informações a fim de contribuir com avanços no processo de descentralização.

O instrumento utilizado será um questionário eletrônico, dirigido aos Responsáveis Técnicos pelos Sistemas SIM e SINASC, o qual solicitamos responder até o dia 20 de abril de 2015 .

A participação de seu município nesta pesquisa é de fundamental importância, para responde-lo , por favor acessar o questionário pelo endereço eletrônico:

http://formsus.datasus.gov.br/site/formulario.php?id_aplicacao=18602

Desde já, eu e minha orientadora, Zilda Pereira da Silva, agradecemos sua preciosa colaboração, e coloco-me a disposição para quaisquer esclarecimentos ou o que for necessário pelo e-mail; catia.mm@gmail.com ou cmartinez@saude.sp.gov.br ou catia.mm@usp.br.

\section{Atenciosamente}

\section{Cátia Martinez}




\section{Anexo VII}

\section{Tabelas Complementares}


Tabela 1A - Número e proporção de responsáveis técnicos municipais do SIM, segundo escolaridade, tempo de trabalho na área de saúde e no SIM, por porte populacional do município, Estado de São Paulo, 2009.

\begin{tabular}{|c|c|c|c|c|c|c|c|c|}
\hline \multirow{3}{*}{ Variáveis } & \multicolumn{6}{|c|}{ Porte dos Municípios (habitantes) } & & \\
\hline & \multicolumn{2}{|c|}{ Até 30.000} & \multicolumn{2}{|c|}{$\begin{array}{c}\text { De } 30.001 \text { a } \\
200.000\end{array}$} & \multicolumn{2}{|c|}{$\begin{array}{c}\text { Maior que } \\
200.000\end{array}$} & \multicolumn{2}{|c|}{ Total } \\
\hline & $\mathrm{N}$ & $\%$ & $\mathrm{~N}$ & $\%$ & $\mathrm{~N}$ & $\%$ & $\mathrm{~N}$ & $\%$ \\
\hline \multicolumn{9}{|l|}{ Escolaridade } \\
\hline Ensino Fundamental completo & 6 & 1,48 & 4 & 2,84 & 0 & 0 & 10 & 1,71 \\
\hline Ensino Médio completo & 61 & 15,02 & 13 & 9,22 & 2 & 5,41 & 76 & 13,01 \\
\hline Superior incompleto & 20 & 4,93 & 14 & 9,93 & 3 & 8,11 & 37 & 6,34 \\
\hline Superior completo & 190 & 46,80 & 53 & 37,59 & 11 & 29,73 & 254 & 43,49 \\
\hline Pós Graduação incompleta & 11 & 2,71 & 1 & 0,71 & 2 & 5,41 & 14 & 2,40 \\
\hline Pós Graduação completa & 118 & 29,06 & 56 & 39,72 & 19 & 51,35 & 193 & 33,05 \\
\hline \multicolumn{9}{|c|}{ Tempo de trabalho na área de Saúde } \\
\hline Menos de 6 meses & 6 & 1,48 & 0 & 0,00 & 0 & 0,00 & 6 & 1,03 \\
\hline 6 a 11 meses & 14 & 3,45 & 1 & 0,71 & 0 & 0,00 & 15 & 2,57 \\
\hline 1 ano & 10 & 2,46 & 5 & 3,55 & 0 & 0,00 & 15 & 2,57 \\
\hline 2 anos & 22 & 5,42 & 6 & 4,26 & 1 & 2,70 & 29 & 4,97 \\
\hline 3 anos ou mais & 354 & 87,19 & 129 & 91,49 & 36 & 97,30 & 519 & 88,87 \\
\hline \multicolumn{9}{|l|}{ Tempo de trabalho no SIM } \\
\hline Menos de 6 meses & 18 & 4,43 & 1 & 0,71 & 1 & 2,70 & 20 & 3,42 \\
\hline 6 a 11 meses & 29 & 7,14 & 11 & 7,80 & 1 & 2,70 & 41 & 7,02 \\
\hline 1 ano & 46 & 11,33 & 13 & 9,22 & 2 & 5,41 & 61 & 10,45 \\
\hline 2 anos & 44 & 10,84 & 14 & 9,93 & 6 & 16,22 & 64 & 10,96 \\
\hline 3 anos ou mais & 269 & 66,26 & 102 & 72,34 & 27 & 72,97 & 398 & 68,15 \\
\hline Total & 406 & 100,00 & 141 & 100,00 & 37 & 100 & 584 & 100,00 \\
\hline
\end{tabular}


Tabela 2A - Número e proporção de responsáveis técnicos municipais do SIM, segundo formação no ensino superior, por porte populacional do município, Estado de São Paulo, 2009.

\begin{tabular}{|c|c|c|c|c|c|c|c|c|}
\hline \multirow{3}{*}{ Categorias } & \multicolumn{6}{|c|}{ Porte dos Municípios (habitantes) } & & \\
\hline & \multicolumn{2}{|c|}{ Até 30.000} & \multicolumn{2}{|c|}{$\begin{array}{c}\text { De 30.001 a } \\
200.000\end{array}$} & \multicolumn{2}{|c|}{$\begin{array}{l}\text { Maior que } \\
200.000\end{array}$} & \multicolumn{2}{|c|}{ Total } \\
\hline & $\mathbf{N}$ & $\%$ & $\mathbf{N}$ & $\%$ & $\mathbf{N}$ & $\%$ & $\mathbf{N}$ & $\%$ \\
\hline Enfermagem & 164 & 71,0 & 46 & 54,8 & 10 & 41,7 & 220 & 64,9 \\
\hline Adminstração & 9 & 3,9 & 2 & 2,4 & 3 & 12,5 & 14 & 4,1 \\
\hline Área Saúde sem especificação & 7 & 3,0 & 3 & 3,6 & 1 & 4,2 & 11 & 3,2 \\
\hline Medicina & 1 & 0,4 & 5 & 6,0 & 5 & 20,8 & 11 & 3,2 \\
\hline Gestão na área da Saúde & 6 & 2,6 & 2 & 2,4 & 0 & 0,0 & 8 & 2,4 \\
\hline Biologia/Ciências biológicas & 3 & 1,3 & 3 & 3,6 & 1 & 4,2 & 7 & 2,1 \\
\hline $\begin{array}{l}\text { Sistemas de informação/ ciências da computação/ } \\
\text { informatica }\end{array}$ & 5 & 2,2 & 2 & 2,4 & 0 & 0,0 & 7 & 2,1 \\
\hline Pedagogia & 5 & 2,2 & 0 & 0,0 & 1 & 4,2 & 6 & 1,8 \\
\hline Gestão Outros & 3 & 1,3 & 2 & 2,4 & 0 & 0,0 & 5 & 1,5 \\
\hline Assistente social & 1 & 0,4 & 1 & 1,2 & 1 & 4,2 & 3 & 0,9 \\
\hline Ciencias Contabeis & 1 & 0,4 & 2 & 2,4 & 0 & 0,0 & 3 & 0,9 \\
\hline Educação Fisica & 0 & 0,0 & 3 & 3,6 & 0 & 0,0 & 3 & 0,9 \\
\hline Farmácia e bioquimica & 3 & 1,3 & 0 & 0,0 & 0 & 0,0 & 3 & 0,9 \\
\hline Saúde Pública & 2 & 0,9 & 1 & 1,2 & 0 & 0,0 & 3 & 0,9 \\
\hline Técnicos área da saúde & 2 & 0,9 & 1 & 1,2 & 0 & 0,0 & 3 & 0,9 \\
\hline Técnicos outros & 2 & 0,9 & 1 & 1,2 & 0 & 0,0 & 3 & 0,9 \\
\hline Biomedicina & 1 & 0,4 & 1 & 1,2 & 0 & 0,0 & 2 & 0,6 \\
\hline Direito & 1 & 0,4 & 1 & 1,2 & 0 & 0,0 & 2 & 0,6 \\
\hline Economia & 1 & 0,4 & 1 & 1,2 & 0 & 0,0 & 2 & 0,6 \\
\hline Letras & 0 & 0,0 & 2 & 2,4 & 0 & 0,0 & 2 & 0,6 \\
\hline Matemática & 2 & 0,9 & 0 & 0,0 & 0 & 0,0 & 2 & 0,6 \\
\hline Outros & 1 & 0,4 & 1 & 1,2 & 0 & 0,0 & 2 & 0,6 \\
\hline Arquitetura e Urbanismo & 0 & 0,0 & 1 & 1,2 & 0 & 0,0 & 1 & 0,3 \\
\hline Biblioteconomia & 0 & 0,0 & 0 & 0,0 & 1 & 4,2 & 1 & 0,3 \\
\hline Ciencias fisicas & 1 & 0,4 & 0 & 0,0 & 0 & 0,0 & 1 & 0,3 \\
\hline Comunicação social & 1 & 0,4 & 0 & 0,0 & 0 & 0,0 & 1 & 0,3 \\
\hline Engenharia & 1 & 0,4 & 0 & 0,0 & 0 & 0,0 & 1 & 0,3 \\
\hline Filosofia & 1 & 0,4 & 0 & 0,0 & 0 & 0,0 & 1 & 0,3 \\
\hline Fisioterapia & 1 & 0,4 & 0 & 0,0 & 0 & 0,0 & 1 & 0,3 \\
\hline Geografia & 1 & 0,4 & 0 & 0,0 & 0 & 0,0 & 1 & 0,3 \\
\hline História & 1 & 0,4 & 0 & 0,0 & 0 & 0,0 & 1 & 0,3 \\
\hline Licenciatura em Ciências & 0 & 0,0 & 1 & 1,2 & 0 & 0,0 & 1 & 0,3 \\
\hline Logistica & 1 & 0,4 & 0 & 0,0 & 0 & 0,0 & 1 & 0,3 \\
\hline Medicina Veterinária & 1 & 0,4 & 0 & 0,0 & 0 & 0,0 & 1 & 0,3 \\
\hline Nutrição & 0 & 0,0 & 0 & 0,0 & 1 & 4,2 & 1 & 0,3 \\
\hline Psicologia & 1 & 0,4 & 0 & 0,0 & 0 & 0,0 & 1 & 0,3 \\
\hline Química & 0 & 0,0 & 1 & 1,2 & 0 & 0,0 & 1 & 0,3 \\
\hline Relações públicas & 0 & 0,0 & 1 & 1,2 & 0 & 0,0 & 1 & 0,3 \\
\hline Zootecnia & 1 & 0,4 & 0 & 0,0 & 0 & 0,0 & 1 & 0,3 \\
\hline Total & 231 & 100,0 & 84 & 100,0 & 24 & 100,0 & 339 & 100,0 \\
\hline
\end{tabular}


Tabela 3A - Número e proporção de responsáveis técnicos municipais do SIM, segundo atividades realizadas, por porte populacional do município, Estado de São Paulo, 2009.

\begin{tabular}{|c|c|c|c|c|c|c|c|c|}
\hline \multirow{3}{*}{ Atividades Realizadas } & \multicolumn{6}{|c|}{ Porte dos Municípios (habitantes) } & \multirow{2}{*}{\multicolumn{2}{|c|}{ Total }} \\
\hline & \multicolumn{2}{|c|}{ Até 30.000 } & \multicolumn{2}{|c|}{ De 30.001 a } & \multicolumn{2}{|c|}{ Maior que } & & \\
\hline & $\mathrm{N}$ & $\%$ & $\mathrm{~N}$ & $\%$ & $\mathrm{~N}$ & $\%$ & $\mathrm{~N}$ & $\%$ \\
\hline Distribuição e controle de impressos da DO & 353 & 86,95 & 141 & 100,00 & 37 & 100,00 & 531 & 90,92 \\
\hline Digitação & 405 & 99,75 & 141 & 100,00 & 37 & 100,00 & 583 & 99,83 \\
\hline $\begin{array}{l}\text { Backup, retroalimentação, arquivos de } \\
\text { transferências e outros }\end{array}$ & 401 & 98,77 & 141 & 100,00 & 37 & 100,00 & 579 & 99,14 \\
\hline $\begin{array}{l}\text { Cancelamento de impressos de DO no } \\
\text { sistema }\end{array}$ & 374 & 92,12 & 139 & 98,58 & 34 & 91,89 & 547 & 93,66 \\
\hline Digitação de ficha de investigação & & & & & & & & \\
\hline epidemiológica no sistema & 391 & 96,31 & 134 & 95,04 & 32 & 86,49 & 557 & 95,38 \\
\hline Elaboração de indicadores & 299 & 73,65 & 123 & 87,23 & 34 & 91,89 & 456 & 78,08 \\
\hline Análise dos dados & 328 & 80,79 & 129 & 91,49 & 32 & 86,49 & 489 & 83,73 \\
\hline Participação do Comitê de Investigação de & & & & & & & & \\
\hline Morte Materna e Infantil & 267 & 65,76 & 121 & 85,82 & 31 & 83,78 & 419 & 71,75 \\
\hline Total & 406 & 100,00 & 141 & 100,00 & 37 & 100,00 & 584 & 100,00 \\
\hline
\end{tabular}

Tabela 4A - Número e proporção de municípios, segundo a utilização do Tabwin do sistema, por porte populacional do município, Estado de São Paulo, 2009.

\begin{tabular}{|c|c|c|c|c|c|c|c|c|}
\hline \multirow{3}{*}{ Tipo de Uso do Tabwin } & \multicolumn{6}{|c|}{ Porte dos Municípios (habitantes) } & \multirow{2}{*}{\multicolumn{2}{|c|}{ Total }} \\
\hline & \multicolumn{2}{|c|}{ Até $\mathbf{3 0 . 0 0 0}$} & \multicolumn{2}{|c|}{$\begin{array}{c}\text { De 30.001 a } \\
200.000\end{array}$} & \multicolumn{2}{|c|}{$\begin{array}{c}\text { Maior que } \\
200.000 \\
\end{array}$} & & \\
\hline & $\mathrm{N}$ & $\%$ & $\mathrm{~N}$ & $\%$ & $\mathrm{~N}$ & $\%$ & $\mathrm{~N}$ & $\%$ \\
\hline Funções básicas & 158 & 90,8 & 80 & 81,6 & 29 & 85,3 & 267 & 87,3 \\
\hline Usos múltiplos & 5 & 2,9 & 11 & 11,2 & 3 & 8,8 & 19 & 6,2 \\
\hline Interface Tabwin - SQL & 6 & 3,4 & 7 & 7,1 & 1 & 2,9 & 14 & 4,6 \\
\hline Módulo de mapas e gráfic & 2 & 1,1 & 0 & 0,0 & 1 & 2,9 & 3 & 1,0 \\
\hline Ferramenta de mapa de fh & 3 & 1,7 & 0 & 0,0 & 0 & 0,0 & 3 & 1,0 \\
\hline Total & 174 & 100,0 & 98 & 100,0 & 34 & 100,0 & 306 & 100,0 \\
\hline
\end{tabular}


Tabela 5A - Número e proporção de municípios, segundo motivos para não utilização de relatórios do sistema para gerar indicadores, Estado São Paulo, 2015

\begin{tabular}{|c|c|c|c|c|c|c|c|c|}
\hline \multirow{3}{*}{ Variáveis } & \multicolumn{6}{|c|}{ Porte dos Municípios (habitantes) } & \multirow{2}{*}{\multicolumn{2}{|c|}{ Total }} \\
\hline & \multicolumn{2}{|c|}{ Até $\mathbf{3 0 . 0 0 0}$} & \multicolumn{2}{|c|}{$\begin{array}{c}\text { De } 30.001 \text { a } \\
200.000\end{array}$} & \multicolumn{2}{|c|}{$\begin{array}{c}\text { Maior que } \\
200.000\end{array}$} & & \\
\hline & $\mathrm{N}$ & $\%$ & $\mathrm{~N}$ & $\%$ & $\mathrm{~N}$ & $\%$ & $\mathrm{~N}$ & $\%$ \\
\hline Por falta de treinamento & 84 & 62,2 & 14 & 63,6 & 1 & 20,0 & 99 & 61,1 \\
\hline Por falta pessoal & 21 & 15,6 & 3 & 13,6 & 0 & 0,0 & 24 & 14,8 \\
\hline $\begin{array}{l}\text { Os relatórios não atendem à } \\
\text { necessidade do município }\end{array}$ & 10 & 7,4 & 0 & 0,0 & 1 & 20,0 & 11 & 6,8 \\
\hline Outros motivos & 14 & 10,4 & 3 & 13,6 & 1 & 20,0 & 18 & 11,1 \\
\hline Outras combinações & 6 & 4,4 & 2 & 9,1 & 2 & 40,0 & 10 & 6,2 \\
\hline Total & $135^{\prime}$ & 100,0 & $22^{\prime}$ & 100,0 & $5^{\prime}$ & 100,0 & 162 & 100,0 \\
\hline
\end{tabular}

Tabela 6A - Municípios segundo grau de dificuldade na realização de algumas atividades do SIM, Estado de São Paulo, 2015

\begin{tabular}{lcccccc}
\hline \multirow{2}{*}{ Dificuldade } & \multicolumn{2}{c}{$\begin{array}{c}\text { Codificação das } \\
\text { causas de morte }\end{array}$} & $\begin{array}{c}\text { Instalação do } \\
\text { sistema no } \\
\text { computador }\end{array}$ & \multicolumn{2}{c}{$\begin{array}{c}\text { Geração de } \\
\text { indicadores }\end{array}$} \\
\cline { 2 - 7 } & $\mathbf{N}$ & $\mathbf{\%}$ & $\mathbf{N}$ & $\mathbf{\%}$ & $\mathbf{N}$ & $\mathbf{\%}$ \\
\hline Nenhuma & 147 & 25,2 & 235 & 40,2 & 176 & 30,1 \\
Baixa & 189 & 32,4 & 124 & 21,2 & 151 & 25,9 \\
Média & 143 & 24,5 & 127 & 21,7 & 132 & 22,6 \\
Alta e Muito & 104 & 17,8 & 97 & 16,6 & 121 & 20,7 \\
Alta & 67 & 11,5 & 54 & 9,2 & 71 & 12,2 \\
Alta & 37 & 6,3 & 43 & 7,4 & 50 & 8,6 \\
Muito alta & $\mathbf{5 8 4}$ & $\mathbf{1 0 0}$ & $\mathbf{5 8 4}$ & $\mathbf{1 0 0}$ & $\mathbf{5 8 4}$ & $\mathbf{1 0 0}$ \\
\hline Total & & & & &
\end{tabular}


Tabela 7A - Proporção de municípios que avaliaram como alto e muito alto benefício da descentralização do SIM, por tipo de benéfico, segundo porte populacional, Estado de São Paulo, 2015.

\begin{tabular}{lcccr}
\hline & \multicolumn{2}{c}{ Porte dos Municípios (habitantes) } & \\
\cline { 2 - 3 } \multicolumn{1}{c}{ Benefícios } & Até & De.000 $\mathbf{3 0 . 0 0 1}$ a & Maior que & Total \\
& $\mathbf{2 0 0 . 0 0 0}$ & $\mathbf{2 0 0 . 0 0 0}$ & \\
\hline Aumento da captação de óbitos & 60,0 & 66,7 & 73,0 & 62,4 \\
Disponibilidade de dados em tempo real & 65,4 & 73,8 & 75,7 & 68,1 \\
Melhoria da qualidade da informação & 66,2 & 72,3 & 81,1 & 68,6 \\
Construção dos principais indicadores de saúde & 61,7 & 72,3 & 83,8 & 65,7 \\
Acesso rápido às informações de evasão de óbitos & 65,9 & 66,7 & 73,0 & 66,6 \\
Agilização da vigilância em saúde & 65,9 & 72,3 & 83,8 & 68,6 \\
Permitir tomada de decisões imediatas & 65,2 & 70,2 & 83,8 & 67,6 \\
Autonomia na gestão do SIM & 64,2 & 73,0 & 78,4 & 67,2 \\
Responsabilização do gestor de saúde local & 62,0 & 66,7 & 67,6 & 63,5 \\
Disseminação da informação & 62,0 & 68,8 & 70,3 & 64,2 \\
\hline
\end{tabular}

